\title{
Partitioning heritability by functional category using GWAS
}

\section{summary statistics}

Hilary K. Finucane ${ }^{* \dagger 1,2}$, Brendan Bulik-Sullivan*3,4, Alexander Gusev² ${ }^{2}$ Gosia Trynka ${ }^{5,6,7,8}$, Yakir Reshef $^{9}$, Po-Ru Loh ${ }^{2}$, Verneri Anttila ${ }^{3,4,8}$, Han Xu10 ${ }^{10}$, Chongzhi Zang ${ }^{10}$, Kyle Farh ${ }^{3,11}$, Stephan Ripke $^{3,4}$, Felix R. Day ${ }^{12}$, ReproGen Consortium, Schizophrenia Working Group of the Psychiatric Genomics Consortium, The RACI Consortium, Shaun Purcell ${ }^{5,6,13}$, Eli Stahl ${ }^{13}$, Sara Lindstrom², John R. B. Perry ${ }^{12}$, Yukinori Okada ${ }^{14,15}$, Soumya Raychaudhuri ${ }^{5,6,7,8,16}$, Mark Daly ${ }^{3,4}$, Nick Patterson $^{8}$, Benjamin M. Neale ${ }^{* * 3,4}$, and Alkes L. Price ${ }^{* * \dagger 2,8}$

\footnotetext{
${ }^{1}$ Department of Mathematics, Massachusetts Institute of Technology, Cambridge, Massachusetts, USA.

${ }^{2}$ Department of Epidemiology, Harvard T.H. Chan School of Public Health, Boston, Massachusetts, USA.

${ }^{3}$ Analytic and Translational Genetics Unit, Massachusetts General Hospital and Harvard Medical School, Boston, Massachusetts, USA.

${ }^{4}$ Stanley Center for Psychiatric Research, Broad Institute of MIT and Harvard, Cambridge, Massachusetts, USA.

${ }^{5}$ Division of Genetics, Brigham and Women's Hospital, Harvard Medical School, Boston, Massachusetts, USA.

${ }^{6}$ Division of Rheumatology, Brigham and Women's Hospital, Harvard Medical School, Boston, Massachusetts, USA.

${ }^{7}$ Partners Center for Personalized Genetic Medicine, Boston, Massachusetts, USA.

${ }^{8}$ Program in Medical and Population Genetics, Broad Institute of MIT and Harvard, Cambridge, Massachusetts, USA.

${ }^{9}$ Department of Computer Science, Harvard University, Massachusetts,USA.

${ }^{10}$ Department of Biostatistics and Computational Biology, Dana-Farber Cancer Institute and Harvard T.H. Chan School of Public Health, Boston, Massachusetts, USA.

${ }^{11}$ Epigenomics Program, Broad Institute of MIT and Harvard, Cambridge, Massachusetts, USA.

${ }^{12}$ MRC Epidemiology Unit, University of Cambridge School of Clinical Medicine, Institute of Metabolic Science, Cambridge Biomedical Campus, Cambridge, CB2 0QQ, UK

${ }^{13}$ The Department of Psychiatry at Mount Sinai School of Medicine, New York, New York, USA.

${ }^{14}$ Department of Human Genetics and Disease Diversity, Graduate School of Medical and Dental Sciences, Tokyo Medical and Dental University, Tokyo 113-8510, Japan.

${ }^{15}$ Laboratory for Statistical Analysis, RIKEN Center for Integrative Medical Sciences, Yokohama 230-0045, Japan.

${ }^{16}$ Faculty of Medical and Human Sciences, University of Manchester, Manchester, UK.
}

\footnotetext{
${ }^{*}$ Co-first authors

${ }^{* *}$ Co-last authors

${ }^{\dagger}$ Correspondence should be addressed to H.K.F. (hilaryf@mit.edu) or A.L.P. (aprice@hsph.harvard.edu)
} 


\begin{abstract}
Recent work has demonstrated that some functional categories of the genome contribute disproportionately to the heritability of complex diseases. Here, we analyze a broad set of functional elements, including cell-type-specific elements, to estimate their polygenic contributions to heritability in genomewide association studies (GWAS) of 17 complex diseases and traits spanning a total of 1.3 million phenotype measurements. To enable this analysis, we introduce a new method for partitioning heritability from GWAS summary statistics while controlling for linked markers. This new method is computationally tractable at very large sample sizes, and leverages genome-wide information. Our results include a large enrichment of heritability in conserved regions across many traits; a very large immunological disease-specific enrichment of heritability in FANTOM5 enhancers; and many cell-type-specific enrichments including significant enrichment of central nervous system cell types in body mass index, age at menarche, educational attainment, and smoking behavior. These results demonstrate that GWAS can aid in understanding the biological basis of disease and provide direction for functional follow-up.
\end{abstract}

\title{
Introduction
}

In GWAS of complex traits, much of the heritability lies in single-nucleotide polymorphisms (SNPs) that do not reach genome-wide significance at current sample sizes. ${ }^{1,2}$ However, many current approaches that leverage functional information ${ }^{3,4}$ and GWAS data to inform disease biology use only SNPs in genome-wide significant loci, ${ }^{5-7}$ assume only one causal SNP per locus, ${ }^{8}$ or do not account for LD. ${ }^{9}$ We can improve power by estimating the proportion of SNP heritability ${ }^{1}$ attributable to various functional categories, using information from all SNPs and explicitly modeling LD.

Previous work on partitioning SNP heritability has used restricted maximum likelihood (REML) as implemented in GCTA. ${ }^{10-13}$ REML requires individual genotypes, but many of the largest GWAS analyses are conducted through meta-analysis of study-specific results, and so typically only summary statistics, not individual genotypes, are available for these studies. Even when individual genotypes are available, using REML to analyze multiple functional categories becomes computationally intractable at sample sizes in the tens of thousands. Here, we introduce a method for partitioning heritability, stratified LD score regression, that requires only GWAS summary statistics and LD information from an external reference panel that matches the population studied in the GWAS.

We apply our novel approach to 17 complex diseases and traits spanning 1,263,072 phenotype measurements. We first analyze non-cell-type-specific annotations and identify heritability enrichment in 
many of these functional annotations, including a large enrichment in conserved regions across many traits and a very large immunological disease-specific enrichment in FANTOM5 enhancers. We then analyze cell-type-specific annotations and identify many cell-type-specific heritability enrichments, including enrichment of central nervous system (CNS) cell types in body mass index, age at menarche, educational attainment, and smoking behavior.

\section{Results}

\section{Overview of methods}

Our method for partitioning heritability from summary statistics, called stratified LD score regression, relies on the fact that the $\chi^{2}$ association statistic for a given SNP includes the effects of all SNPs that it tags. ${ }^{14,15}$ Thus, for a polygenic trait, SNPs with high linkage disequilibrium (LD) will have higher $\chi^{2}$ statistics on average than SNPs with low LD. ${ }^{15}$ This might be driven either by the higher likelihood of these SNPs to tag an individual large effect, or their ability to tag multiple weak effects. If we partition SNPs into functional categories with different contributions to heritability, then LD to a category that is enriched for heritability will increase the $\chi^{2}$ statistic of a SNP more than LD to a category that does not contribute to heritability. Thus, our method determines that a category of SNPs is enriched for heritability if SNPs with high LD to that category have higher $\chi^{2}$ statistics than SNPs with low LD to that category.

More precisely, under a polygenic model, ${ }^{1}$ the expected $\chi^{2}$ statistic of $\operatorname{SNP} j$ is

$$
\mathrm{E}\left[\chi_{j}^{2}\right]=N \sum_{C} \tau_{C} \ell(j, C)+N a+1
$$

where $N$ is sample size, $C$ indexes disjoint categories, $\ell(j, C)$ is the LD Score of SNP $j$ with respect to category $C$ (defined as $\ell(j, C):=\sum_{k \in C} r^{2}(j, k)$ ), $a$ is a term that measures the contribution of confounding biases, ${ }^{15}$ and $\tau_{C}$ is the per-SNP heritability in category $C$ (Methods). Equation (1) allows us to estimate $\tau_{C}$ via a (computationally simple) multiple regression of $\chi_{j}^{2}$ against $\ell(j, C)$. The method easily generalizes to overlapping categories and case-control studies ${ }^{16}$ (Methods). We define the enrichment of a category to be the proportion of SNP heritability explained divided by the proportion of SNPs. We estimate standard errors with a block jackknife, ${ }^{15}$ and use these standard errors to calculate $z$-scores, $P$-values, and FDRs (Methods). We have released open-source software implementing the method (Web Resources). 
To apply LD score regression (or REML) we must first specify which categories we include in our model. We created a "full baseline model" from 24 main annotations that are not specific to any cell type (Table S1; see Methods and Web Resources). Below, we show that including many categories in our model leads to more accurate estimates of enrichment. The 24 main annotations include: coding, UTR, promoter, and intron; ${ }^{17}$ histone marks H3K4me1, H3K4me3, H3K9ac ${ }^{5}$ and two versions of H3K27ac; ${ }^{18,19}$ open chromatin reflected by DNase I hypersensitivity Site (DHS) regions; ${ }^{5}$ combined chromHMM/Segway predictions, ${ }^{20}$ which are a computational combination of many ENCODE annotations into a single partition of the genome into seven underlying "chromatin states,"; regions that are conserved in mammals; ${ }^{21}$ super-enhancers, which are large clusters of highly active enhancers; ${ }^{19}$ and active enhancers from the FANTOM5 panel of samples, which we call FANTOM5 enhancers. ${ }^{22}$ For the histone marks and other annotations that differ among cell types, we combined the different cell types into a single annotation for the baseline model by taking a union. To prevent our estimates from being biased upwards by enrichment in nearby regions, ${ }^{13}$ we also included $500 \mathrm{bp}$ windows around each functional category as separate functional categories in the baseline model, as well as 100bp windows around ChIP-seq peaks when appropriate (see Methods). This yielded a total of 53 (overlapping) functional categories in the baseline model, including a category containing all SNPs.

To prevent our estimates from being biased upwards by enrichment in nearby regions, ${ }^{13}$ we also included 500bp windows around each functional category as separate categories in the full baseline model, as well as 100bp windows around ChIP-seq peaks when appropriate (Methods). The 24 main annotations plus additional windows and a category containing all SNPs yielded a total of 53 (overlapping) functional categories in the full baseline model.

\section{Simulation results}

In order to assess the robustness of the method, we performed a variety of simulations. We used chromosome 1 genotypes of controls from the Wellcome Trust Case Control Consortium, ${ }^{23}$ imputed using a 1000 Genomes reference panel. ${ }^{24}$ After quality control, we had 2,680 individuals and 360,106 SNPs (Methods). We simulated quantitative phenotypes with a heritability of 0.5 using an additive model. For each simulation, SNP effect sizes were drawn from a normal distribution with mean zero and variance (i.e., average per-SNP heritability) determined by functional categories. We estimated the enrichment of the DHS category, i.e., $\left(\% h^{2}\right) /(\% \mathrm{SNPs})$, using three methods:(1) REML with two categories (DHS/Other), (2) LD score regression with two categories (DHS/Other), and (3) LD score 
regression with the full baseline model (53 categories, described above). Since REML with 53 categories did not converge at this sample size and would be computationally intractable at sample sizes in the tens of thousands, we did not include it in our comparison; an advantage of LD score regression is that it is possible to include a large number of categories in the underlying model. We report means and standard errors of the mean over 100 independent simulations.

We first performed three sets of simulations where the causal pattern of enrichment was well modeled by the two-category (DHS/Other) model; for these, all three methods performed well, although LD score regression with the full baseline model had larger standard errors around the mean (Figure 1a). For example, the standard errors around the mean in simulations with no DHS enrichment were 0.08 for REML, 0.11 for two-category LD score regression and 0.19 for LD score regression with the full baseline model. For the first set of simulations, all SNPs were causal and SNP effect sizes were drawn i.i.d. from a normal distribution. For the second set of simulations, all SNPs were causal and SNP effect sizes were drawn independently from a normal distribution, but the variance of the normal distribution depended on whether the SNP was in a DHS region, and two variances (DHS and Other) were chosen so that the proportion of heritability of DHS would be 3x more than the proportion of SNPs. For the third set of simulations, only SNPs in DHS regions were causal, and effect sizes of DHS SNPs were drawn i.i.d. from a normal distribution.

Next, to explore the realistic scenario where the model used to estimate enrichment does not match the (unknown) causal model, we performed three sets of simulations where all causal SNPs were in a particular category, but the model used to estimate heritability did not include this causal category. The three sets of simulations were (1) all causal SNPs in coding regions, yielding 1.6x DHS enrichment due to coding/DHS overlap, (2) all causal SNPs in FANTOM5 enhancers, yielding 4.0x DHS enrichment due to FANTOM5 enhancer/DHS overlap, and (3) all causal SNPs in 200bp DHS flanking regions, yielding 0x DHS enrichment. For the coding and FANTOM5 enhancer causal simulations, we made the full baseline model into a misspecified model by removing the causal category (and windows around the causal category). Results from these simulations are displayed in Figure 1b).

The two-category estimators were not robust to model misspecification and consistently over-estimated DHS enrichment by a wide margin. LD score regression with the full baseline model gave more accurate mean estimates of enrichment. Specifically, for the simulations with coding and FANTOM5 Enhancers causal, LD score regression with the full baseline model gave unbiased mean enrichment estimates of $1.8 \mathrm{x}$ (s.e. 0.22 ) and $4.2 \mathrm{x}$ (s.e. 0.22 ), respectively, while the mean enrichment estimates of REML and two-category LD score regression were nearly double these. The full baseline model includes a 500bp 


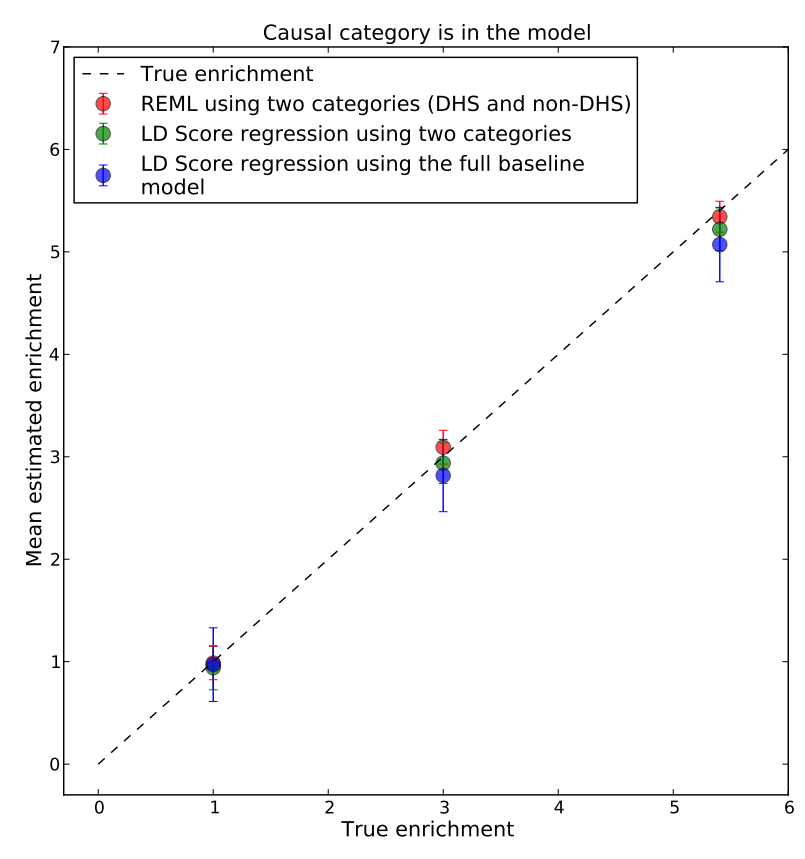

(a) No model misspecification.

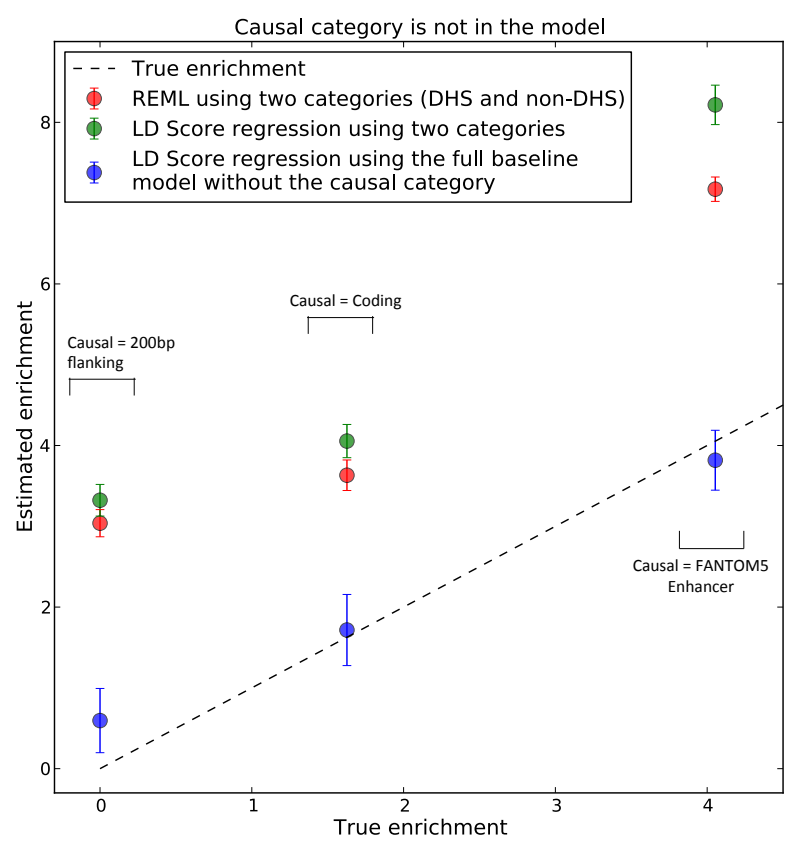

(b) Model is misspecified.

Figure 1: Simulation results. Enrichment is the proportion of heritability in DHS regions divided by the proportion of SNPs in DHS regions. Bars show 95\% confidence intervals around the mean of 100 trials. (a) From left to right, the simulated genetic architectures are 1x DHS enrichment, 3x DHS enrichment, and 5.5x DHS enrichment (100\% of heritability in DHS SNPs). (b) From left to right, the simulated genetic architectures are 200bp flanking regions causal, coding regions causal, and FANTOM5 Enhancer regions causal. For simulations with coding or FANTOM5 Enhancer as the causal category, we removed the causal category and the window around that category from the full baseline model in order to simulate enrichment in an unknown functional category.

window around DHS but not a 200bp window, and gave a mean estimated DHS enrichment of $0.65 \mathrm{x}$ (s.e. 0.22 ) when the $200 \mathrm{bp}$ flanking regions were causal, which is inflated relative to the true enrichment of $0 \mathrm{x}$ but much less inflated than $>3 \mathrm{x}$ mean enrichment estimates given by the two-category methods.

In summary, while these simulations include exaggerated patterns of enrichment (e.g., $100 \%$ of heritability in DHS flanking regions), the results highlight the possibility that two-category estimators of enrichment can yield incorrect conclusions. Although we cannot entirely rule out model misspecification as a source of bias for LD score regression with the full baseline model, we have shown here that it is robust to a wide variety of patterns of enrichment, because including many categories gives it the flexibility to adapt to the unknown causal model. 


\section{Application to real data}

We applied LD score regression with the full baseline model to 17 diseases and quantitative traits: height, BMI, age at menarche, LDL levels, HDL levels, triglyceride levels, coronary artery disease, type 2 diabetes, fasting glucose levels, schizophrenia, bipolar disorder, anorexia, educational attainment, smoking behavior, rheumatoid arthritis, Crohn's disease, and ulcerative colitis (Table S2, Web resources). This includes all traits with publicly available summary statistics with sufficient sample size and SNP heritability, measured by the z-score of total SNP-heritability (Methods), spanning a total of of 1,263,072 unique phenotype measurements. We removed the MHC region from all analyses, due to its unusual LD and genetic architecture. Figure 2 shows results for the 24 main functional annotations, averaged across nine independent traits (Methods). Figure 3 shows trait-specific results for selected annotations and traits (Methods). Tables S3 and S4 show meta-analysis and trait-specific results for all traits and all 53 categories in the full baseline model.

We observed large and statistically significant enrichments for many functional categories. A few categories stood out in particular. First, regions conserved in mammals ${ }^{21}$ showed the largest enrichment of any category, with $2.6 \%$ of SNPs explaining an estimated $35 \%$ of SNP heritability on average across traits $\left(P<10^{-15}\right.$ for enrichment). This is a significantly higher average enrichment than for coding regions, and provides evidence for the biological importance of conserved regions, even though the biochemical function of many conserved regions remains uncharacterized. ${ }^{25}$ Second, FANTOM5 Enhancers $^{22}$ were extremely enriched in the three immunological diseases, with $0.4 \%$ of SNPs explaining an estimated $15 \%$ of SNP heritability on average across these three diseases $\left(P<10^{-5}\right)$, but showed no evidence of enrichment for non-immunological traits (Figure 3). Third, repressed regions were depleted: $46 \%$ of SNPs explain only $29 \%$ of heritability on average $(P<0.006)$, consistent with the hypothesis that these are regions of low activity. ${ }^{20}$ We did not see a large enrichment of H3K27ac regions marked as super-enhancers over all H3K27ac regions; the estimates for enrichment were 1.8x (s.e. 0.2) and 1.6x (s.e. 0.1 , respectively. This lack of enrichment supports the argument that super-enhancers may not play a much more important role in regulating transcription than regular enhancers. ${ }^{26}$ For many annotations, there was also enrichment in the 500bp flanking regions (Table S3). Analyses stratified by minor allele frequency produced broadly similar results for all of these enrichments (Table S5; see Methods).

We performed two different cell-type-specific analyses: an analysis of 220 individual cell-type-specific annotations, and an analysis of 10 cell-type groups. The 220 individual cell-type-specific annotations are a combination of cell-type-specific annotations from four histone marks: 77 from H3K4me1, ${ }^{5} 81$ from 


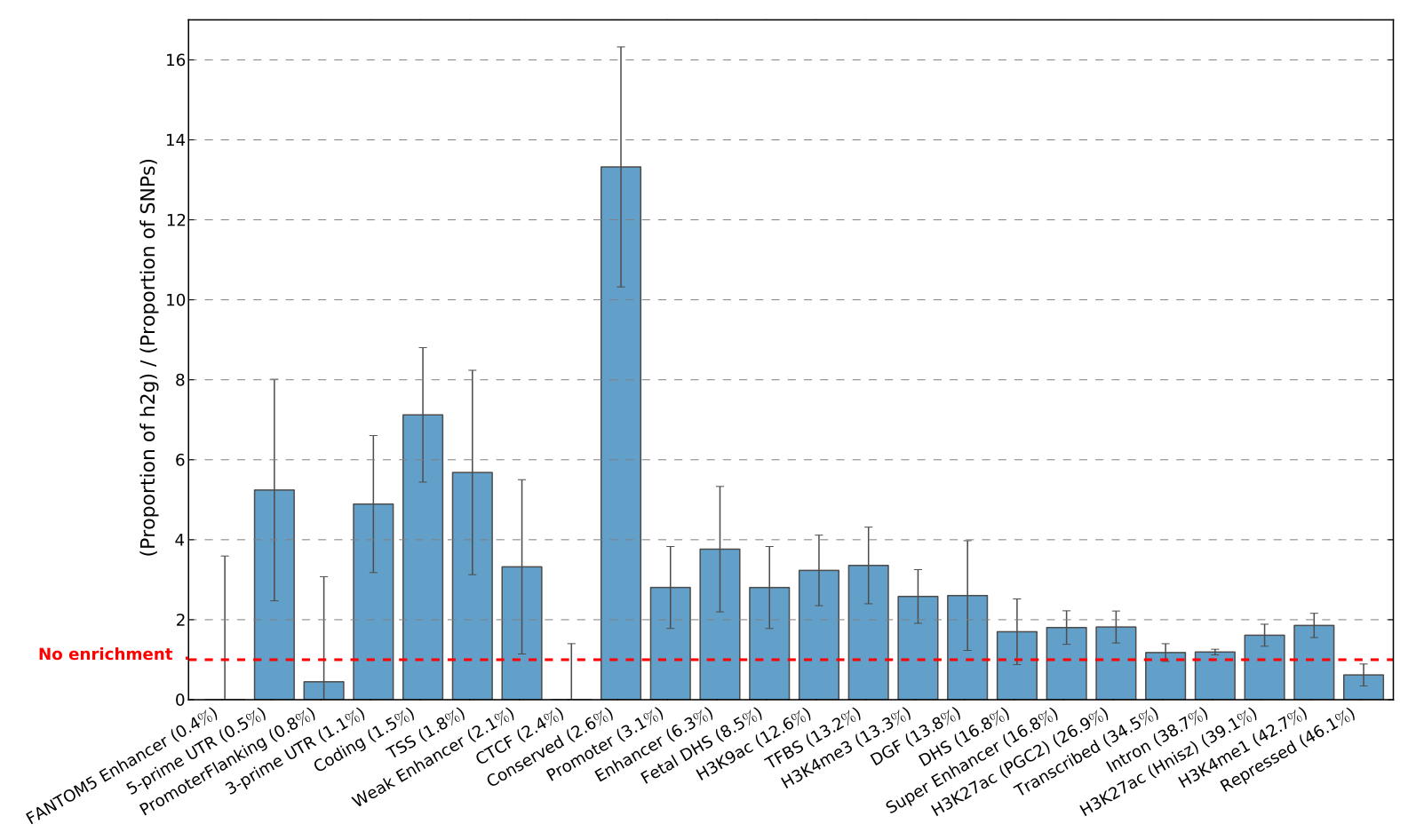

Figure 2: Enrichment estimates for the 24 main annotations, averaged over nine independent traits. Error bars represent $95 \%$ confidence intervals around the estimate.

H3K4me $3,{ }^{5} 27$ from H3K9ac, ${ }^{5}$ and 35 from H3K27ac ${ }^{18}$ (Table S6, Methods). When ranking these 220 cell-type-specific annotations, we wanted to control for overlap with the functional categories in the full baseline model, but not for overlap with the 219 other cell-type-specific annotations. Thus, we added the 220 cell-type-specific annotations individually, one at a time, to the full baseline model, and ranked these 220 annotations by the $P$-value for the coefficient corresponding to the annotation. This $P$-value tests whether the annotation contributes significantly to per-SNP heritability after controlling for the effects of the annotations in the full baseline model. We assessed statistical significance at the 0.05 level after Bonferroni correction for $220 \times 17=3,740$ hypotheses tested. (This is conservative, since the 220 annotations are not independent.) We also report results with false discovery rate (FDR) $<0.05$ (computed over 220 cell types for each trait). For 15 of the 17 traits, the top cell type passed an FDR threshold of 0.05 . The top cell type for each trait is displayed in Table 1, with additional top cell types reported in Table $\mathrm{S} 7$. 


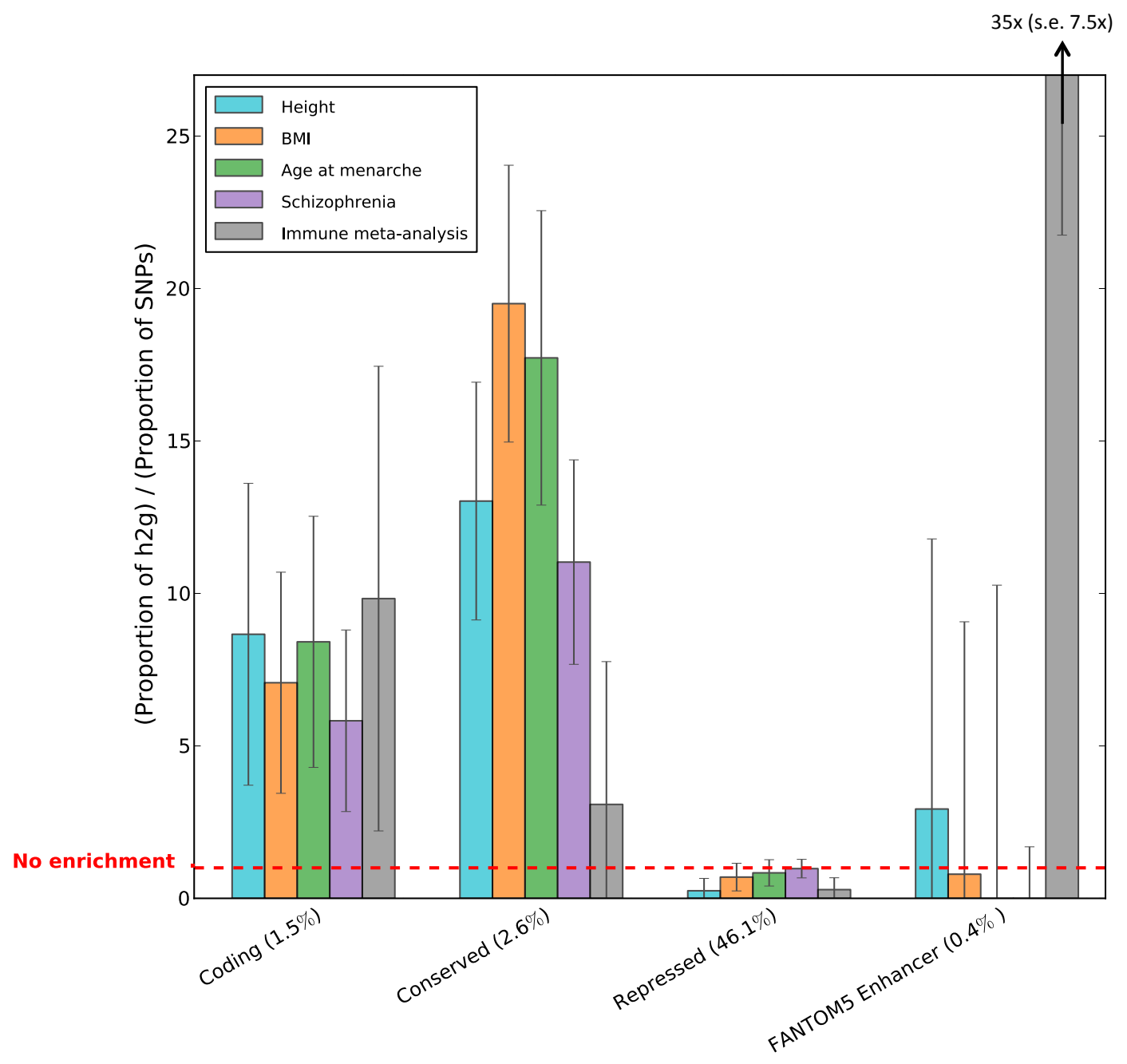

Figure 3: Enrichment estimates for selected annotations and traits. Error bars represent $95 \%$ confidence intervals around the estimate.

We combined information from related cell types by aggregating the 220 cell-type-specific annotations into 10 groups (Figure 4 legend and Table S6; see Methods). For each trait, we performed the same analysis on the 10 group-specific annotations as with the 220 cell-type-specific annotations. We assessed statistical significance at the 0.05 level after Bonferroni correction for $10 \times 17=170$ hypotheses tested, and we again also report results with false discovery rate $(\mathrm{FDR})<0.05$ (now computed over all cell-type groups and traits). For 16 of the 17 traits (all traits except anorexia), the top cell type group passed an FDR threshold of 0.05 . Results for the 11 traits with the most significant enrichments (after pruning closely related traits) are shown in Figure 4, with remaining traits in Figure S1.

These two analyses are generally concordant, and show highly trait-specific patterns of cell-type 


\begin{tabular}{|c|c|c|c|c|}
\hline Phenotype & Cell type & Tissue & Mark & $-\log _{10}(p)$ \\
\hline Height & Chondrogenic dif** & Bone & H3K27ac & 6.81 \\
\hline BMI & Fetal brain* & Fetal brain & $\mathrm{H} 3 \mathrm{~K} 4 \mathrm{me} 3$ & 4.48 \\
\hline Age at menarche & Fetal brain** & Fetal brain & $\mathrm{H} 3 \mathrm{~K} 4 \mathrm{me} 3$ & 12.25 \\
\hline LDL & Liver $(\mathrm{BI})^{*}$ & Liver & H3K4me1 & 4.76 \\
\hline HDL & Liver $(\mathrm{BI})^{*}$ & Liver & H3K4me1 & 4.51 \\
\hline Triglycerides & Liver $(\mathrm{BI})^{*}$ & Liver & H3K4me1 & 3.99 \\
\hline Coronary artery disease & Adipose nuclei* & Adipose & H3K4me1 & 4.21 \\
\hline Type 2 Diabetes & Pancreatic islets & Pancreas & $\mathrm{H} 3 \mathrm{~K} 4 \mathrm{me} 3$ & 2.87 \\
\hline Fasting Glucose & Pancreatic islets* & Pancreas & $\mathrm{H} 3 \mathrm{~K} 27 \mathrm{ac}$ & 3.93 \\
\hline Schizophrenia & Fetal brain** & Fetal brain & $\mathrm{H} 3 \mathrm{~K} 4 \mathrm{me} 3$ & 18.51 \\
\hline Bipolar disorder & Mid frontal lobe* & Brain & H3K27ac & 4.42 \\
\hline Anorexia & Angular gyrus & Brain & H3К9ac & 2.61 \\
\hline Years of education & Angular gyrus** & Brain & H3K4me3 & 6.63 \\
\hline Ever smoked & Inferior temporal lobe* & Brain & $\mathrm{H} 3 \mathrm{~K} 4 \mathrm{me} 3$ & 3.21 \\
\hline Rheumatoid arthritis & CD4+ CD25- IL17+ stim Th17** & Immune & H3K4me1 & 6.76 \\
\hline Crohn's disease & CD4+ CD25- IL17+ stim Th17** & Immune & H3K4me1 & 7.59 \\
\hline Ulcerative colitis & CD4+ CD25- IL17+ stim Th17** & Immune & H3K4me1 & 6.37 \\
\hline
\end{tabular}

Table 1: Enrichment of individual cell types. We report the cell type with the lowest $P$-value for each trait analyzed. ${ }^{*}$ denotes FDR $<0.05 .{ }^{* *}$ denotes significant at $\mathrm{p}<0.05$ after Bonferroni correction for multiple hypotheses. Sample sizes are in Table S2.

enrichment. They also recapitulate several well-known findings. For example, the top cell type for each of the three lipid traits is liver (FDR $<0.05$ for all three traits). For both type 2 diabetes and fasting glucose, the top cell type is pancreatic islets (FDR $<0.05$ for fasting glucose but not type 2 diabetes). For the three psychiatric traits, the top cell type is a brain cell type (FDR $<0.05$ for schizophrenia and bipolar disorder but not for anorexia) and the top cell-type group is CNS (significant after multiple testing for schizophrenia and bipolar disorder but not for anorexia).

There are also several new insights among these results. For example, the three immunological disorders show patterns of enrichment that reflect biological differences among the three disorders. Crohn's disease has 40 cell types with FDR $<0.05$, of which 39 are immune cell types and one (colonic mucosa) is a GI cell type. On the other hand, the 39 cell types with FDR $<0.05$ for ulcerative colitis include nine GI cell types in addition to 30 immune cell types, whereas all 39 cell types with FDR $<0.05$ for rheumatoid arthritis are immune cell types. The top cell type for all three traits is CD4+ CD25IL17+ PMA Ionomycin simulated Th17 primary. Th17 cells are thought to act in opposition to Treg cells, which have been shown to suppress immune activity and whose malfunction has been associated with immunological disorders. ${ }^{27}$

We also identified several non-psychiatric phenotypes with enrichments in brain cell types. For both BMI and age at menarche, cell types in the central nervous system (CNS) ranked highest among 

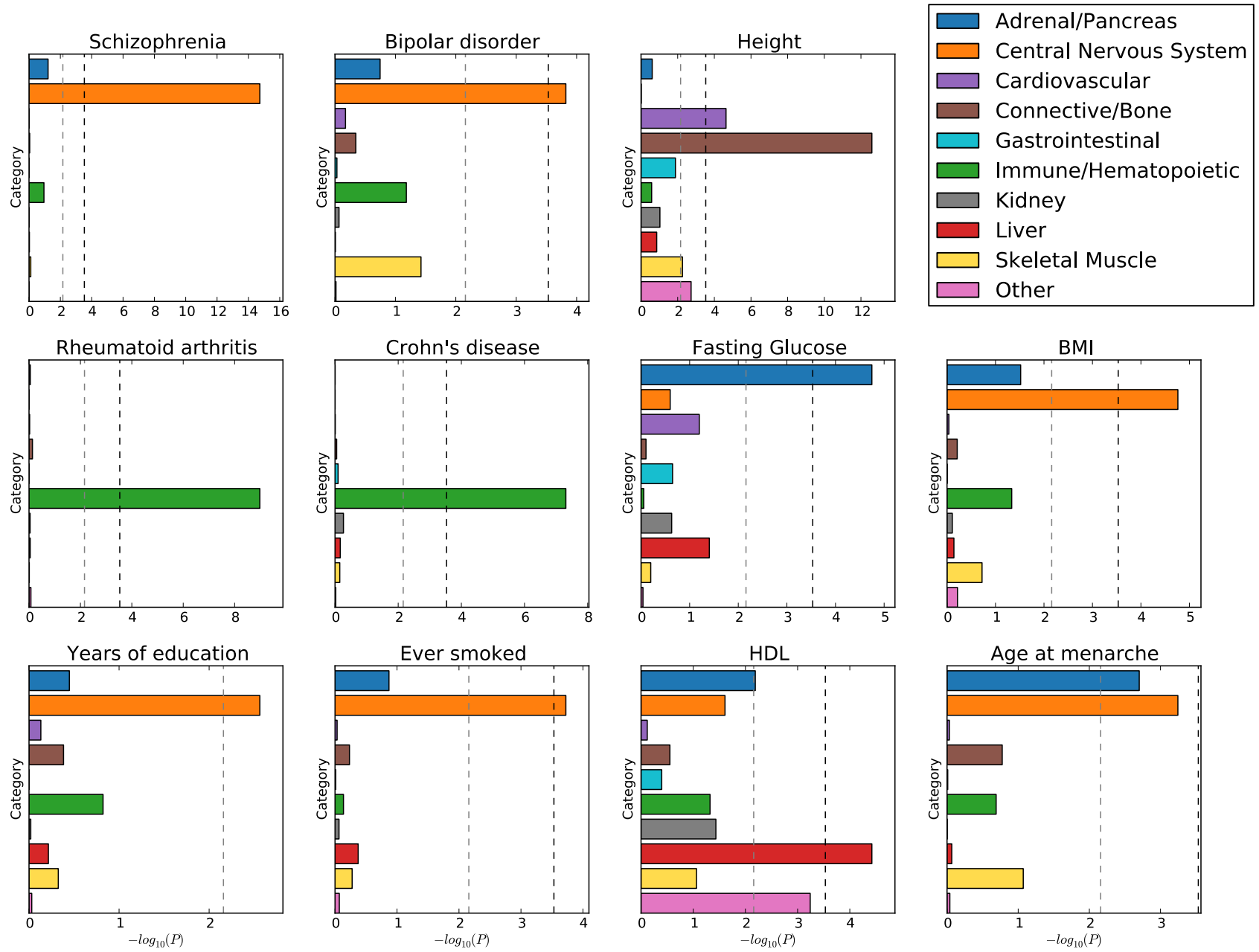

Figure 4: Enrichment of cell type groups. We report significance of enrichment for each of 10 cell-type groups, for each of 11 traits. The black dotted line at $-\log _{10}(P)=3.5$ is the cutoff for Bonferroni significance. The grey dotted line at $-\log _{10}(P)=2.1$ is the cutoff for FDR $<0.05$. For HDL, three of the top individual cell types are adipose nuclei, which explains the enrichment of the "Other" category.

individual cell types, and the top cell-type group was CNS, all with FDR $<0.05$. These enrichments support previous human and animal studies that propose a strong neural basis for the regulation of energy homeostasis. ${ }^{28}$ For educational attainment, the top cell-type group is CNS (FDR $<0.05$ ) and of the ten cell types that are significant after multiple testing, nine are CNS cell types. This is consistent with our understanding that the genetic component of educational attainment, which excludes environmental factors and population structure, is highly correlated with IQ. ${ }^{29}$ Finally, for smoking behavior, the CNS cell-type group is significant after multiple testing correction, and the top cell type is again a brain cell type, likely reflecting CNS involvement in nicotine processing. 


\section{Discussion}

We developed a new statistical method, stratified LD score regression, for identifying functional enrichment from GWAS data that uses information from all SNPs and explicitly models LD. We applied this method to GWAS data spanning 17 traits and 1.3 million phenotype measurements. Our method identified strong enrichment for conserved regions across all traits, and immunological disease-specific enrichment for FANTOM5 enhancers. Our cell-type-specific enrichment results confirmed previously known enrichments, such as liver enrichment for HDL levels and pancreatic islet enrichment for fasting glucose. In addition, we identified enrichments that would have been challenging to detect using existing methods, such as CNS enrichment for smoking behavior and educational attainment - traits with one and three genome-wide significant loci, respectively. ${ }^{29,30}$ Stratified LD score regression represents a significant departure from previous methods that require raw genotypes, ${ }^{10}$ use only SNPs in genome-wide significant loci, ${ }^{5-7}$ assume only one causal SNP per locus, ${ }^{8}$ or do not account for $\operatorname{LD}^{9}$ (see Methods for a discussion of other methods). Our method is also computationally efficient, despite the 53 overlapping functional categories analyzed.

Although our polygenic approach has enabled a powerful analysis of genome-wide summary statistics, it has several limitations. First, the method requires a very large sample size and/or large SNP heritability, and the trait analyzed must be polygenic. Second, it requires an LD reference panel matched to the population studied; all results in this paper are from European datasets and use 1000G Europeans as a reference panel. Third, our method is currently not applicable to studies using custom genotyping arrays (e.g., Metabochip; see Methods). Fourth, our method is based on an additive model and does not consider the contribution of epistatic or other non-additive effects, nor does it model causal contributions of SNPs not in the reference panel; in particular, it is possible that patterns of enrichment may be different at extremely rare variants. Fifth, the method is limited by available functional data: if a trait is enriched in a cell type for which we have no data, we cannot detect the enrichment. Last, though we have shown our method to be robust in a wide range of scenarios, we cannot rule out model misspecification caused by enrichment in an unidentified functional category as a possible source of bias.

The polygenic approach described here is a powerful and efficient way to learn about functional enrichments from summary statistics, and it will become increasingly useful as functional data continues to grow and improve, and as GWAS studies of larger sample size are conducted. 


\section{Web Resources}

- Idsc software:

github.com/bulik/ldsc

- DNaseI Digital Genomic Footprinting (DGF) annotations: ${ }^{3,13}$

http://hgdownload.cse.ucsc.edu/goldenPath/hg19/encodeDCC/wgEncodeUwDgf /

- Transcription factor binding sites: $:^{3,13}$

http://hgdownload.cse.ucsc.edu/goldenPath/hg19/encodeDCC/wgEncodeAwgTfbsUniform/

- Segway-chromHMM combined enhancer annotations: ${ }^{20}$

ftp://ftp.ebi.ac.uk/pub/databases/ensembl/encode/integration_data_jan2011/

byDataType/segmentations/jan2011

- Super-enhancers and H3K27ac: Available as a supplementary table to Hnisz et al $2014 .{ }^{19}$

- Conserved regions: ${ }^{21,31}$

http://compbio.mit.edu/human-constraint/data/gff/

- FANTOM5 Enhancers: ${ }^{22}$

http://enhancer.binf.ku.dk/presets/

- Post-processed H3K4me1, H3K4me3, and H3K9ac: ${ }^{5}$

https://www . broadinstitute.org/mpg/goshifter/

- Height ${ }^{32}$ and $\mathrm{BMI}^{33}$ summary statistics:

wWw.broadinstitute.org/collaboration/giant/index.php/GIANT_consortium_data_files

- Menarche summary statistics: ${ }^{34}$

www.reprogen.org

- LDL, HDL, and Triglycerides summary statistics: ${ }^{35}$

wWw. broadinstitute.org/mpg/pubs/lipids2010/

- Coronary artery disease summary statistics: ${ }^{36}$

WwW . cardiogramplusc4d.org

- Type 2 diabetes summary statistics: ${ }^{37}$

www.diagram-consortium.org

- Fasting glucose summary statistics: ${ }^{38}$

www.magicinvestigators . org/downloads / 
- Schizophrenia,${ }^{18}$ Bipolar Disorder ${ }^{39}$ Anorexia,${ }^{40}$ and Smoking behavior ${ }^{30}$ summary statistics:

www.med.unc.edu/pgc/downloads

- Education attainment summary statistics: ${ }^{29}$

WWW.ssgac.org

- Rheumatoid arthritis summary statistics: ${ }^{41}$

http://plaza.umin.ac.jp/ yokada/datasource/software.htm

- Crohn's disease and ulcerative colitis summary statistics: ${ }^{42}$

www. ibdgenetics.org/downloads.html

We used a newer version of these data with 1000 Genomes imputation.

\section{Acknowledgements}

We thank Brad Bernstein, Mariel Finucane, Eran Hodis, Dylan Kotliar, X. Shirley Liu, Manolis Kellis, Michael O’Donovan, Bogdan Pasaniuc, Abhishek Sarkar, Patrick Sullivan, Bjarni Vilhjalmsson, and Adrian Veres for helpful discussions. This research was funded by NIH grants R01 MH101244, R03 CA173785, and 1U01HG0070033. H.K.F. was supported by the Fannie and John Hertz Foundation. S.R. is supported by funding from the Arthritis Foundation and by a Doris Duke Clinical Scientisit Development Award. This study made use of data generated by the Wellcome Trust Case Control Consortium (WTCCC) and the Wellcome Trust Sanger Institute. A full list of the investigators who contributed to the generation of the WTCCC data is available at www.wtccc.org.uk. Funding for the WTCCC project was provided by the Wellcome Trust under award 076113. The members of the Schizophrenia Working Group of the Psychiatric Genetics Consortium are listed in the Supplementary Information.

\section{References}

${ }^{1}$ Jian Yang, Beben Benyamin, Brian P McEvoy, Scott Gordon, Anjali K Henders, Dale R Nyholt, Pamela A Madden, Andrew C Heath, Nicholas G Martin, Grant W Montgomery, et al. Common snps explain a large proportion of the heritability for human height. Nature Genetics, 42(7):565-569, 2010.

${ }^{2}$ Eli A. Stahl, Daniel Wegmann, Gosia Trynka, Javier Gutierrez-Achury, Ron Do, et al. Bayesian inference analyses of the polygenic architecture of rheumatoid arthritis. Nature Genetics, 44(5):483489, 2012. 
${ }^{3}$ ENCODE Project Consortium. An integrated encyclopedia of DNA elements in the human genome. Nature, 489:57-74, 2012.

${ }^{4}$ Bradley E. Bernstein, John A. Stamatoyannopoulos, Joseph F. Costello, Bing Ren, and Aleksandar Milosavljevic. The NIH Roadmap Epigenomics Mapping Consortium. Nature Biotechnology, 28:1045$1048,2010$.

${ }^{5}$ Gosia Trynka, Cynthia Sandor, Buhm Han, Han Xu, Barbara E. Stranger, X. Shirley Liu, and Soumya Raychaudhuri. Chromatin marks identify critical cell types for fine mapping complex trait variants. Nature Genetics, 45(2), 2013.

${ }^{6}$ Kyle Kai-How Farh, Alexander Marson, Jiang Zhu, Markus Kleinewietfeld, William J. Housley, et al. Genetic and epigenetic fine mapping of causal autoimmune disease variants. Nature, 2014.

${ }^{7}$ Gleb Kichaev, Wen-Yun Yang, Sara Lindstrom, Farhad Hormozdiari, Eleazar Eskin, et al. Integrating functional data to prioritize causal variants in statistical fine-mapping studies. PLOS Genetics, 2014.

${ }^{8}$ Joseph K. Pickrell. Joint analysis of functional genomic data and genome-wide association studies of 18 human traits. American Journal of Human Genetics, 94:559-573, 2014.

${ }^{9}$ Matthew T. Maurano, Richard Humbert, Eric Rynes, Robert E. Thurman, Eric Haugen, et al. Systematic localization of common disease-associated variation in regulatory DNA. Science, 337(6099):1190$1195,2012$.

${ }^{10}$ Jian Yang, S Hong Lee, Michael E Goddard, and Peter M Visscher. GCTA: a tool for genome-wide complex trait analysis. The American Journal of Human Genetics, 88(1):76-82, 2011.

${ }^{11}$ S. Hong Lee, Teresa R. DeCandia, Stephan Ripke, Jian Yang, The Schizophrenia Psychiatric GenomeWide Association Study Consortium, et al. Estimating the proportion of variation in susceptibility to schizophrenia captured by common SNPs. Nature Genetics, 44(3):247-250, 2012.

${ }^{12}$ Lea K. Davis, Dongmei Yu, Clare L. Keenan, Eric R. Gamazon, Anua I. Konkashbaev, et al. Partitioning the heritability of Tourette syndrome and obsessive compulsive disorder reveals differences in genetic architecture. PLOS Genetics, 2013.

${ }^{13}$ Alexander Gusev, S. Hong Lee, Gosia Trynka, Hilary Finucane, Bjarni J. Vilhjalmsson, et al. Partitioning heritability of regulatory and cell-type-specific variants across 11 common diseases. American Journal of Human Genetics, 95:535-552, 2014.

${ }^{14}$ Jian Yang, Michael Weedon, Shaun Purcell, Guillaume Lettre, Karol Estrada, et al. Genomic inflation factors under polygenic inheritance. European Journal of Human Genetics, 19:807-812, 2011. 
${ }^{15}$ Brendan Bulik-Sullivan, Po-Ru Loh, Hilary Finucane, Stephan Ripke, Jian Yang, Nick Patterson, Mark J Daly, Alkes L Price, and Benjamin M Neale. LD Score regression distinguishes confounding from polygenicity in genome-wide association studies. Nature Genetics, In press.

${ }^{16}$ Brendan Bulik-Sullivan, Hilary Finucane, et al. Estimating genetic correlations between traits from GWAS summary statistics. arxiv.

${ }^{17}$ UCSC Genome Browser: http://genome.ucsc.edu.

${ }^{18}$ Schizophrenia Working Group of the Psychiatric Genomics Consortium. Biological insights from 108 schizophrenia-associated genetic loci. Nature, 511:421-427, 2014.

${ }^{19}$ Denes Hnisz, Brian J. Abraham, Tong Ihn Lee, Ashley Lau, Violaine Saint-Andre, Alla A. Sigova, Heather A. Hoke, and Richard A. Young. Super-enhancers in the control of cell identity and disease. Cell, 155(4):934-947, 2013.

${ }^{20}$ Michael M. Hoffman, Jason Ernst, Steven P. Wilder, Anshul Kundaje, Robert S. Harris, et al. Integrative annotation of chromatin elements from ENCODE data. Nucleic Acids Research, 41:827-841, 2013.

${ }^{21}$ Kerstin Lindblad-Toh, Manuel Garber, Or Zuk, Michael Lin, Brian Parker, Stefan Washietl, et al. A high-resolution map of human evolutionary constraint using 29 mammals. Nature, 478:476-482, 2011.

${ }^{22}$ Robin Andersson, Claudia Gebhard, Irene Miguel-Escalada, Ilka Hoof, Jette Bornholdt, et al. An atlas of active enhancers across human cell types and tissues. Nature, 507:455-461, 2014.

${ }^{23}$ Wellcome Trust Case Control Consortium. Genome-wide association study of 14,000 cases of seven common diseases and 3,000 shared controls. Nature, 446:661-678, 2007.

${ }^{24} 1000$ Genomes Project Consortium. An integrated map of genetic variation from 1,092 human genomes. Nature, 491:56-65, 2012.

${ }^{25}$ John A. Stamatoyannopoulos. What does our genome encode? Genome Research, 22:1602-1611, 2012 .

${ }^{26}$ Sebastian Pott and Jason D. Lieb. What are super-enhancers? Nature Genetics, 47(1), 2015.

${ }^{27}$ Wenhong Wang, Shihe Shao, Zhijun Jiao, Mingquan Guo, Huaxi Xu, and Shengjun Wang. The th17/treg imbalance and cytokine environment in peripheral blood of patients with rheumatoid arthritis. Rheumatology International, 32:887-893, 2012.

${ }^{28}$ Farooqi I. Sadaf. Defining the neural basis of appetite and obesity: from genes to behaviour. Clinical Medicine, 14(3):286-289, 2014. 
${ }^{29}$ Cornelius A Rietveld, Sarah E Medland, Jaime Derringer, Jian Yang, Tõnu Esko, Nicolas W Martin, Harm-Jan Westra, Konstantin Shakhbazov, Abdel Abdellaoui, Arpana Agrawal, et al. GWAS of 126,559 individuals identifies genetic variants associated with educational attainment. Science, 340(6139):1467-1471, 2013.

30 Tobacco and Genetics Consortium et al. Genome-wide meta-analyses identify multiple loci associated with smoking behavior. Nature Genetics, 42(5):441-447, 2010.

${ }^{31}$ Lucas D. Ward and Manolis Kellis. Evidence of abundant purifying selection in humans for recentlyacquired regulatory functions. Science, 337(6102):1675-1678, 2012.

32 Hana Lango Allen, Karol Estrada, Guillaume Lettre, Sonja I. Berndt, Mihcale N. Weedon, et al. Hundreds of variants clustered in genomic loci and biological pathways affect human height. Nature, $467: 832-838,2010$.

${ }^{33}$ Elizabeth K Speliotes, Cristen J Willer, Sonja I Berndt, Keri L Monda, Gudmar Thorleifsson, Anne U Jackson, Hana Lango Allen, Cecilia M Lindgren, Jian'an Luan, Reedik Mägi, et al. Association analyses of 249,796 individuals reveal 18 new loci associated with body mass index. Nature genetics, 42(11):937-948, 2010 .

${ }^{34}$ John R. Perry, Felix Day, Cathy E. Elks, Patrick Sulem, Deborah Thompson, et al. Parent-of-originspecific allelic associations among 106 genomic loci for age at menarche. Nature, 514:92-97, 2014.

35 Tanya M Teslovich, Kiran Musunuru, Albert V Smith, Andrew C Edmondson, Ioannis M Stylianou, Masahiro Koseki, James P Pirruccello, Samuli Ripatti, Daniel I Chasman, Cristen J Willer, et al. Biological, clinical and population relevance of 95 loci for blood lipids. Nature, 466(7307):707-713, 2010 .

${ }^{36}$ Heribert Schunkert, Inke R König, Sekar Kathiresan, Muredach P Reilly, Themistocles L Assimes, Hilma Holm, Michael Preuss, Alexandre FR Stewart, Maja Barbalic, Christian Gieger, et al. Largescale association analysis identifies 13 new susceptibility loci for coronary artery disease. Nature genetics, 43(4):333-338, 2011.

${ }^{37}$ Andrew P Morris, Benjamin F Voight, Tanya M Teslovich, Teresa Ferreira, Ayellet V Segre, Valgerdur Steinthorsdottir, Rona J Strawbridge, Hassan Khan, Harald Grallert, Anubha Mahajan, et al. Largescale association analysis provides insights into the genetic architecture and pathophysiology of type 2 diabetes. Nature genetics, 44(9):981, 2012.

38 Alisa K Manning, Marie-France Hivert, Robert A Scott, Jonna L Grimsby, Nabila Bouatia-Naji, Han Chen, Denis Rybin, Ching-Ti Liu, Lawrence F Bielak, Inga Prokopenko, et al. A genome-wide 
approach accounting for body mass index identifies genetic variants influencing fasting glycemic traits and insulin resistance. Nature genetics, 44(6):659-669, 2012.

${ }^{39}$ Pamela Sklar, Stephan Ripke, Laura J Scott, Ole A Andreassen, Sven Cichon, Nick Craddock, Howard J Edenberg, John I Nurnberger, Marcella Rietschel, Douglas Blackwood, et al. Large-scale genome-wide association analysis of bipolar disorder identifies a new susceptibility locus near odz4. Nature Genetics, 43(10):977, 2011.

${ }^{40}$ Vesna Boraska, Christopher S Franklin, James AB Floyd, Laura M Thornton, Laura M Huckins, Lorraine Southam, N William Rayner, Ioanna Tachmazidou, Kelly L Klump, Janet Treasure, et al. A genome-wide association study of anorexia nervosa. Molecular psychiatry, 2014.

${ }^{41}$ Yukinori Okada, Di Wu, Gosia Trynka, Towfique Raj, Chikashi Terao, et al. Genetics of rheumatoid arthritis contributes to biology and drug discovery. Nature, 506:376-381, 2014.

${ }^{42}$ Luke Jostins, Stephan Ripke, Rinse K Weersma, Richard H Duerr, Dermot P McGovern, Ken Y Hui, James C Lee, L Philip Schumm, Yashoda Sharma, Carl A Anderson, et al. Host-microbe interactions have shaped the genetic architecture of inflammatory bowel disease. Nature, 491(7422):119-124, 2012.

${ }^{43}$ International HapMap 3 Consortium. Integrating common and rare genetic variation in diverse human populations. Nature, 467:52-58, 2010.

${ }^{44}$ Gosia Trynka, Harm-Jan Westra, Kamil Slowikowski, Xinli Hu, and Han Xu. Disentangling effects of colocalizing genomic annotations to functionally prioritize non-coding variants within complex trait loci, 2014. bioRxivdoi: http://dx.doi.org/10.1101/004309. 


\section{Methods}

\section{Stratified LD score regression}

We begin with a derivation of Equation (1) for overlapping categories in a sample with no population structure or other confounding. The derivation of the intercept term in the presence of confounding is identical to the derivation in previous work. ${ }^{15}$

Let $y_{i}$ be a quantitative phenotype in individual $i$, standardized to mean 0 and variance 1 in the population, and let $X_{i j}$ be the genotype of individual $i$ at the $j$-th SNP, standardized so that for each SNP $j, X_{i j}$ has mean 0 and variance 1 in the population. We will assume a linear model:

$$
y_{i}=\sum_{j \in G} X_{i j} \beta_{j}(G)+\epsilon_{i}
$$

where $G$ is some fixed set of SNPs, $\beta_{j}(G)$ is the effect size of SNP $j$, and $\epsilon_{i}$ is mean-0 noise.

We define $\beta(G)=\left(\beta_{1}(G), \ldots, \beta_{M}(G)\right)$ as the hypothetical result of multiple linear regression of $y$ on $X$ at infinite sample size. Thus, $\beta(G)$ depends on the set $G$; for example, if $G$ is the set of genotyped SNPs then $\beta_{j}(G)$ includes the causal effects of non-typed SNPs that are tagged by SNP $j$, whereas if $G$ contains all SNPs, then $\beta_{j}(G)$ will reflect only the true effect at SNP $j$.

We will define the heritability of the set $G$ of SNPs to be

$$
h_{G}^{2}=\sum_{j \in G} \beta_{j}(G)^{2}
$$

and the heritability of a category $\mathcal{C} \subset G$ to be

$$
h_{G}^{2}(\mathcal{C})=\sum_{j \in \mathcal{C}} \beta_{j}(G)^{2}
$$

The definition of $h_{G}^{2}(\mathcal{C})$ depends on both $G$ and $\mathcal{C}$; for example, if $\mathcal{C}$ is the set of SNPs with minor allele frequency (MAF) greater than $5 \%, h_{G}^{2}(\mathcal{C})$ will be larger if $G=\mathcal{C}$ than if $G$ contains SNPs with lower MAF since in the first case $h_{G}^{2}(\mathcal{C})$ includes tagged effects of low-frequency SNPs, whereas in the second case the low-frequency effects are included in $h_{G}^{2}(G \backslash \mathcal{C})$.

Suppose that we have a sample of $N$ individuals. Let $y=\left(y_{1}, \ldots, y_{N}\right)$, and let $X$ be the $N \times M$ matrix of standardized genotypes, where $M=|G|$. (We will assume that our sample is large enough that normalizing each SNP within our sample is roughly equivalent to normalizing each SNP in the 
population.) Let $\epsilon=\left(\epsilon_{1}, \ldots, \epsilon_{N}\right)$ be a vector of residuals. Then we can write

$$
y=X \beta(G)+\epsilon
$$

Let $\hat{\beta}_{j}$ be the estimate of the marginal effect of SNP $j$ in our sample, given by

$$
\hat{\beta}_{j}:=\frac{1}{N} X_{j}^{T} y,
$$

where $X_{j}$ is the $j$-th column of $X$. Define $\chi^{2}$ statistics $\chi_{j}^{2}:=N \hat{\beta}_{j}^{2}$.

Our goal here is to estimate $h_{G}^{2}(\mathcal{C})$, where $G$ is the set of 1000G SNPs that have minor allele count greater than five in Europeans, and $\mathcal{C}$ is a functional category, such as coding SNPs or SNPs that are in H3K4me3 regions in fetal brain tissue. From now on, we will omit the dependence on $G$, understanding $G$ to be the set of $1000 \mathrm{G}$ SNPs with minor allele count greater than five in Europeans. We would like to estimate this quantity from summary statistics; i.e., the input to our method will be $\left\{\chi_{j}^{2}\right\}_{j \in R}$, where $R$ is the set of SNPs that were tested in a GWAS. We will also need LD information from a reference panel.

Substituting $y=X \beta+\epsilon$ into the the definition of $\hat{\beta}_{j}$, we get

$$
\hat{\beta}_{j}=\frac{1}{N} X_{j}^{T} X \beta+\frac{1}{N} X_{j}^{T} \epsilon=\hat{D}_{j} \beta+\epsilon_{j}^{\prime},
$$

where $\hat{D}_{j}$ is the $j$-th row of the in-sample LD matrix $\hat{D}=X^{T} X / N$ and $\epsilon_{j}^{\prime}=X_{j}^{T} \epsilon / N$. For a single entry $\beta_{j}$, this means that

$$
\hat{\beta}_{j}=\sum_{k} \hat{r}_{j k} \beta_{k}+\epsilon_{j}^{\prime}
$$

where $\hat{r}_{j k}:=\hat{D}(j, k)$ and $\epsilon_{j}^{\prime}$ has mean 0 and variance $\sigma_{e}^{2} / N$.

To estimate $h_{G}^{2}(\mathcal{C})$, we will model $\beta$ as a mean-0 random vector with independent entries. We will allow the variance of $\beta_{j}$ to depend on certain functional properties of SNP $j$; for example, we will allow coding and non-coding SNPs to have different variances. More precisely, we will assume we have $C$ functional categories $\mathcal{C}_{1}, \ldots, \mathcal{C}_{C} \subset\{1, \ldots, M\}$. One of the categories must always contain all SNPs to allow for baseline heritability. We will model the variance of $\beta_{j}$ as

$$
\operatorname{Var}\left(\beta_{j}\right)=\sum_{c: j \in \mathcal{C}_{c}} \tau_{c}
$$


In the case that the $\mathcal{C}_{c}$ are disjoint, we will have $\tau_{c}=h^{2}\left(\mathcal{C}_{c}\right) / M\left(\mathcal{C}_{c}\right)$, where $M\left(\mathcal{C}_{c}\right)$ is the number of SNPs in $\mathcal{C}_{c}$.

Consider the expectation of $\chi_{j}^{2}=N \hat{\beta}_{j}^{2}$.

$$
\begin{aligned}
\mathrm{E}\left[\chi_{j}^{2}\right] & =N \mathrm{E}\left(\sum_{k} \hat{r}_{j k} \beta_{k}+\epsilon_{j}^{\prime}\right)^{2} \\
& =N \sum_{k} \hat{r}_{j k}^{2} \mathrm{E}\left[\beta_{k}^{2}\right]+N \mathrm{E}\left[\epsilon_{j}^{\prime 2}\right] \\
& =N \sum_{k} \hat{r}_{j k}^{2}\left(\sum_{c: k \in \mathcal{C}_{c}} \tau_{c}\right)+N \sigma_{e}^{2} \\
& =N \sum_{c} \tau_{c} \sum_{k \in \mathcal{C}_{c}} \hat{r}_{j k}^{2}+N \sigma_{e}^{2},
\end{aligned}
$$

where the second equality follows because the random variables are all independent with mean 0 .

Let $r_{j k}$ denote the true correlation between SNPs $j$ and $k$ in the underlying population. In an unstructured sample, $\mathrm{E}\left[\hat{r}_{j k}^{2}\right] \approx r_{j k}^{2}+1 / N$.

We now have

$$
\begin{aligned}
\mathrm{E}\left[\chi_{j}^{2}\right] & =N \sum_{c} \tau_{c} \sum_{c: k \in \mathcal{C}_{c}} \hat{r}_{j k}^{2}+N \sigma_{e}^{2} \\
& =N \sum_{c} \tau_{c} \sum_{c: k \in \mathcal{C}_{c}}\left(\hat{r}_{j k}^{2}-1 / N\right)+N \sum_{c} \tau_{c} \sum_{k \in \mathcal{C}) c}(1 / N)+N \sigma_{e}^{2} \\
& \approx N \sum_{c} \tau_{c} \sum_{k \in \mathcal{C}_{c}} r_{j k}^{2} \\
& =N \sum_{c} \tau_{c} \ell(j, c)+\sum_{k} \operatorname{Var}\left(\beta_{k}\right)+N \sigma_{e}^{2},
\end{aligned}
$$

where $\ell(j, c):=\sum_{k \in \mathcal{C}_{c}} r_{j k}^{2}$. The variance of $y_{j}$ is $\sum_{j} \operatorname{Var}\left(\beta_{j}\right)+\sigma_{e}^{2}$. Since our phenotype has variance one, we can replace $\sum_{j} \operatorname{Var}\left(\beta_{j}\right)+\sigma_{e}^{2}$ with 1 , giving us our main equation:

$$
\mathrm{E}\left[\chi_{j}^{2}\right]=N \sum_{c} \tau_{c} \ell(j, c)+1
$$

Our goal is to estimate $h^{2}\left(\mathcal{C}_{c}\right):=\sum_{j \in \mathcal{C}_{c}} \beta_{j}^{2} \approx \sum_{j \in \mathcal{C}_{c}} \operatorname{Var}\left(\beta_{j}\right)$, given a vector of $\chi^{2}$ statistics and LD information either from the sample or from a reference panel. To estimate $\operatorname{Var}\left(\beta_{j}\right)$, we need to estimate each of the coefficients $\tau_{c}$, and then we apply Equation (2). To estimate $\tau_{c}$, we first compute $\ell(j, c)$, then 
we regress $\chi_{j}^{2}$ on $\ell(j, c)$. This is called stratified LD score regression.

We estimate standard errors using a block jackknife over SNPs with 200 equally-sized blocks of adjacent SNPs, ${ }^{15}$ and use these standard errors to calculate z-scores, $P$-values, and FDRs. To minimize standard error, we remove outliers by excluding SNPs $j$ with $\chi_{j}^{2}>\max \{80,0.001 N\}$, where $N$ is the maximum sample size in the study, and we also weight the regression in a way that takes into account both over-counting and heteroskedasticity due to LD (see below). We remove the MHC region from all analyses.

Proportion of heritability and GC correction. As described above, stratified LD score regression is a method for estimating $h^{2}(\mathcal{C})$ for a given category $\mathcal{C}$. However, we are often more interested in estimating the proportion of heritability $h^{2}(\mathcal{C}) / h^{2}$. For this, we estimate $h^{2}(\mathcal{C})$ and $h^{2}$ separately and divide the estimates. For inference, we jackknife the proportion, rather than jackknifing the numerator and denominator separately.

Estimating the proportion of heritability is possible for summary statistics with GC correction, even though GC correction makes estimating the category specific heritability and total heritability impossible. This is because GC correction introduces a multiplicative error into estimates of both $h^{2}(\mathcal{C})$ and $h^{2},{ }^{15}$ but the two multiplicative errors are equal, and cancel out in the ratio.

Choice of regression SNPs and reference SNPs. The derivation above does not incorporate imperfect imputation. Ideally, we would prune our $\chi^{2}$ statistics to a set of "regression SNPs" with imputation accuracy above 0.9 , but since imputation accuracy is not always available, we instead use HapMap Project Phase 3 (HapMap3 ${ }^{43}$ ) SNPs as a proxy for well-imputed SNPs. So for the purposes of this paper, our regression SNPs are always the HapMap3 SNPs.

However, we do not assume that only HapMap3 SNPs are causal. It is important that our model allow as many SNPs as possible to contribute causally, since if we use a model with, for example, only HapMap3 SNPs causal then we are assigning causality of any SNP that is tagged by HapMap3 but not included in HapMap3 to the HapMap3 SNPs that tag it. This is problematic specifically for functional partitioning because the functional categories containing the causal SNP may not be the same as the functional categories of the HapMap3 SNPs that tag it.

Recall that $h_{A}^{2}(B)$ is the heritability of set $B$ defined using a model that allows any SNP in set $A$ to be causal. Another way to restate our above point is that we are interested in $h_{1000 G}^{2}(\mathcal{C})$ rather than $h_{\text {HapMap } 3}^{2}(\mathcal{C})$ because a model that only allows HapMap3 SNPs to be causal is allowing non-HapMap3 
heritability to be tagged by HapMap3 SNPs and therefore potentially assigning heritability to the wrong functional category. For this reason, our set of potentially causal SNPs-i.e., the set of SNPs in our reference panel - is the set of $1000 \mathrm{G} \mathrm{SNPs}{ }^{24}$ with minor allele count greater than five in Europeans.

However, there is a problem introduced by having many reference panel SNPs that are not tagged by regression SNPs: it leads us to extrapolate the enrichments at well-tagged SNPs to the rare SNPs on our reference panel that are not well-tagged. In other words, we estimate $\tau_{c}$ using summary statistics at HapMap3 SNPs, and then we multiply these coefficients by the number of SNPs in the relevant categories in 1000G, extrapolating the enrichments observed at HapMap3 SNPs to all 1000G SNPs.

To prevent ourselves from this extrapolation, we only estimate enrichments of categories containing common SNPs - i.e., SNPs with MAF > 0.05, all of which we assume to be well-tagged by HapMap3. Let $\mathcal{G}$ denote the set of SNPs with $M A F>0.05$. Then for any category $\mathcal{C}$, we can estimate $\mathcal{C} \cap \mathcal{G}$ without potentially inaccurate extrapolation. For this reason, the proportions of heritability that we report throughout this manuscript are $h_{1000 G}^{2}(\mathcal{C} \cap \mathcal{G}) / h_{1000 G}^{2}(\mathcal{G})$.

Out-of-bounds estimates. Stratified LD score regression can give heritability estimates that are not between 0 and 1 . When an unbiasedness is important - for example, when we are averaging estimates over several simulation replicates - we do not adjust these out-of-bounds estimates. However when mean squared error is more important than unbiasedness - for example, when reporting the results of a single analysis - we truncate these estimates to be between 0 and 1 . To get a confidence interval around the truncated estimate, we intersect the original confidence interval with the interval $[0,1]$.

Custom genotyping arrays. LD score regression is not currently applicable to studies using a custom genotyping arrays. For these arrays, SNPs that are more likely to have a large effect size also have a larger sample size, and this dependency is not modeled in the above derivation.

Regression weights. To minimize standard error, we weight the regression in a way that takes into account both over-counting and heteroskedasticity due to LD. For over-counting, we compute LD Scores within HapMap3 SNPs; call these $\ell_{h m 3}(j)$. We also compute $\ell_{1000 G}(j, c)$ for all categories $c$ in our model. The variance of $\chi_{j}^{2}$ is proportional to $\left(1+N \sum_{c} \tau_{c} \ell_{1000 G}(j, c)\right)^{2}$, but we do not have $\tau_{c}$. We use a rough approximation of $\tau_{c}$ obtained by taking the mean over regression SNPs of both sides of Equation (3) and assuming that all the $\tau_{c}$ are equal. This gives us $\hat{\tau}=\left(\bar{\chi}^{2}-1\right) /(N \cdot \bar{\ell}(j))$, where $\bar{\chi}^{2}$ is the mean of $\chi_{j}^{2}$ and $\bar{\ell}(j)$ is the mean of $\sum_{c} \ell_{1000 G}(j, c)$, both taken over regression SNPs. We then 
weight SNP $j$ by the inverse product of the over counting weights and heteroskedasticity weights:

$$
w_{j}:=\frac{1}{\ell_{h m 3}(j)\left(1+N \hat{\tau} \sum_{c} \ell_{1000 G}(j, c)\right)^{2}} .
$$

Baseline model. The 53 functional categories, derived from 24 main annotations, were obtained as follows:

- Coding, 3'-UTR, 5'-UTR promoter, and intron annotations from the RefSeq gene model were obtained from $\mathrm{UCSC}^{17}$ and post-processed by Gusev et al. ${ }^{13}$

- Digital genomic footprint and transcription factor binding site annotations were obtained from ENCODE $^{3}$ and post-processed by Gusev et al. ${ }^{13}$

- The combined chromHMM/Segway annotations for six cell lines were obtained from Hoffman et al. ${ }^{20} \mathrm{CTCF}$, promoter flanking, transcribed, transcription start site, strong enhancer, and weak enhancers are a union the six cell lines; repressed is an intersection over the six cell lines.

- DNase I hypersensitive sites (DHSs) are a combination of ENCODE and Roadmap data, postprocessed by Trynka et al. ${ }^{5}$ We combined the cell-type-specific annotations into two annotations for inclusion in the full baseline model: a union of all cell types, and a union of only fetal cell types. DHS and fetal DHS.

- H3K4me1, H3K4me, and H3K9ac were all obtained from Roadmap and post-processed by Trynka et al. ${ }^{5}$ For each, we took a union over cell types for the full baseline model, and used the individual cell types for our cell-type-specific analysis.

- One version of H3K27ac was obtained from Roadmap, post-processed, ${ }^{18}$ and a second version of H3K27ac was obtained from the data of Hnisz et al. ${ }^{19}$ For each, we took a union over cell types for the full baseline model, and used the individual cell types for our cell-type-specific analysis.

- Super enhancers were also obtained from Hnisz et al, ${ }^{19}$ and comprise a subset of the H3K27ac annotation from that paper. We took a union over cell types for the full baseline model

- Regions conserved in mammals were obtained from Lindblad-Toh et al., ${ }^{21}$ post-processed by Ward and Kellis. ${ }^{31}$

- FANTOM5 enhancers were obtained from Andersson et al. ${ }^{22}$

- For each of these 24 categories, we added a 500bp window around the category as an additional category to keep our heritability estimates from being inflated by heritability in flanking regions. ${ }^{13}$ 
- For each of DHS, H3K4me1, H3K4me3, and H3K9ac, we added a 100bp window around the ChIPseq peak as an additional category.

- We added an additional category containing all SNPs.

WTCCC1 genotypes. We used chromosome 1 genotypes from the NBS and 1966BC control cohorts from the Wellcome Trust Case-Control Consortium. ${ }^{23}$ Imputation of the genotypes to integrated phase1 v3 1000 Genomes and QC were done as in Gusev et al.; ${ }^{13}$ we removed any SNPs that were below a MAF of 0.01 , were above 0.002 missingness, or deviated from Hardy-Weinberg equilibrium at a $P<0.01$.

Choice of phenotypes. We quantified the combination of sample size and heritability by the zscore of total SNP-heritability in the baseline analysis. We applied our method to all traits with available summary statistics, and removed all traits with a heritability z-score less than six. We then removed one of each pair of traits with a large genetic correlation $(>0.95)$ : college attendance, which has a very high genetic correlation with years of education, and total cholesterol, which has a very high genetic correlation with LDL. ${ }^{16}$

Meta-analysis over traits. For our meta-analysis over traits, we identified pairs of traits with substantial sample overlap and trait correlation by using the intercept of LD score regression for genetic covariance. Specifically, we identified pairs of traits for which the intercept on N1N2 scale, which is an unbiased estimator of phenotypic correlation times sample overlap, was at least $10 \%$ of the sample size of either of the traits, and we excluded one of each such pair. The remaining set of traits was: Height, BMI, menarche, LDL levels, coronary artery disease, schizophrenia, educational attainment, smoking behavior, and rheumatoid arthritis. We then performed a random-effects meta-analysis of proportion of heritability over these phenotypes for each functional category. The results are in Figure 2 and Table S3.

Choice of traits to include in Figure 3. Height, BMI, age at menarche, and schizophrenia are the four traits with the highest combination of SNP heritability and sample size, which we quantify by the z-score of total heritability in the baseline analysis. We also included a meta-analysis of immunological diseases, since they have a different pattern of enrichment from other traits; for example FANTOM5 enhancers are very enriched for immunological diseases but not for other traits. This meta-analysis included only rheumatoid arthritis and Crohn's disease; we excluded ulcerative colitis because that dataset shares controls with the Crohn's disease dataset. 
Robustness to derived allele frequency. To check that our results are not affected by a derivedallele-frequency-dependent genetic architecture, we repeated the meta-analysis over traits with a model that contained all of the categories of the full baseline model as well as seven derived allele frequency bins to the model as extra annotations: $0-0.1,0.1-0.2,0.2-0.3,0.3-0.4,0.4-0.6,0.6-0.8$, and $0.8-1$. This allowed for effect size to depend on derived allele frequency, independently of functional annotation. These results are very similar to our results without derived allele frequency bins, and are displayed in Table S5.

Cell-type specific analysis. We used all available cell types from the four histone marks, excluding cell lines and cells labeled as cultured cells to limit ourselves to data with the clearest biological interpretation. The resulting cell-type-specific annotations are listed in Table S6. We then added each annotation individually to the baseline model and evaluated the significance of the coefficient $\tau_{c}$ of the cell-type-specific annofarh2014naturetation. Next, we combined the 220 cell-type-specific annotations into 10 cell-type groups and repeated the same analysis.

Discussion of other methods. There are no other methods designed to estimate genome-wide components of heritability from summary statistics. However, there are existing methods that identify enriched functional categories and cell types from summary statistics; here, we discuss a few of these methods.

A paper by Pickrell ${ }^{8}$ combines GWAS data with functional data to identify enriched and depleted functional categories, and leverages the resulting model to increase GWAS power. While the method is effective at increasing power and identifies many interesting enrichments, it is unclear whether the method is effective at ranking cell types; for example, fetal fibroblasts are the top cell type for Crohn's disease. This could be because the model only allows for one causal SNP per locus, or could be a result of including all cell types simultaneously, thereby penalizing redundant cell types.

Kichaev et al. ${ }^{7}$ introduce a new method that leverages functional data for improved fine-mapping. Their method also outputs annotations associated with disease. While their method is effective in increasing fine-mapping resolution, it is again unclear whether the method is effective at ranking cell types; for example, the cell types they identify as contributing the most to HDL, LDL, and Triglycerides are muscle, kidney, and fetal small intestine, respectively, whereas the top cell types for those three phenotypes identified using our method are liver, liver, and liver. The lower power of this method in ranking cell types is likely because it considers only genome-wide significant loci. Similarly, a recent 
method from Farh et al. ${ }^{6}$ focuses on fine-mapping and considers only genome-wide significant loci, although their cell-type-specific results are more concordant with known biology.

Maurano et al. use enrichment of SNPs passing $P$-value thresholds of increasing stringency to identify important cell types. However, they are implicitly assuming that the functional annotation at a GWAS SNP matches the functional annotation at the causal SNP. While this could be true for functional annotations composed of very wide regions, it is not likely to be true for functional annotations composed of smaller regions, such as conserved regions. Moreover, their method does not account for total LD, and so could give biased results if used to compare functional annotations with different average amounts of total LD.

The method of Trynka et al. ${ }^{5}$ (also see a more recent manuscript ${ }^{44}$ ) is conservative in its identification of enrichment, comparing to a null obtained by local shifting rather than a genome-wide null, and leverages only genome-wide significant SNPs. As a result, they have very low power not only in traits such as bipolar disorder which have few genome-wide significant loci, but even for traits such as rheumatoid arthritis that have many significant loci. (Lowest $P$-value $10^{-4}$ much larger than the lowest $P$-value given by LD Score regression, $2 \times 10^{-7}$.) 


\section{Supplementary Information}

\section{Members of the Schizophrenia Working Group of the Psychiatric Genetics Consor-}

tium. The members of the Schizophrenia Working Group of the Psychiatric Genetics Consortium are Stephan Ripke, Benjamin M. Neale, Aiden Corvin, James T.R. Walters, Kai-How Farh, Peter A. Holmans, Phil Lee, Brendan Bulik-Sullivan, David A. Collier, Hailiang Huang, Tune H. Pers, Ingrid Agartz, Esben Agerbo, Margot Albus, Madeline Alexander, Farooq Amin, Silviu A. Bacanu, Martin Begemann, Richard A. Belliveau, Jr., Judit Bene, Sarah E. Bergen, Elizabeth Bevilacqua, Tim B. Bigdeli, Donald W. Black, Anders D. Brglum, Richard Bruggeman, Nancy G. Buccola, Randy L. Buckner, William Byerley, Wiepke Cahn, Guiqing Cai, Dominique Campion, Rita M. Cantor, Vaughan J. Carr, Noa Carrera, Stanley V. Catts, Kimberly D. Chambert, Raymond C.K. Chan, Ronald Y.L. Chen, Eric Y.H. Chen, Wei Cheng, Eric F.C. Cheung, Siow Ann Chong, C. Robert Cloninger, David Cohen, Nadine Cohen, Paul Cormican, Nick Craddock, James J. Crowley, David Curtis, Michael Davidson, Kenneth L. Davis, Franziska Degenhardt, Jurgen Del Favero, Lynn E. DeLisi, Ditte Demontis, Dimitris Dikeos, Timothy Dinan, Srdjan Djurovic, Gary Donohoe, Elodie Drapeau, Jubao Duan, Frank Dudbridge, Naser Durmishi, Peter Eichhammer, Johan Eriksson, Valentina Escott-Price, Laurent Essioux, Ayman H. Fanous, Martilias S. Farrell, Josef Frank, Lude Franke, Robert Freedman, Nelson B. Freimer, Marion Friedl, Joseph I. Friedman, Menachem Fromer, Giulio Genovese, Lyudmila Georgieva, Elliot S. Gershon, Ina Giegling, Paola Giusti-Rodrguez, Stephanie Godard, Jacqueline I. Goldstein, Vera Golimbet, Srihari Gopal, Jacob Gratten, Jakob Grove, Lieuwe de Haan, Christian Hammer, Marian L. Hamshere, Mark Hansen, Thomas Hansen, Vahram Haroutunian, Annette M. Hartmann, Frans A. Henskens, Stefan Herms, Joel N. Hirschhorn, Per Hoffmann, Andrea Hofman, Mads V. Hollegaard, David M. Hougaard, Masashi Ikeda, Inge Joa, Antonio Julia, Rene S. Kahn, Luba Kalaydjieva, Sena Karachanak-Yankova, Juha Karjalainen, David Kavanagh, Matthew C. Keller, Brian J. Kelly, James L. Kennedy, Andrey Khrunin, Yunjung Kim, Janis Klovins, James A. Knowles, Bettina Konte, Vaidutis Kucinskas, Zita Ausrele Kucinskiene, Hana Kuzelova-Ptackova, Anna K. Kahler, Claudine Laurent, Jimmy Lee Chee Keong, S. Hong Lee, Sophie E. Legge, Bernard Lerer, Miaoxin Li, Tao Li, Kung-Yee Liang, Jeffrey Lieberman, Svetlana Limborska, Carmel M. Loughland, Jan Lubinski, Jouko Lnnqvist, Milan Macek, Jr., Patrik K.E. Magnusson, Brion S. Maher, Wolfgang Maier, Jacques Mallet, Sara Marsal, Manuel Mattheisen, Morten Mattingsdal, Robert W. McCarley, Colm McDonald, Andrew M. McIntosh, Sandra Meier, Carin J. Meijer, Bela Melegh, Ingrid Melle, Raquelle I. Mesholam-Gately, Andres Metspalu, Patricia T. Michie, Lili Milani, Vihra Milanova, Younes Mokrab, Derek W. Morris, Ole Mors, Preben 
B. Mortensen, Kieran C. Murphy, Robin M. Murray, Inez Myin-Germeys, Bertram Mller-Myhsok, Mari Nelis, Igor Nenadic, Deborah A. Nertney, Gerald Nestadt, Kristin K. Nicodemus, Liene Nikitina-Zake, Laura Nisenbaum, Annelie Nordin, Eadbhard O'Callaghan, Colm O'Dushlaine, F. Anthony O'Neill, Sang-Yun Oh, Ann Olincy, Line Olsen, Jim Van Os, Psychosis Endophenotypes International Consortium, Christos Pantelis, George N. Papadimitriou, Sergi Papiol, Elena Parkhomenko, Michele T. Pato, Tiina Paunio, Milica Pejovic-Milovancevic, Diana O. Perkins, Olli Pietilinen, Jonathan Pimm, Andrew J. Pocklington, John Powell, Alkes Price, Ann E. Pulver, Shaun M. Purcell, Digby Quested, Henrik B. Rasmussen, Abraham Reichenberg, Mark A. Reimers, Alexander L. Richards, Joshua L. Roffman, Panos Roussos, Douglas M. Ruderfer, Veikko Salomaa, Alan R. Sanders, Ulrich Schall, Christian R. Schubert, Thomas G. Schulze, Sibylle G. Schwab, Edward M. Scolnick, Rodney J. Scott, Larry J. Seidman, Jianxin Shi, Engilbert Sigurdsson, Teimuraz Silagadze, Jeremy M. Silverman, Kang Sim, Petr Slominsky, Jordan W. Smoller, Hon-Cheong So, Chris C.A. Spencer, Eli A. Stahl, Hreinn Stefansson, Stacy Steinberg, Elisabeth Stogmann, Richard E. Straub, Eric Strengman, Jana Strohmaier, T. Scott Stroup, Mythily Subramaniam, Jaana Suvisaari, Dragan M. Svrakic, Jin P. Szatkiewicz, Erik Sderman, Srinivas Thirumalai, Draga Toncheva, Paul A. Tooney, Sarah Tosato, Juha Veijola, John Waddington, Dermot Walsh, Dai Wang, Qiang Wang, Bradley T. Webb, Mark Weiser, Dieter B. Wildenauer, Nigel M. Williams, Stephanie Williams, Stephanie H. Witt, Aaron R. Wolen, Emily H.M. Wong, Brandon K. Wormley, Jing Qin Wu, Hualin Simon Xi, Clement C. Zai, Xuebin Zheng, Fritz Zimprich, Naomi R. Wray, Kari Stefansson, Peter M. Visscher, Wellcome Trust Case Control Consortium, Rolf Adolfsson, Ole A. Andreassen, Douglas H.R. Blackwood, Elvira Bramon, Joseph D. Buxbaum, Anders D. Brglum, Sven Cichon, Ariel Darvasi, Enrico Domenici, Hannelore Ehrenreich, Tonu Esko, Pablo V. Gejman, Michael Gill, Hugh Gurling, Christina M. Hultman, Nakao Iwata, Assen V. Jablensky, Erik G. Jonsson, Kenneth S. Kendler, George Kirov, Jo Knight, Todd Lencz, Douglas F. Levinson, Qingqin S. Li, Jianjun Liu, Anil K. Malhotra, Steven A. McCarroll, Andrew McQuillin, Jennifer L. Moran, Preben B. Mortensen, Bryan J. Mowry, Markus M. Nthen, Roel A. Ophoff, Michael J. Owen, Aarno Palotie, Carlos N. Pato, Tracey L. Petryshen, Danielle Posthuma, Marcella Rietschel, Brien P. Riley, Dan Rujescu, Pak C. Sham, Pamela Sklar, David St. Clair, Daniel R. Weinberger, Jens R. Wendland, Thomas Werge, Mark J. Daly, Patrick F. Sullivan, and Michael C. O’Donovan. 


\begin{tabular}{|c|c|c|}
\hline Annotation & Prop. SNPs & $\begin{array}{l}\text { Mean segment } \\
\text { length (bp) }\end{array}$ \\
\hline Coding & 0.015 & 315 \\
\hline Conserved & 0.026 & 34 \\
\hline CTCF & 0.024 & 490 \\
\hline DGF & 0.138 & 208 \\
\hline DHS & 0.168 & 358 \\
\hline FANTOM5 Enhancer & 0.004 & 289 \\
\hline Enhancer & 0.063 & 678 \\
\hline Fetal DHS & 0.085 & 339 \\
\hline $\mathrm{H} 3 \mathrm{~K} 27 \mathrm{ac}^{19}$ & 0.391 & 12411 \\
\hline H3K27ac ${ }^{18}$ & 0.269 & 1051 \\
\hline H3K4me1 & 0.427 & 1676 \\
\hline H3K4me3 & 0.133 & 941 \\
\hline H3К9ас & 0.126 & 964 \\
\hline Intron & 0.387 & 6537 \\
\hline PromoterFlanking & 0.008 & 266 \\
\hline Promoter & 0.031 & 4192 \\
\hline Repressed & 0.461 & 572 \\
\hline Super Enhancer & 0.168 & 54744 \\
\hline TFBS & 0.132 & 509 \\
\hline Transcribed & 0.345 & 484 \\
\hline TSS & 0.018 & 813 \\
\hline 3-prime UTR & 0.011 & 844 \\
\hline 5-prime UTR & 0.005 & 197 \\
\hline Weak Enhancer & 0.021 & 249 \\
\hline
\end{tabular}

Table S1: Annotations used. For DHS, H3K4me1, H3K4me3, and H3K9ac, we include peaks and regions as two annotations. For the annotations from the Hoffman segmentation, ${ }^{20}$ we union over six cell lines for each category except Repressed, where we take an intersection instead. We also include a 500bp window around each annotation as a separate annotation in the model. 


\begin{tabular}{lll} 
Phenotype & Reference/consortium & $N$ \\
\hline Height & Lango Allen et al., 2010 Nature & 133,858 \\
BMI & Speliotes et al., 2010 Nat Genet & 123,912 \\
Age at menarche & Perry et al., 2014 Nature & 132,989 \\
LDL & Teslovich et al., 2010 Nature & 95,454 \\
HDL & Teslovich et al., 2010 Nature & 99,900 \\
Triglycerides & Teslovich et al., 2010 Nature & 96,598 \\
Coronary Artery Disease & Schunkert et al., Nat Genet 2011 & 86,995 \\
Type-2 Diabetes & Morris et al., 2012 Nat Genet & 69,033 \\
Fasting glucose & Manning et. al., Nat Genet, 2012 & 58,074 \\
Schizophrenia & SCZ Working Group of the PGC, 2014 Nature & 70,100 \\
Bipolar Disorder & Bip Working Group of the PGC, 2011 Nat Genet & 16,731 \\
Anorexia & Boraska et al., 2014 Mol Psych & 17,767 \\
Educational attainment & Rietveld et al., Science 2013 & 101,069 \\
Ever smoked & TAG Consortium, 2010 Nat Genet & 74,035 \\
Rheumatoid Arthritis & Okada et al., 2014 Nature & 38,242 \\
Crohn's Disease & Jostins et al., 2012 Nature & 20,883 \\
Ulcerative Colitis & Jostins et al., 2012 Nature & 27,432
\end{tabular}

Table S2: Phenotypes used in the main analyses. The total number of phenotype measurements is 1,263,072. There is sample overlap among the studies, so the number of unique individuals is lower. 
bioRxiv preprint doi: https://doi.org/10.1101/014241; this version posted January 23, 2015. The copyright holder for this preprint (which was not certified by peer review) is the author/funder, who has granted bioRxiv a license to display the preprint in perpetuity. It is made available under aCC-BY-ND 4.0 International license.

\begin{tabular}{|c|c|c|c|}
\hline Annotation & Prop. SNPs & Prop. $h^{2}$ & Enrichment \\
\hline Coding & 0.015 & $0.104(0.012)$ & $7.122(0.840)$ \\
\hline Coding $+500 \mathrm{bp}$ & 0.065 & $0.190(0.030)$ & $2.938(0.467)$ \\
\hline Conserved & 0.026 & $0.347(0.039)$ & $13.322(1.500$ \\
\hline Conserved $+500 \mathrm{bp}$ & 0.333 & $0.654(0.026)$ & $1.966(0.078)$ \\
\hline CTCF & 0.024 & $-0.004(0.019)$ & $-0.176(0.789)$ \\
\hline $\mathrm{CTCF}+500 \mathrm{bp}$ & 0.071 & $0.059(0.019)$ & $0.825(0.272)$ \\
\hline DGF & 0.138 & $0.358(0.094)$ & $2.604(0.686)$ \\
\hline $\mathrm{DGF}+500 \mathrm{bp}$ & 0.542 & $0.761(0.069)$ & $1.405(0.128)$ \\
\hline DHS peaks & 0.112 & $0.224(0.063)$ & $2.005(0.566)$ \\
\hline DHS & 0.168 & $0.285(0.069)$ & $1.699(0.410)$ \\
\hline DHS $+500 \mathrm{bp}$ & 0.499 & $0.788(0.041)$ & $1.580(0.082)$ \\
\hline FANTOM5 Enhancer & 0.004 & $-0.003(0.009)$ & $-0.727(2.160)$ \\
\hline FANTOM5 Enhancer + 500bp & 0.019 & $0.017(0.017)$ & $0.878(0.896)$ \\
\hline Enhancer & 0.063 & $0.238(0.050)$ & $3.764(0.784)$ \\
\hline Enhancer $+500 \mathrm{bp}$ & 0.154 & $0.359(0.042)$ & $2.334(0.272)$ \\
\hline Fetal DHS & 0.085 & $0.238(0.043)$ & $2.805(0.512)$ \\
\hline Fetal DHS + 500bp & 0.285 & $0.591(0.058)$ & $2.073(0.204)$ \\
\hline $\mathrm{H} 3 \mathrm{~K} 27 \mathrm{ac}^{19}$ & 0.391 & $0.631(0.054)$ & $1.612(0.138)$ \\
\hline $\mathrm{H} 3 \mathrm{~K} 27 \mathrm{ac}^{19}+500 \mathrm{bp}$ & 0.423 & $0.664(0.059)$ & $1.572(0.140)$ \\
\hline $\mathrm{H} 3 \mathrm{~K} 27 \mathrm{ac}^{18}$ & 0.269 & $0.490(0.054)$ & $1.818(0.200)$ \\
\hline $\mathrm{H} 3 \mathrm{~K} 27 \mathrm{ac}^{18}+500 \mathrm{bp}$ & 0.336 & $0.611(0.040)$ & $1.817(0.118)$ \\
\hline H3K4me1 peaks & 0.171 & $0.447(0.040)$ & $2.611(0.235)$ \\
\hline H3K4me1 & 0.427 & $0.792(0.065)$ & $1.857(0.152)$ \\
\hline H3K4me1 + 500bp & 0.609 & $0.910(0.039)$ & $1.494(0.064)$ \\
\hline H3K4me3 peaks & 0.042 & $0.158(0.025)$ & $3.780(0.599)$ \\
\hline H3K4me3 & 0.133 & $0.344(0.045)$ & $2.582(0.336)$ \\
\hline H3K4me3 + 500bp & 0.255 & $0.487(0.056)$ & $1.905(0.220)$ \\
\hline H3K9ac peaks & 0.039 & $0.248(0.024)$ & $6.399(0.618)$ \\
\hline H3К9ас & 0.126 & $0.408(0.056)$ & $3.233(0.441)$ \\
\hline H3K9ac $+500 \mathrm{bp}$ & 0.231 & $0.504(0.040)$ & $2.184(0.172)$ \\
\hline Intron & 0.387 & $0.462(0.014)$ & $1.192(0.035)$ \\
\hline Intron $+500 \mathrm{bp}$ & 0.397 & $0.521(0.015)$ & $1.313(0.037)$ \\
\hline PromoterFlanking & 0.008 & $0.004(0.011)$ & $0.448(1.314)$ \\
\hline PromoterFlanking $+500 \mathrm{bp}$ & 0.033 & $0.081(0.018)$ & $2.433(0.531)$ \\
\hline Promoter & 0.031 & $0.087(0.016)$ & $2.806(0.512)$ \\
\hline Promoter $+500 \mathrm{bp}$ & 0.039 & $0.080(0.016)$ & $2.063(0.424)$ \\
\hline Repressed & 0.461 & $0.286(0.063)$ & $0.619(0.137)$ \\
\hline Repressed $+500 \mathrm{bp}$ & 0.719 & $0.446(0.049)$ & $0.620(0.068)$ \\
\hline Super Enhancer & 0.168 & $0.304(0.035)$ & $1.804(0.210)$ \\
\hline Super Enhancer $+500 \mathrm{bp}$ & 0.172 & $0.319(0.037)$ & $1.857(0.216)$ \\
\hline TFBS & 0.132 & $0.445(0.063)$ & $3.357(0.479)$ \\
\hline $\mathrm{TFBS}+500 \mathrm{bp}$ & 0.343 & $0.503(0.052)$ & $1.464(0.152)$ \\
\hline Transcribed & 0.345 & $0.407(0.038)$ & $1.179(0.111)$ \\
\hline Transcribed $+500 \mathrm{bp}$ & 0.763 & $0.721(0.028)$ & $0.945(0.036)$ \\
\hline TSS & 0.018 & $0.104(0.023)$ & $5.682(1.278)$ \\
\hline $\mathrm{TSS}+500 \mathrm{bp}$ & 0.035 & $0.172(0.029)$ & $4.940(0.827)$ \\
\hline 3-prime UTR & 0.011 & $0.054(0.009)$ & $4.892(0.856)$ \\
\hline 3-prime UTR + 500bp & 0.027 & $0.074(0.011)$ & $2.730(0.412)$ \\
\hline 5-prime UTR & 0.005 & $0.028(0.008)$ & $5.243(1.385)$ \\
\hline 5-prime UTR $+500 \mathrm{bp}$ & 0.028 & $0.065(0.010)$ & $2.340(0.374)$ \\
\hline Weak Enhancer & 0.021 & $0.070(0.023)$ & $3.323(1.090)$ \\
\hline Weak Enhancer $+500 \mathrm{bp}$ & 0.089 & $0.199(0.030)$ & $2.238(0.335)$ \\
\hline
\end{tabular}

Table S3: Proportion of SNP-heritability and enrichment for different functional categories. We display results meta-analyzed across nine traits for each of the 53 annotations, including two distinct H3K27ac annotations (Methods). Although true SNP-heritability is non-negative, we report here unbiased estimates, we can be neg\&ve (Methods). 
bioRxiv preprint doi: https://doi.org/10.1101/014241; this version posted January 23, 2015. The copyright holder for this preprint (which was not certified by peer review) is the author/funder, who has granted bioRxiv a license to display the preprint in perpetuity. It is made available under aCC-BY-ND 4.0 International license.

\begin{tabular}{|c|c|c|c|}
\hline Annotation & Prop. SNPs & Prop. $h^{2}$ & Enrichment \\
\hline Coding & 0.015 & $0.127(0.036)$ & $8.661(2.475)$ \\
\hline Coding $+500 \mathrm{bp}$ & 0.065 & $0.192(0.034)$ & $2.979(0.521)$ \\
\hline Conserved & 0.026 & $0.340(0.051)$ & $13.029(1.950)$ \\
\hline Conserved $+500 \mathrm{bp}$ & 0.333 & $0.636(0.053)$ & $1.913(0.159)$ \\
\hline CTCF & 0.024 & $0.050(0.045)$ & $2.118(1.909)$ \\
\hline $\mathrm{CTCF}+500 \mathrm{bp}$ & 0.071 & $0.089(0.048)$ & $1.249(0.669)$ \\
\hline DGF & 0.138 & $0.585(0.085)$ & $4.253(0.621)$ \\
\hline $\mathrm{DGF}+500 \mathrm{bp}$ & 0.542 & $0.983(0.066)$ & $1.815(0.122)$ \\
\hline DHS peaks & 0.112 & $0.429(0.107)$ & $3.837(0.958)$ \\
\hline DHS & 0.168 & $0.512(0.120)$ & $3.050(0.717)$ \\
\hline DHS $+500 \mathrm{bp}$ & 0.499 & $0.787(0.062)$ & $1.579(0.124)$ \\
\hline FANTOM5 Enhancer & 0.004 & $0.013(0.019)$ & $2.930(4.429)$ \\
\hline FANTOM5 Enhancer + 500bp & 0.019 & $0.014(0.023)$ & $0.711(1.224)$ \\
\hline Enhancer & 0.063 & $0.184(0.064)$ & $2.906(1.018)$ \\
\hline Enhancer $+500 \mathrm{bp}$ & 0.154 & $0.396(0.054)$ & $2.573(0.353)$ \\
\hline Fetal DHS & 0.085 & $0.281(0.089)$ & $3.311(1.050)$ \\
\hline Fetal DHS + 500bp & 0.285 & $0.504(0.080)$ & $1.770(0.280)$ \\
\hline $\mathrm{H} 3 \mathrm{~K} 27 \mathrm{ac}^{19}$ & 0.391 & $0.782(0.035)$ & $1.999(0.089)$ \\
\hline $\mathrm{H} 3 \mathrm{~K} 27 \mathrm{ac}^{19}+500 \mathrm{bp}$ & 0.423 & $0.780(0.043)$ & $1.846(0.101)$ \\
\hline $\mathrm{H} 3 \mathrm{~K} 27 \mathrm{ac}^{18}$ & 0.269 & $0.533(0.065)$ & $1.978(0.243)$ \\
\hline $\mathrm{H} 3 \mathrm{~K} 27 \mathrm{ac}^{18}+500 \mathrm{bp}$ & 0.336 & $0.674(0.061)$ & $2.005(0.181)$ \\
\hline H3K4me1 peaks & 0.171 & $0.422(0.091)$ & $2.465(0.530)$ \\
\hline H3K4me1 & 0.427 & $0.965(0.074)$ & $2.261(0.173)$ \\
\hline H3K4me1 + 500bp & 0.609 & $0.946(0.036)$ & $1.553(0.060)$ \\
\hline H3K4me3 peaks & 0.042 & $0.075(0.053)$ & $1.791(1.263)$ \\
\hline $\mathrm{H} 3 \mathrm{~K} 4 \mathrm{me} 3$ & 0.133 & $0.429(0.071)$ & $3.215(0.535)$ \\
\hline $\mathrm{H} 3 \mathrm{~K} 4 \mathrm{me} 3+500 \mathrm{bp}$ & 0.255 & $0.584(0.054)$ & $2.286(0.211)$ \\
\hline H3K9ac peaks & 0.039 & $0.266(0.060)$ & $6.851(1.539)$ \\
\hline H3К9ac & 0.126 & $0.558(0.066)$ & $4.428(0.520)$ \\
\hline H3K9ac $+500 \mathrm{bp}$ & 0.231 & $0.602(0.055)$ & $2.612(0.237)$ \\
\hline Intron & 0.387 & $0.448(0.031)$ & $1.156(0.081)$ \\
\hline Intron $+500 \mathrm{bp}$ & 0.397 & $0.532(0.025)$ & $1.340(0.064)$ \\
\hline PromoterFlanking & 0.008 & $-0.046(0.025)$ & $-5.400(3.021)$ \\
\hline PromoterFlanking $+500 \mathrm{bp}$ & 0.033 & $0.116(0.034)$ & $3.453(1.029)$ \\
\hline Promoter & 0.031 & $0.089(0.033)$ & $2.848(1.057)$ \\
\hline Promoter $+500 \mathrm{bp}$ & 0.039 & $0.101(0.020)$ & $2.603(0.528)$ \\
\hline Repressed & 0.461 & $0.115(0.093)$ & $0.248(0.203)$ \\
\hline Repressed $+500 \mathrm{bp}$ & 0.719 & $0.369(0.039)$ & $0.513(0.054)$ \\
\hline Super Enhancer & 0.168 & $0.384(0.026)$ & $2.280(0.155)$ \\
\hline Super Enhancer $+500 \mathrm{bp}$ & 0.172 & $0.398(0.023)$ & $2.317(0.137)$ \\
\hline TFBS & 0.132 & $0.455(0.083)$ & $3.438(0.628)$ \\
\hline TFBS $+500 \mathrm{bp}$ & 0.343 & $0.682(0.065)$ & $1.984(0.190)$ \\
\hline Transcribed & 0.345 & $0.572(0.094)$ & $1.657(0.272)$ \\
\hline Transcribed $+500 \mathrm{bp}$ & 0.763 & $0.652(0.052)$ & $0.854(0.068)$ \\
\hline TSS & 0.018 & $0.107(0.038)$ & $5.853(2.103)$ \\
\hline $\mathrm{TSS}+500 \mathrm{bp}$ & 0.035 & $0.174(0.032)$ & $4.991(0.905)$ \\
\hline 3-prime UTR & 0.011 & $0.102(0.032)$ & $9.240(2.857)$ \\
\hline 3 -prime UTR $+500 \mathrm{bp}$ & 0.027 & $0.118(0.032)$ & $4.380(1.176)$ \\
\hline 5-prime UTR & 0.005 & $0.045(0.022)$ & $8.310(4.056)$ \\
\hline 5 -prime UTR $+500 \mathrm{bp}$ & 0.028 & $0.069(0.023)$ & $2.470(0.840)$ \\
\hline Weak Enhancer & 0.021 & $0.018(0.043)$ & $0.853(2.025)$ \\
\hline Weak Enhancer $+500 \mathrm{bp}$ & 0.089 & $0.109(0.048)$ & $1.229(0.539)$ \\
\hline
\end{tabular}

(S4.A) Proportion of heritability and enrichment for different functional categories for Height. 
bioRxiv preprint doi: https://doi.org/10.1101/014241; this version posted January 23, 2015. The copyright holder for this preprint (which was not certified by peer review) is the author/funder, who has granted bioRxiv a license to display the preprint in perpetuity. It is made available under aCC-BY-ND 4.0 International license.

\begin{tabular}{|c|c|c|c|}
\hline Annotation & Prop. SNPs & Prop. $h^{2}$ & Enrichment \\
\hline Coding & 0.015 & $0.104(0.027)$ & $7.071(1.813)$ \\
\hline Coding $+500 \mathrm{bp}$ & 0.065 & $0.129(0.032)$ & $1.992(0.500)$ \\
\hline Conserved & 0.026 & $0.508(0.059)$ & $19.504(2.270)$ \\
\hline Conserved $+500 \mathrm{bp}$ & 0.333 & $0.545(0.068)$ & $1.640(0.205)$ \\
\hline CTCF & 0.024 & $-0.027(0.049)$ & $-1.135(2.051)$ \\
\hline $\mathrm{CTCF}+500 \mathrm{bp}$ & 0.071 & $0.025(0.045)$ & $0.358(0.640)$ \\
\hline DGF & 0.138 & $0.034(0.124)$ & $0.249(0.899)$ \\
\hline $\mathrm{DGF}+500 \mathrm{bp}$ & 0.542 & $0.674(0.068)$ & $1.244(0.125)$ \\
\hline DHS peaks & 0.112 & $0.125(0.100)$ & $1.123(0.894)$ \\
\hline DHS & 0.168 & $0.093(0.123)$ & $0.554(0.733)$ \\
\hline DHS $+500 \mathrm{bp}$ & 0.499 & $0.890(0.123)$ & $1.785(0.246)$ \\
\hline FANTOM5 Enhancer & 0.004 & $0.003(0.018)$ & $0.792(4.139)$ \\
\hline FANTOM5 Enhancer + 500bp & 0.019 & $-0.004(0.026)$ & $-0.218(1.364)$ \\
\hline Enhancer & 0.063 & $0.259(0.052)$ & $4.083(0.829)$ \\
\hline Enhancer $+500 \mathrm{bp}$ & 0.154 & $0.305(0.052)$ & $1.980(0.337)$ \\
\hline Fetal DHS & 0.085 & $0.112(0.089)$ & $1.320(1.045)$ \\
\hline Fetal DHS + 500bp & 0.285 & $0.572(0.081)$ & $2.008(0.284)$ \\
\hline $\mathrm{H} 3 \mathrm{~K} 27 \mathrm{ac}^{19}$ & 0.391 & $0.514(0.037)$ & $1.315(0.096)$ \\
\hline $\mathrm{H} 3 \mathrm{~K} 27 \mathrm{ac}^{19}+500 \mathrm{bp}$ & 0.423 & $0.564(0.039)$ & $1.334(0.093)$ \\
\hline $\mathrm{H} 3 \mathrm{~K} 27 \mathrm{ac}^{18}$ & 0.269 & $0.447(0.059)$ & $1.660(0.221)$ \\
\hline $\mathrm{H} 3 \mathrm{~K} 27 \mathrm{ac}^{18}+500 \mathrm{bp}$ & 0.336 & $0.557(0.067)$ & $1.657(0.199)$ \\
\hline H3K4me1 peaks & 0.171 & $0.394(0.102)$ & $2.298(0.595)$ \\
\hline H3K4me1 & 0.427 & $0.668(0.092)$ & $1.565(0.216)$ \\
\hline H3K4me1 + 500bp & 0.609 & $0.880(0.052)$ & $1.445(0.086)$ \\
\hline H3K4me 3 peaks & 0.042 & $0.150(0.054)$ & $3.583(1.295)$ \\
\hline $\mathrm{H} 3 \mathrm{~K} 4 \mathrm{me} 3$ & 0.133 & $0.219(0.057)$ & $1.646(0.429)$ \\
\hline $\mathrm{H} 3 \mathrm{~K} 4 \mathrm{me} 3+500 \mathrm{bp}$ & 0.255 & $0.405(0.054)$ & $1.585(0.212)$ \\
\hline H3K9ac peaks & 0.039 & $0.279(0.056)$ & $7.206(1.452)$ \\
\hline H3К9ac & 0.126 & $0.214(0.066)$ & $1.699(0.520)$ \\
\hline H3K9ac $+500 \mathrm{bp}$ & 0.231 & $0.450(0.051)$ & $1.952(0.222)$ \\
\hline Intron & 0.387 & $0.424(0.032)$ & $1.094(0.083)$ \\
\hline Intron $+500 \mathrm{bp}$ & 0.397 & $0.490(0.030)$ & $1.233(0.076)$ \\
\hline PromoterFlanking & 0.008 & $0.004(0.023)$ & $0.477(2.702)$ \\
\hline PromoterFlanking $+500 \mathrm{bp}$ & 0.033 & $0.042(0.035)$ & $1.262(1.035)$ \\
\hline Promoter & 0.031 & $0.080(0.031)$ & $2.559(0.989)$ \\
\hline Promoter $+500 \mathrm{bp}$ & 0.039 & $0.060(0.024)$ & $1.565(0.615)$ \\
\hline Repressed & 0.461 & $0.321(0.105)$ & $0.696(0.227)$ \\
\hline Repressed $+500 \mathrm{bp}$ & 0.719 & $0.619(0.032)$ & $0.860(0.045)$ \\
\hline Super Enhancer & 0.168 & $0.217(0.019)$ & $1.289(0.114)$ \\
\hline Super Enhancer $+500 \mathrm{bp}$ & 0.172 & $0.251(0.022)$ & $1.464(0.129)$ \\
\hline TFBS & 0.132 & $0.357(0.087)$ & $2.692(0.659)$ \\
\hline $\mathrm{TFBS}+500 \mathrm{bp}$ & 0.343 & $0.438(0.071)$ & $1.275(0.207)$ \\
\hline Transcribed & 0.345 & $0.442(0.088)$ & $1.280(0.256)$ \\
\hline Transcribed $+500 \mathrm{bp}$ & 0.763 & $0.775(0.051)$ & $1.015(0.067)$ \\
\hline TSS & 0.018 & $0.059(0.030)$ & $3.239(1.670)$ \\
\hline $\mathrm{TSS}+500 \mathrm{bp}$ & 0.035 & $0.097(0.030)$ & $2.792(0.874)$ \\
\hline 3-prime UTR & 0.011 & $0.059(0.022)$ & $5.352(2.007)$ \\
\hline 3 -prime UTR $+500 \mathrm{bp}$ & 0.027 & $0.054(0.021)$ & $2.013(0.796)$ \\
\hline 5-prime UTR & 0.005 & $0.035(0.018)$ & $6.541(3.287)$ \\
\hline 5 -prime UTR $+500 \mathrm{bp}$ & 0.028 & $0.055(0.022)$ & $1.984(0.794)$ \\
\hline Weak Enhancer & 0.021 & $0.119(0.039)$ & $5.640(1.837)$ \\
\hline Weak Enhancer $+500 \mathrm{bp}$ & 0.089 & $0.236(0.044)$ & $2.658(0.495)$ \\
\hline
\end{tabular}

(S4.B) Proportion of heritability and enrichment for different functional categories for BMI. 
bioRxiv preprint doi: https://doi.org/10.1101/014241; this version posted January 23, 2015. The copyright holder for this preprint (which was not certified by peer review) is the author/funder, who has granted bioRxiv a license to display the preprint in perpetuity. It is made available under aCC-BY-ND 4.0 International license.

\begin{tabular}{|c|c|c|c|}
\hline Annotation & Prop. SNPs & Prop. $h^{2}$ & Enrichment \\
\hline Coding & 0.015 & $0.123(0.030)$ & $8.413(2.059)$ \\
\hline Coding $+500 \mathrm{bp}$ & 0.065 & $0.094(0.035)$ & $1.453(0.537)$ \\
\hline Conserved & 0.026 & $0.462(0.063)$ & $17.725(2.414)$ \\
\hline Conserved $+500 \mathrm{bp}$ & 0.333 & $0.616(0.090)$ & $1.853(0.271)$ \\
\hline CTCF & 0.024 & $0.022(0.051)$ & $0.935(2.150)$ \\
\hline $\mathrm{CTCF}+500 \mathrm{bp}$ & 0.071 & $0.049(0.053)$ & $0.689(0.749)$ \\
\hline DGF & 0.138 & $0.207(0.113)$ & $1.508(0.823)$ \\
\hline $\mathrm{DGF}+500 \mathrm{bp}$ & 0.542 & $0.429(0.084)$ & $0.793(0.155)$ \\
\hline DHS peaks & 0.112 & $0.008(0.120)$ & $0.071(1.071)$ \\
\hline DHS & 0.168 & $0.052(0.135)$ & $0.311(0.806)$ \\
\hline DHS $+500 \mathrm{bp}$ & 0.499 & $0.631(0.096)$ & $1.265(0.193)$ \\
\hline FANTOM5 Enhancer & 0.004 & $-0.000(0.022)$ & $-0.028(5.150)$ \\
\hline FANTOM5 Enhancer + 500bp & 0.019 & $0.006(0.025)$ & $0.321(1.315)$ \\
\hline Enhancer & 0.063 & $0.137(0.061)$ & $2.163(0.960)$ \\
\hline Enhancer $+500 \mathrm{bp}$ & 0.154 & $0.215(0.059)$ & $1.397(0.384)$ \\
\hline Fetal DHS & 0.085 & $0.108(0.093)$ & $1.272(1.100)$ \\
\hline Fetal DHS + 500bp & 0.285 & $0.291(0.101)$ & $1.020(0.356)$ \\
\hline $\mathrm{H} 3 \mathrm{~K} 27 \mathrm{ac}^{19}$ & 0.391 & $0.455(0.037)$ & $1.164(0.094)$ \\
\hline $\mathrm{H} 3 \mathrm{~K} 27 \mathrm{ac}^{19}+500 \mathrm{bp}$ & 0.423 & $0.489(0.052)$ & $1.158(0.123)$ \\
\hline $\mathrm{H} 3 \mathrm{~K} 27 \mathrm{ac}^{18}$ & 0.269 & $0.409(0.071)$ & $1.517(0.264)$ \\
\hline $\mathrm{H} 3 \mathrm{~K} 27 \mathrm{ac}^{18}+500 \mathrm{bp}$ & 0.336 & $0.486(0.070)$ & $1.446(0.207)$ \\
\hline H3K4me1 peaks & 0.171 & $0.471(0.116)$ & $2.747(0.678)$ \\
\hline H3K4me1 & 0.427 & $0.621(0.085)$ & $1.455(0.200)$ \\
\hline H3K4me1 + 500bp & 0.609 & $0.847(0.057)$ & $1.391(0.094)$ \\
\hline H3K4me3 peaks & 0.042 & $0.211(0.071)$ & $5.042(1.695)$ \\
\hline $\mathrm{H} 3 \mathrm{~K} 4 \mathrm{me} 3$ & 0.133 & $0.237(0.067)$ & $1.779(0.502)$ \\
\hline $\mathrm{H} 3 \mathrm{~K} 4 \mathrm{me} 3+500 \mathrm{bp}$ & 0.255 & $0.308(0.064)$ & $1.207(0.249)$ \\
\hline H3K9ac peaks & 0.039 & $0.220(0.062)$ & $5.671(1.596)$ \\
\hline H3К9ac & 0.126 & $0.345(0.066)$ & $2.736(0.520)$ \\
\hline H3K9ac $+500 \mathrm{bp}$ & 0.231 & $0.460(0.055)$ & $1.996(0.240)$ \\
\hline Intron & 0.387 & $0.437(0.035)$ & $1.129(0.090)$ \\
\hline Intron $+500 \mathrm{bp}$ & 0.397 & $0.537(0.031)$ & $1.353(0.078)$ \\
\hline PromoterFlanking & 0.008 & $0.020(0.031)$ & $2.394(3.660)$ \\
\hline PromoterFlanking $+500 \mathrm{bp}$ & 0.033 & $0.056(0.033)$ & $1.684(0.992)$ \\
\hline Promoter & 0.031 & $0.123(0.033)$ & $3.945(1.051)$ \\
\hline Promoter $+500 \mathrm{bp}$ & 0.039 & $0.116(0.025)$ & $2.995(0.660)$ \\
\hline Repressed & 0.461 & $0.385(0.100)$ & $0.835(0.216)$ \\
\hline Repressed $+500 \mathrm{bp}$ & 0.719 & $0.513(0.038)$ & $0.714(0.053)$ \\
\hline Super Enhancer & 0.168 & $0.213(0.030)$ & $1.264(0.176)$ \\
\hline Super Enhancer $+500 \mathrm{bp}$ & 0.172 & $0.233(0.029)$ & $1.357(0.171)$ \\
\hline TFBS & 0.132 & $0.437(0.098)$ & $3.301(0.737)$ \\
\hline $\mathrm{TFBS}+500 \mathrm{bp}$ & 0.343 & $0.427(0.092)$ & $1.244(0.268)$ \\
\hline Transcribed & 0.345 & $0.436(0.086)$ & $1.263(0.250)$ \\
\hline Transcribed $+500 \mathrm{bp}$ & 0.763 & $0.681(0.057)$ & $0.893(0.075)$ \\
\hline TSS & 0.018 & $0.165(0.043)$ & $9.064(2.354)$ \\
\hline $\mathrm{TSS}+500 \mathrm{bp}$ & 0.035 & $0.167(0.036)$ & $4.786(1.040)$ \\
\hline 3-prime UTR & 0.011 & $0.034(0.022)$ & $3.053(1.948)$ \\
\hline 3 -prime UTR $+500 \mathrm{bp}$ & 0.027 & $0.047(0.020)$ & $1.762(0.761)$ \\
\hline 5-prime UTR & 0.005 & $0.042(0.021)$ & $7.792(3.826)$ \\
\hline 5 -prime UTR $+500 \mathrm{bp}$ & 0.028 & $0.059(0.031)$ & $2.129(1.101)$ \\
\hline Weak Enhancer & 0.021 & $0.011(0.045)$ & $0.542(2.148)$ \\
\hline Weak Enhancer $+500 \mathrm{bp}$ & 0.089 & $0.113(0.054)$ & $1.274(0.602)$ \\
\hline
\end{tabular}

(S4.C) Proportion of heritability and enrichment for different functional categories for Age at menarche. 
bioRxiv preprint doi: https://doi.org/10.1101/014241; this version posted January 23, 2015. The copyright holder for this preprint (which was not certified by peer review) is the author/funder, who has granted bioRxiv a license to display the preprint in perpetuity. It is made available under aCC-BY-ND 4.0 International license.

\begin{tabular}{|c|c|c|c|}
\hline Annotation & Prop. SNPs & Prop. $h^{2}$ & Enrichment \\
\hline Coding & 0.015 & $0.128(0.093)$ & $8.740(6.337)$ \\
\hline Coding $+500 \mathrm{bp}$ & 0.065 & $0.502(0.089)$ & $7.782(1.380)$ \\
\hline Conserved & 0.026 & $0.264(0.124)$ & $10.111(4.756)$ \\
\hline Conserved $+500 \mathrm{bp}$ & 0.333 & $0.811(0.143)$ & $2.438(0.429)$ \\
\hline $\mathrm{CTCF}$ & 0.024 & $0.179(0.109)$ & $7.506(4.590)$ \\
\hline $\mathrm{CTCF}+500 \mathrm{bp}$ & 0.071 & $0.079(0.106)$ & $1.109(1.493)$ \\
\hline DGF & 0.138 & $0.542(0.192)$ & $3.938(1.398)$ \\
\hline $\mathrm{DGF}+500 \mathrm{bp}$ & 0.542 & $0.806(0.149)$ & $1.489(0.276)$ \\
\hline DHS peaks & 0.112 & $0.417(0.189)$ & $3.730(1.691)$ \\
\hline DHS & 0.168 & $0.505(0.247)$ & $3.008(1.473)$ \\
\hline DHS $+500 \mathrm{bp}$ & 0.499 & $0.810(0.162)$ & $1.623(0.325)$ \\
\hline FANTOM5 Enhancer & 0.004 & $-0.050(0.047)$ & $-11.493(10.749)$ \\
\hline FANTOM5 Enhancer + 500bp & 0.019 & $-0.006(0.047)$ & $-0.323(2.442)$ \\
\hline Enhancer & 0.063 & $0.500(0.157)$ & $7.895(2.477)$ \\
\hline Enhancer $+500 \mathrm{bp}$ & 0.154 & $0.524(0.121)$ & $3.406(0.783)$ \\
\hline Fetal DHS & 0.085 & $0.370(0.194)$ & $4.370(2.290)$ \\
\hline Fetal DHS + 500bp & 0.285 & $0.783(0.133)$ & $2.746(0.466)$ \\
\hline H3К $27 \mathrm{ac}^{19}$ & 0.391 & $0.776(0.093)$ & $1.984(0.237)$ \\
\hline $\mathrm{H} 3 \mathrm{~K} 27 \mathrm{ac}^{19}+500 \mathrm{bp}$ & 0.423 & $0.962(0.075)$ & $2.277(0.177)$ \\
\hline $\mathrm{H} 3 \mathrm{~K} 27 \mathrm{ac}^{18}$ & 0.269 & $0.829(0.155)$ & $3.075(0.575)$ \\
\hline $\mathrm{H} 3 \mathrm{~K} 27 \mathrm{ac}^{18}+500 \mathrm{bp}$ & 0.336 & $0.772(0.100)$ & $2.298(0.298)$ \\
\hline H3K4me1 peaks & 0.171 & $0.430(0.264)$ & $2.512(1.539)$ \\
\hline H3K4me1 & 0.427 & $1.179(0.151)$ & $2.765(0.354)$ \\
\hline H3K4me1 + 500bp & 0.609 & $1.056(0.094)$ & $1.733(0.154)$ \\
\hline H3K4me3 peaks & 0.042 & $0.069(0.186)$ & $1.658(4.459)$ \\
\hline H3K4me3 & 0.133 & $0.628(0.173)$ & $4.715(1.296)$ \\
\hline $\mathrm{H} 3 \mathrm{~K} 4 \mathrm{me} 3+500 \mathrm{bp}$ & 0.255 & $0.933(0.181)$ & $3.652(0.710)$ \\
\hline H3K9ac peaks & 0.039 & $-0.028(0.165)$ & $-0.712(4.249)$ \\
\hline H3K9ac & 0.126 & $0.751(0.167)$ & $5.951(1.324)$ \\
\hline H3K9ac $+500 \mathrm{bp}$ & 0.231 & $0.832(0.187)$ & $3.607(0.812)$ \\
\hline Intron & 0.387 & $0.472(0.082)$ & $1.218(0.212)$ \\
\hline Intron $+500 \mathrm{bp}$ & 0.397 & $0.657(0.050)$ & $1.654(0.126)$ \\
\hline PromoterFlanking & 0.008 & $0.055(0.073)$ & $6.544(8.609)$ \\
\hline PromoterFlanking $+500 \mathrm{bp}$ & 0.033 & $0.264(0.087)$ & $7.895(2.605)$ \\
\hline Promoter & 0.031 & $0.140(0.073)$ & $4.499(2.352)$ \\
\hline Promoter $+500 \mathrm{bp}$ & 0.039 & $0.173(0.048)$ & $4.475(1.248)$ \\
\hline Repressed & 0.461 & $-0.077(0.140)$ & $-0.167(0.304)$ \\
\hline Repressed $+500 \mathrm{bp}$ & 0.719 & $0.168(0.077)$ & $0.234(0.107)$ \\
\hline Super Enhancer & 0.168 & $0.439(0.059)$ & $2.608(0.351)$ \\
\hline Super Enhancer $+500 \mathrm{bp}$ & 0.172 & $0.467(0.059)$ & $2.721(0.345)$ \\
\hline TFBS & 0.132 & $0.871(0.231)$ & $6.576(1.747)$ \\
\hline $\mathrm{TFBS}+500 \mathrm{bp}$ & 0.343 & $0.787(0.152)$ & $2.291(0.443)$ \\
\hline Transcribed & 0.345 & $0.573(0.139)$ & $1.659(0.403)$ \\
\hline Transcribed $+500 \mathrm{bp}$ & 0.763 & $0.627(0.106)$ & $0.821(0.139)$ \\
\hline TSS & 0.018 & $0.086(0.097)$ & $4.746(5.306)$ \\
\hline $\mathrm{TSS}+500 \mathrm{bp}$ & 0.035 & $0.452(0.083)$ & $12.976(2.387)$ \\
\hline 3-prime UTR & 0.011 & $0.035(0.045)$ & $3.190(4.086)$ \\
\hline 3-prime UTR $+500 \mathrm{bp}$ & 0.027 & $0.109(0.041)$ & $4.044(1.528)$ \\
\hline 5-prime UTR & 0.005 & $0.015(0.041)$ & $2.768(7.486)$ \\
\hline 5-prime UTR $+500 \mathrm{bp}$ & 0.028 & $0.088(0.069)$ & $3.154(2.471)$ \\
\hline Weak Enhancer & 0.021 & $0.145(0.096)$ & $6.876(4.532)$ \\
\hline Weak Enhancer $+500 \mathrm{bp}$ & 0.089 & $0.257(0.109)$ & $2.890(1.221)$ \\
\hline
\end{tabular}

(S4.D) Proportion of heritability and enrichment for different functional categories for LDL. 
bioRxiv preprint doi: https://doi.org/10.1101/014241; this version posted January 23, 2015. The copyright holder for this preprint (which was not certified by peer review) is the author/funder, who has granted bioRxiv a license to display the preprint in perpetuity. It is made available under aCC-BY-ND 4.0 International license.

\begin{tabular}{|c|c|c|c|}
\hline Annotation & Prop. SNPs & Prop. $h^{2}$ & Enrichment \\
\hline Coding & 0.015 & $0.058(0.058)$ & $3.986(3.937)$ \\
\hline Coding $+500 \mathrm{bp}$ & 0.065 & $0.309(0.064)$ & $4.788(0.993)$ \\
\hline Conserved & 0.026 & $0.269(0.075)$ & $10.339(2.870)$ \\
\hline Conserved $+500 \mathrm{bp}$ & 0.333 & $0.582(0.121)$ & $1.749(0.364)$ \\
\hline CTCF & 0.024 & $-0.049(0.068)$ & $-2.077(2.851)$ \\
\hline $\mathrm{CTCF}+500 \mathrm{bp}$ & 0.071 & $0.032(0.084)$ & $0.453(1.178)$ \\
\hline DGF & 0.138 & $0.093(0.195)$ & $0.676(1.420)$ \\
\hline $\mathrm{DGF}+500 \mathrm{bp}$ & 0.542 & $0.735(0.149)$ & $1.358(0.275)$ \\
\hline DHS peaks & 0.112 & $0.219(0.193)$ & $1.960(1.727)$ \\
\hline DHS & 0.168 & $0.289(0.190)$ & $1.721(1.132)$ \\
\hline DHS $+500 \mathrm{bp}$ & 0.499 & $0.921(0.214)$ & $1.846(0.428)$ \\
\hline FANTOM5 Enhancer & 0.004 & $0.001(0.049)$ & $0.162(11.325)$ \\
\hline FANTOM5 Enhancer + 500bp & 0.019 & $-0.004(0.051)$ & $-0.213(2.700)$ \\
\hline Enhancer & 0.063 & $0.211(0.125)$ & $3.332(1.971)$ \\
\hline Enhancer $+500 \mathrm{bp}$ & 0.154 & $0.512(0.101)$ & $3.327(0.658)$ \\
\hline Fetal DHS & 0.085 & $0.091(0.137)$ & $1.079(1.620)$ \\
\hline Fetal DHS + 500bp & 0.285 & $0.736(0.116)$ & $2.583(0.407)$ \\
\hline $\mathrm{H} 3 \mathrm{~K} 27 \mathrm{ac}^{19}$ & 0.391 & $0.802(0.067)$ & $2.051(0.172)$ \\
\hline $\mathrm{H} 3 \mathrm{~K} 27 \mathrm{ac}^{19}+500 \mathrm{bp}$ & 0.423 & $0.828(0.072)$ & $1.960(0.171)$ \\
\hline $\mathrm{H} 3 \mathrm{~K} 27 \mathrm{ac}^{18}$ & 0.269 & $0.904(0.190)$ & $3.353(0.705)$ \\
\hline $\mathrm{H} 3 \mathrm{~K} 27 \mathrm{ac}^{18}+500 \mathrm{bp}$ & 0.336 & $0.839(0.082)$ & $2.495(0.244)$ \\
\hline H3K4me1 peaks & 0.171 & $0.602(0.221)$ & $3.515(1.291)$ \\
\hline H3K4me1 & 0.427 & $1.055(0.165)$ & $2.474(0.388)$ \\
\hline H3K4me1 + 500bp & 0.609 & $1.035(0.093)$ & $1.699(0.153)$ \\
\hline H3K4me 3 peaks & 0.042 & $0.019(0.129)$ & $0.451(3.082)$ \\
\hline $\mathrm{H} 3 \mathrm{~K} 4 \mathrm{me} 3$ & 0.133 & $0.530(0.129)$ & $3.975(0.970)$ \\
\hline $\mathrm{H} 3 \mathrm{~K} 4 \mathrm{me} 3+500 \mathrm{bp}$ & 0.255 & $0.690(0.111)$ & $2.702(0.435)$ \\
\hline H3K9ac peaks & 0.039 & $0.240(0.121)$ & $6.195(3.118)$ \\
\hline H3К9ac & 0.126 & $0.632(0.106)$ & $5.015(0.842)$ \\
\hline H3K9ac $+500 \mathrm{bp}$ & 0.231 & $0.856(0.110)$ & $3.714(0.477)$ \\
\hline Intron & 0.387 & $0.523(0.070)$ & $1.349(0.180)$ \\
\hline Intron $+500 \mathrm{bp}$ & 0.397 & $0.603(0.048)$ & $1.518(0.120)$ \\
\hline PromoterFlanking & 0.008 & $-0.039(0.038)$ & $-4.590(4.512)$ \\
\hline PromoterFlanking $+500 \mathrm{bp}$ & 0.033 & $0.071(0.058)$ & $2.111(1.727)$ \\
\hline Promoter & 0.031 & $0.180(0.073)$ & $5.785(2.340)$ \\
\hline Promoter $+500 \mathrm{bp}$ & 0.039 & $0.162(0.046)$ & $4.197(1.182)$ \\
\hline Repressed & 0.461 & $0.143(0.114)$ & $0.310(0.246)$ \\
\hline Repressed $+500 \mathrm{bp}$ & 0.719 & $0.312(0.072)$ & $0.434(0.100)$ \\
\hline Super Enhancer & 0.168 & $0.531(0.051)$ & $3.151(0.305)$ \\
\hline Super Enhancer $+500 \mathrm{bp}$ & 0.172 & $0.535(0.048)$ & $3.120(0.281)$ \\
\hline TFBS & 0.132 & $0.358(0.189)$ & $2.706(1.428)$ \\
\hline TFBS $+500 \mathrm{bp}$ & 0.343 & $0.601(0.142)$ & $1.749(0.413)$ \\
\hline Transcribed & 0.345 & $0.445(0.108)$ & $1.289(0.314)$ \\
\hline Transcribed $+500 \mathrm{bp}$ & 0.763 & $0.839(0.070)$ & $1.100(0.091)$ \\
\hline TSS & 0.018 & $0.066(0.057)$ & $3.601(3.136)$ \\
\hline $\mathrm{TSS}+500 \mathrm{bp}$ & 0.035 & $0.306(0.072)$ & $8.782(2.072)$ \\
\hline 3-prime UTR & 0.011 & $-0.014(0.036)$ & $-1.224(3.289)$ \\
\hline 3 -prime UTR $+500 \mathrm{bp}$ & 0.027 & $0.071(0.040)$ & $2.623(1.498)$ \\
\hline 5-prime UTR & 0.005 & $0.082(0.041)$ & $15.172(7.520)$ \\
\hline 5 -prime UTR $+500 \mathrm{bp}$ & 0.028 & $0.086(0.039)$ & $3.076(1.410)$ \\
\hline Weak Enhancer & 0.021 & $0.081(0.077)$ & $3.859(3.629)$ \\
\hline Weak Enhancer $+500 \mathrm{bp}$ & 0.089 & $0.321(0.105)$ & $3.605(1.181)$ \\
\hline
\end{tabular}

(S4.E) Proportion of heritability and enrichment for different functional categories for HDL. 
bioRxiv preprint doi: https://doi.org/10.1101/014241; this version posted January 23, 2015. The copyright holder for this preprint (which was not certified by peer review) is the author/funder, who has granted bioRxiv a license to display the preprint in perpetuity. It is made available under aCC-BY-ND 4.0 International license.

\begin{tabular}{|c|c|c|c|}
\hline Annotation & Prop. SNPs & Prop. $h^{2}$ & Enrichment \\
\hline Coding & 0.015 & $0.052(0.049)$ & $3.542(3.318)$ \\
\hline Coding $+500 \mathrm{bp}$ & 0.065 & $0.252(0.051)$ & $3.899(0.786)$ \\
\hline Conserved & 0.026 & $0.269(0.080)$ & $10.309(3.077)$ \\
\hline Conserved $+500 \mathrm{bp}$ & 0.333 & $0.664(0.090)$ & $1.997(0.271)$ \\
\hline CTCF & 0.024 & $-0.019(0.078)$ & $-0.814(3.294)$ \\
\hline $\mathrm{CTCF}+500 \mathrm{bp}$ & 0.071 & $0.010(0.077)$ & $0.137(1.078)$ \\
\hline DGF & 0.138 & $0.237(0.150)$ & $1.724(1.092)$ \\
\hline $\mathrm{DGF}+500 \mathrm{bp}$ & 0.542 & $0.690(0.108)$ & $1.275(0.199)$ \\
\hline DHS peaks & 0.112 & $0.145(0.162)$ & $1.293(1.447)$ \\
\hline DHS & 0.168 & $0.249(0.166)$ & $1.484(0.989)$ \\
\hline DHS + 500bp & 0.499 & $0.941(0.125)$ & $1.886(0.250)$ \\
\hline FANTOM5 Enhancer & 0.004 & $-0.047(0.030)$ & $-10.766(6.886)$ \\
\hline FANTOM5 Enhancer + 500bp & 0.019 & $0.030(0.052)$ & $1.551(2.737)$ \\
\hline Enhancer & 0.063 & $0.232(0.115)$ & $3.657(1.815)$ \\
\hline Enhancer $+500 \mathrm{bp}$ & 0.154 & $0.559(0.105)$ & $3.630(0.685)$ \\
\hline Fetal DHS & 0.085 & $0.333(0.128)$ & $3.929(1.512)$ \\
\hline Fetal DHS + 500bp & 0.285 & $0.649(0.119)$ & $2.276(0.419)$ \\
\hline $\mathrm{H} 3 \mathrm{~K} 27 \mathrm{ac}^{19}$ & 0.391 & $0.768(0.060)$ & $1.964(0.152)$ \\
\hline $\mathrm{H} 3 \mathrm{~K} 27 \mathrm{ac}^{19}+500 \mathrm{bp}$ & 0.423 & $0.759(0.054)$ & $1.797(0.127)$ \\
\hline $\mathrm{H} 3 \mathrm{~K} 27 \mathrm{ac}^{18}$ & 0.269 & $0.750(0.149)$ & $2.783(0.551)$ \\
\hline $\mathrm{H} 3 \mathrm{~K} 27 \mathrm{ac}^{18}+500 \mathrm{bp}$ & 0.336 & $0.797(0.091)$ & $2.373(0.272)$ \\
\hline H3K4me1 peaks & 0.171 & $0.132(0.163)$ & $0.772(0.951)$ \\
\hline H3K4me1 & 0.427 & $0.823(0.144)$ & $1.929(0.337)$ \\
\hline $\mathrm{H} 3 \mathrm{~K} 4 \mathrm{me} 1+500 \mathrm{bp}$ & 0.609 & $1.181(0.072)$ & $1.939(0.119)$ \\
\hline H3K4me3 peaks & 0.042 & $0.121(0.112)$ & $2.907(2.685)$ \\
\hline H3K4me3 & 0.133 & $0.452(0.083)$ & $3.394(0.622)$ \\
\hline H3K4me3 + 500bp & 0.255 & $0.736(0.104)$ & $2.881(0.406)$ \\
\hline H3K9ac peaks & 0.039 & $0.172(0.095)$ & $4.441(2.449)$ \\
\hline H3K9ac & 0.126 & $0.502(0.088)$ & $3.978(0.699)$ \\
\hline $\mathrm{H} 3 \mathrm{~K} 9 \mathrm{ac}+500 \mathrm{bp}$ & 0.231 & $0.751(0.108)$ & $3.259(0.469)$ \\
\hline Intron & 0.387 & $0.475(0.055)$ & $1.225(0.141)$ \\
\hline Intron $+500 \mathrm{bp}$ & 0.397 & $0.550(0.037)$ & $1.385(0.094)$ \\
\hline PromoterFlanking & 0.008 & $0.050(0.043)$ & $5.945(5.067)$ \\
\hline PromoterFlanking $+500 \mathrm{bp}$ & 0.033 & $0.112(0.060)$ & $3.356(1.806)$ \\
\hline Promoter & 0.031 & $0.162(0.052)$ & $5.203(1.657)$ \\
\hline Promoter $+500 \mathrm{bp}$ & 0.039 & $0.153(0.045)$ & $3.962(1.160)$ \\
\hline Repressed & 0.461 & $0.081(0.102)$ & $0.176(0.222)$ \\
\hline Repressed $+500 \mathrm{bp}$ & 0.719 & $0.400(0.066)$ & $0.556(0.091)$ \\
\hline Super Enhancer & 0.168 & $0.395(0.038)$ & $2.346(0.224)$ \\
\hline Super Enhancer $+500 \mathrm{bp}$ & 0.172 & $0.425(0.035)$ & $2.477(0.203)$ \\
\hline TFBS & 0.132 & $0.435(0.159)$ & $3.284(1.204)$ \\
\hline $\mathrm{TFBS}+500 \mathrm{bp}$ & 0.343 & $0.545(0.121)$ & $1.586(0.353)$ \\
\hline Transcribed & 0.345 & $0.512(0.097)$ & $1.483(0.281)$ \\
\hline Transcribed $+500 \mathrm{bp}$ & 0.763 & $0.582(0.097)$ & $0.763(0.128)$ \\
\hline TSS & 0.018 & $0.065(0.051)$ & $3.562(2.801)$ \\
\hline $\mathrm{TSS}+500 \mathrm{bp}$ & 0.035 & $0.290(0.058)$ & $8.341(1.661)$ \\
\hline 3-prime UTR & 0.011 & $0.003(0.037)$ & $0.253(3.372)$ \\
\hline 3-prime UTR $+500 \mathrm{bp}$ & 0.027 & $0.057(0.031)$ & $2.101(1.152)$ \\
\hline 5-prime UTR & 0.005 & $-0.012(0.025)$ & $-2.291(4.617)$ \\
\hline 5 -prime UTR $+500 \mathrm{bp}$ & 0.028 & $0.046(0.035)$ & $1.652(1.244)$ \\
\hline Weak Enhancer & 0.021 & $0.047(0.069)$ & $2.237(3.266)$ \\
\hline Weak Enhancer $+500 b p$ & 0.089 & $0.265(0.093)$ & $2.982(1.042)$ \\
\hline
\end{tabular}

(S4.F) Proportion of heritability and enrichment for different functional categories for Triglycerides. 
bioRxiv preprint doi: https://doi.org/10.1101/014241; this version posted January 23, 2015. The copyright holder for this preprint (which was not certified by peer review) is the author/funder, who has granted bioRxiv a license to display the preprint in perpetuity. It is made available under aCC-BY-ND 4.0 International license.

\begin{tabular}{|c|c|c|c|}
\hline Annotation & Prop. SNPs & Prop. $h^{2}$ & Enrichment \\
\hline Coding & 0.015 & $0.074(0.057)$ & $5.050(3.886)$ \\
\hline Coding $+500 \mathrm{bp}$ & 0.065 & $0.261(0.068)$ & $4.043(1.049)$ \\
\hline Conserved & 0.026 & $0.203(0.096)$ & $7.808(3.677)$ \\
\hline Conserved $+500 \mathrm{bp}$ & 0.333 & $0.568(0.144)$ & $1.708(0.433)$ \\
\hline $\mathrm{CTCF}$ & 0.024 & $-0.040(0.105)$ & $-1.659(4.397)$ \\
\hline $\mathrm{CTCF}+500 \mathrm{bp}$ & 0.071 & $-0.070(0.122)$ & $-0.980(1.713)$ \\
\hline DGF & 0.138 & $0.743(0.256)$ & $5.402(1.858)$ \\
\hline $\mathrm{DGF}+500 \mathrm{bp}$ & 0.542 & $0.860(0.143)$ & $1.587(0.265)$ \\
\hline DHS peaks & 0.112 & $0.361(0.254)$ & $3.229(2.271)$ \\
\hline DHS & 0.168 & $0.514(0.264)$ & $3.063(1.575)$ \\
\hline DHS $+500 b p$ & 0.499 & $0.943(0.164)$ & $1.891(0.330)$ \\
\hline FANTOM5 Enhancer & 0.004 & $-0.040(0.053)$ & $-9.331(12.124)$ \\
\hline FANTOM5 Enhancer + 500bp & 0.019 & $0.045(0.063)$ & $2.359(3.329)$ \\
\hline Enhancer & 0.063 & $0.394(0.130)$ & $6.217(2.046)$ \\
\hline Enhancer $+500 \mathrm{bp}$ & 0.154 & $0.406(0.120)$ & $2.635(0.777)$ \\
\hline Fetal DHS & 0.085 & $0.282(0.200)$ & $3.324(2.364)$ \\
\hline Fetal DHS + 500bp & 0.285 & $0.746(0.164)$ & $2.618(0.575)$ \\
\hline H3К $27 \mathrm{ac}^{19}$ & 0.391 & $0.727(0.087)$ & $1.859(0.221)$ \\
\hline $\mathrm{H} 3 \mathrm{~K} 27 \mathrm{ac}^{19}+500 \mathrm{bp}$ & 0.423 & $0.801(0.084)$ & $1.895(0.198)$ \\
\hline $\mathrm{H} 3 \mathrm{~K} 27 \mathrm{ac}^{18}$ & 0.269 & $0.639(0.141)$ & $2.370(0.523)$ \\
\hline $\mathrm{H} 3 \mathrm{~K} 27 \mathrm{ac}^{18}+500 \mathrm{bp}$ & 0.336 & $0.837(0.129)$ & $2.490(0.384)$ \\
\hline H3K4me1 peaks & 0.171 & $0.497(0.197)$ & $2.901(1.148)$ \\
\hline H3K4me1 & 0.427 & $0.783(0.164)$ & $1.835(0.384)$ \\
\hline H3K4me1 + 500bp & 0.609 & $1.137(0.086)$ & $1.866(0.141)$ \\
\hline H3K4me3 peaks & 0.042 & $0.266(0.156)$ & $6.363(3.724)$ \\
\hline H3K4me3 & 0.133 & $0.288(0.126)$ & $2.161(0.949)$ \\
\hline $\mathrm{H} 3 \mathrm{~K} 4 \mathrm{me} 3+500 \mathrm{bp}$ & 0.255 & $0.890(0.146)$ & $3.482(0.571)$ \\
\hline H3K9ac peaks & 0.039 & $0.381(0.141)$ & $9.820(3.633)$ \\
\hline Н3К $9 \mathrm{ac}$ & 0.126 & $0.686(0.139)$ & $5.439(1.105)$ \\
\hline H3K9ac $+500 \mathrm{bp}$ & 0.231 & $0.788(0.123)$ & $3.418(0.535)$ \\
\hline Intron & 0.387 & $0.483(0.065)$ & $1.248(0.167)$ \\
\hline Intron $+500 \mathrm{bp}$ & 0.397 & $0.525(0.049)$ & $1.323(0.124)$ \\
\hline PromoterFlanking & 0.008 & $0.001(0.057)$ & $0.071(6.744)$ \\
\hline PromoterFlanking $+500 \mathrm{bp}$ & 0.033 & $0.108(0.071)$ & $3.237(2.115)$ \\
\hline Promoter & 0.031 & $0.104(0.071)$ & $3.344(2.270)$ \\
\hline Promoter $+500 \mathrm{bp}$ & 0.039 & $0.068(0.047)$ & $1.765(1.220)$ \\
\hline Repressed & 0.461 & $0.395(0.168)$ & $0.856(0.365)$ \\
\hline Repressed $+500 \mathrm{bp}$ & 0.719 & $0.359(0.074)$ & $0.499(0.103)$ \\
\hline Super Enhancer & 0.168 & $0.414(0.053)$ & $2.459(0.317)$ \\
\hline Super Enhancer $+500 \mathrm{bp}$ & 0.172 & $0.415(0.058)$ & $2.418(0.337)$ \\
\hline TFBS & 0.132 & $0.364(0.211)$ & $2.751(1.595)$ \\
\hline $\mathrm{TFBS}+500 \mathrm{bp}$ & 0.343 & $0.487(0.156)$ & $1.418(0.454)$ \\
\hline Transcribed & 0.345 & $0.302(0.142)$ & $0.874(0.410)$ \\
\hline Transcribed $+500 \mathrm{bp}$ & 0.763 & $0.677(0.113)$ & $0.887(0.148)$ \\
\hline TSS & 0.018 & $0.185(0.077)$ & $10.152(4.239)$ \\
\hline $\mathrm{TSS}+500 \mathrm{bp}$ & 0.035 & $0.141(0.080)$ & $4.061(2.291)$ \\
\hline 3-prime UTR & 0.011 & $0.055(0.045)$ & $5.018(4.040)$ \\
\hline 3 -prime UTR $+500 \mathrm{bp}$ & 0.027 & $0.151(0.064)$ & $5.624(2.358)$ \\
\hline 5-prime UTR & 0.005 & $-0.003(0.037)$ & $-0.542(6.731)$ \\
\hline 5-prime UTR $+500 \mathrm{bp}$ & 0.028 & $0.029(0.054)$ & $1.036(1.958)$ \\
\hline Weak Enhancer & 0.021 & $0.128(0.091)$ & $6.055(4.326)$ \\
\hline Weak Enhancer $+500 b p$ & 0.089 & $0.285(0.113)$ & $3.200(1.266)$ \\
\hline
\end{tabular}

(S4.G) Proportion of heritability and enrichment for different functional categories for Coronary artery disease. 
bioRxiv preprint doi: https://doi.org/10.1101/014241; this version posted January 23, 2015. The copyright holder for this preprint (which was not certified by peer review) is the author/funder, who has granted bioRxiv a license to display the preprint in perpetuity. It is made available under aCC-BY-ND 4.0 International license.

\begin{tabular}{|c|c|c|c|}
\hline Annotation & Prop. SNPs & Prop. $h^{2}$ & Enrichment \\
\hline Coding & 0.015 & $0.026(0.071)$ & $1.784(4.820)$ \\
\hline Coding $+500 \mathrm{bp}$ & 0.065 & $0.104(0.089)$ & $1.614(1.378)$ \\
\hline Conserved & 0.026 & $0.347(0.130)$ & $13.300(4.990)$ \\
\hline Conserved $+500 \mathrm{bp}$ & 0.333 & $0.688(0.178)$ & $2.068(0.536)$ \\
\hline CTCF & 0.024 & $-0.080(0.120)$ & $-3.350(5.048)$ \\
\hline $\mathrm{CTCF}+500 \mathrm{bp}$ & 0.071 & $0.013(0.112)$ & $0.182(1.580)$ \\
\hline DGF & 0.138 & $0.014(0.330)$ & $0.099(2.402)$ \\
\hline $\mathrm{DGF}+500 \mathrm{bp}$ & 0.542 & $1.011(0.184)$ & $1.867(0.340)$ \\
\hline DHS peaks & 0.112 & $0.130(0.303)$ & $1.167(2.710)$ \\
\hline DHS & 0.168 & $0.385(0.329)$ & $2.296(1.963)$ \\
\hline $\mathrm{DHS}+500 \mathrm{bp}$ & 0.499 & $1.009(0.173)$ & $2.022(0.346)$ \\
\hline FANTOM5 Enhancer & 0.004 & $-0.004(0.055)$ & $-0.922(12.664)$ \\
\hline FANTOM5 Enhancer $+500 \mathrm{bp}$ & 0.019 & $-0.050(0.070)$ & $-2.628(3.653)$ \\
\hline Enhancer & 0.063 & $0.258(0.147)$ & $4.068(2.315)$ \\
\hline Enhancer $+500 \mathrm{bp}$ & 0.154 & $0.503(0.141)$ & $3.270(0.916)$ \\
\hline Fetal DHS & 0.085 & $0.208(0.271)$ & $2.458(3.193)$ \\
\hline Fetal DHS + 500bp & 0.285 & $0.577(0.180)$ & $2.025(0.631)$ \\
\hline $\mathrm{H} 3 \mathrm{~K} 27 \mathrm{ac}^{19}$ & 0.391 & $0.581(0.110)$ & $1.485(0.280)$ \\
\hline $\mathrm{H} 3 \mathrm{~K} 27 \mathrm{ac} \mathrm{c}^{19}+500 \mathrm{bp}$ & 0.423 & $0.748(0.107)$ & $1.771(0.253)$ \\
\hline $\mathrm{H} 3 \mathrm{~K} 27 \mathrm{ac}^{18}$ & 0.269 & $0.699(0.189)$ & $2.593(0.703)$ \\
\hline $\mathrm{H} 3 \mathrm{~K} 27 \mathrm{ac}^{18}+500 \mathrm{bp}$ & 0.336 & $0.760(0.135)$ & $2.263(0.403)$ \\
\hline H3K4me1 peaks & 0.171 & $0.586(0.242)$ & $3.419(1.413)$ \\
\hline H3K4me1 & 0.427 & $0.799(0.232)$ & $1.873(0.544)$ \\
\hline H3K4me1 + 500bp & 0.609 & $1.006(0.102)$ & $1.652(0.168)$ \\
\hline H3K4me3 peaks & 0.042 & $0.186(0.152)$ & $4.460(3.639)$ \\
\hline H3K4me3 & 0.133 & $0.517(0.159)$ & $3.879(1.195)$ \\
\hline $\mathrm{H} 3 \mathrm{~K} 4 \mathrm{me} 3+500 \mathrm{bp}$ & 0.255 & $0.651(0.142)$ & $2.549(0.557)$ \\
\hline H3K9ac peaks & 0.039 & $0.043(0.174)$ & $1.120(4.494)$ \\
\hline H3K9ac & 0.126 & $0.632(0.186)$ & $5.012(1.472)$ \\
\hline H3K9ac $+500 \mathrm{bp}$ & 0.231 & $0.746(0.147)$ & $3.237(0.638)$ \\
\hline Intron & 0.387 & $0.526(0.071)$ & $1.357(0.184)$ \\
\hline Intron $+500 \mathrm{bp}$ & 0.397 & $0.510(0.056)$ & $1.283(0.140)$ \\
\hline PromoterFlanking & 0.008 & $0.064(0.081)$ & $7.616(9.630)$ \\
\hline PromoterFlanking $+500 \mathrm{bp}$ & 0.033 & $0.122(0.110)$ & $3.631(3.298)$ \\
\hline Promoter & 0.031 & $0.098(0.086)$ & $3.132(2.762)$ \\
\hline Promoter $+500 \mathrm{bp}$ & 0.039 & $0.059(0.053)$ & $1.522(1.381)$ \\
\hline Repressed & 0.461 & $0.122(0.230)$ & $0.264(0.500)$ \\
\hline Repressed $+500 \mathrm{bp}$ & 0.719 & $0.380(0.084)$ & $0.528(0.117)$ \\
\hline Super Enhancer & 0.168 & $0.307(0.068)$ & $1.824(0.405)$ \\
\hline Super Enhancer $+500 \mathrm{bp}$ & 0.172 & $0.317(0.062)$ & $1.850(0.364)$ \\
\hline TFBS & 0.132 & $0.242(0.248)$ & $1.827(1.876)$ \\
\hline $\mathrm{TFBS}+500 \mathrm{bp}$ & 0.343 & $0.628(0.184)$ & $1.829(0.535)$ \\
\hline Transcribed & 0.345 & $0.695(0.219)$ & $2.013(0.634)$ \\
\hline Transcribed $+500 \mathrm{bp}$ & 0.763 & $0.557(0.124)$ & $0.730(0.162)$ \\
\hline TSS & 0.018 & $0.140(0.087)$ & $7.668(4.788)$ \\
\hline $\mathrm{TSS}+500 \mathrm{bp}$ & 0.035 & $0.044(0.090)$ & $1.276(2.595)$ \\
\hline 3-prime UTR & 0.011 & $-0.021(0.048)$ & $-1.927(4.355)$ \\
\hline 3 -prime UTR $+500 \mathrm{bp}$ & 0.027 & $0.020(0.057)$ & $0.751(2.105)$ \\
\hline 5-prime UTR & 0.005 & $0.077(0.116)$ & $14.223(21.390)$ \\
\hline 5-prime UTR $+500 \mathrm{bp}$ & 0.028 & $0.097(0.072)$ & $3.480(2.576)$ \\
\hline Weak Enhancer & 0.021 & $0.143(0.140)$ & $6.792(6.655)$ \\
\hline Weak Enhancer $+500 \mathrm{bp}$ & 0.089 & $0.280(0.127)$ & $3.152(1.423)$ \\
\hline
\end{tabular}

(S4.H) Proportion of heritability and enrichment for different functional categories for Type 2 Diabetes. 
bioRxiv preprint doi: https://doi.org/10.1101/014241; this version posted January 23, 2015. The copyright holder for this preprint (which was not certified by peer review) is the author/funder, who has granted bioRxiv a license to display the preprint in perpetuity. It is made available under aCC-BY-ND 4.0 International license.

\begin{tabular}{|c|c|c|c|}
\hline Annotation & Prop. SNPs & Prop. $h^{2}$ & Enrichment \\
\hline Coding & 0.015 & $-0.014(0.085)$ & $-0.960(5.787)$ \\
\hline Coding $+500 \mathrm{bp}$ & 0.065 & $0.206(0.087)$ & $3.184(1.342)$ \\
\hline Conserved & 0.026 & $0.286(0.120)$ & $10.982(4.588)$ \\
\hline Conserved $+500 \mathrm{bp}$ & 0.333 & $0.874(0.153)$ & $2.629(0.460)$ \\
\hline CTCF & 0.024 & $-0.044(0.117)$ & $-1.842(4.905)$ \\
\hline $\mathrm{CTCF}+500 \mathrm{bp}$ & 0.071 & $-0.036(0.132)$ & $-0.501(1.862)$ \\
\hline DGF & 0.138 & $0.394(0.297)$ & $2.861(2.156)$ \\
\hline $\mathrm{DGF}+500 \mathrm{bp}$ & 0.542 & $0.723(0.173)$ & $1.335(0.319)$ \\
\hline DHS peaks & 0.112 & $0.170(0.291)$ & $1.523(2.607)$ \\
\hline DHS & 0.168 & $0.711(0.307)$ & $4.238(1.829)$ \\
\hline DHS $+500 \mathrm{bp}$ & 0.499 & $0.564(0.204)$ & $1.132(0.410)$ \\
\hline FANTOM5 Enhancer & 0.004 & $-0.001(0.057)$ & $-0.176(13.183)$ \\
\hline FANTOM5 Enhancer $+500 \mathrm{bp}$ & 0.019 & $0.057(0.072)$ & $2.975(3.775)$ \\
\hline Enhancer & 0.063 & $0.358(0.172)$ & $5.658(2.710)$ \\
\hline Enhancer $+500 \mathrm{bp}$ & 0.154 & $0.519(0.139)$ & $3.370(0.900)$ \\
\hline Fetal DHS & 0.085 & $0.375(0.215)$ & $4.424(2.537)$ \\
\hline Fetal DHS + 500bp & 0.285 & $0.763(0.206)$ & $2.677(0.722)$ \\
\hline $\mathrm{H} 3 \mathrm{~K} 27 \mathrm{ac}^{19}$ & 0.391 & $0.679(0.097)$ & $1.737(0.248)$ \\
\hline $\mathrm{H} 3 \mathrm{~K} 27 \mathrm{ac}^{19}+500 \mathrm{bp}$ & 0.423 & $0.734(0.096)$ & $1.737(0.227)$ \\
\hline $\mathrm{H} 3 \mathrm{~K} 27 \mathrm{ac}^{18}$ & 0.269 & $0.734(0.175)$ & $2.723(0.649)$ \\
\hline $\mathrm{H} 3 \mathrm{~K} 27 \mathrm{ac}^{18}+500 \mathrm{bp}$ & 0.336 & $0.952(0.158)$ & $2.833(0.471)$ \\
\hline H3K4me1 peaks & 0.171 & $0.865(0.281)$ & $5.049(1.641)$ \\
\hline H3K4me1 & 0.427 & $0.743(0.179)$ & $1.742(0.420)$ \\
\hline H3K4me1 + 500bp & 0.609 & $1.017(0.117)$ & $1.670(0.193)$ \\
\hline H3K4me3 peaks & 0.042 & $-0.014(0.157)$ & $-0.323(3.750)$ \\
\hline H3K4me3 & 0.133 & $0.583(0.154)$ & $4.372(1.156)$ \\
\hline $\mathrm{H} 3 \mathrm{~K} 4 \mathrm{me} 3+500 \mathrm{bp}$ & 0.255 & $0.638(0.141)$ & $2.496(0.553)$ \\
\hline H3K9ac peaks & 0.039 & $0.297(0.153)$ & $7.658(3.941)$ \\
\hline H3К9ac & 0.126 & $0.753(0.173)$ & $5.973(1.370)$ \\
\hline H3K9ac $+500 \mathrm{bp}$ & 0.231 & $0.542(0.151)$ & $2.350(0.654)$ \\
\hline Intron & 0.387 & $0.596(0.086)$ & $1.539(0.223)$ \\
\hline Intron $+500 \mathrm{bp}$ & 0.397 & $0.593(0.064)$ & $1.492(0.162)$ \\
\hline PromoterFlanking & 0.008 & $-0.075(0.071)$ & $-8.868(8.458)$ \\
\hline PromoterFlanking $+500 \mathrm{bp}$ & 0.033 & $0.126(0.084)$ & $3.750(2.512)$ \\
\hline Promoter & 0.031 & $0.087(0.080)$ & $2.795(2.576)$ \\
\hline Promoter $+500 \mathrm{bp}$ & 0.039 & $0.163(0.067)$ & $4.214(1.722)$ \\
\hline Repressed & 0.461 & $0.326(0.195)$ & $0.707(0.423)$ \\
\hline Repressed $+500 \mathrm{bp}$ & 0.719 & $0.308(0.096)$ & $0.429(0.133)$ \\
\hline Super Enhancer & 0.168 & $0.311(0.064)$ & $1.848(0.381)$ \\
\hline Super Enhancer $+500 \mathrm{bp}$ & 0.172 & $0.436(0.064)$ & $2.541(0.371)$ \\
\hline TFBS & 0.132 & $0.420(0.230)$ & $3.173(1.733)$ \\
\hline TFBS $+500 \mathrm{bp}$ & 0.343 & $0.497(0.179)$ & $1.446(0.523)$ \\
\hline Transcribed & 0.345 & $0.502(0.186)$ & $1.454(0.539)$ \\
\hline Transcribed $+500 \mathrm{bp}$ & 0.763 & $0.511(0.139)$ & $0.670(0.182)$ \\
\hline TSS & 0.018 & $-0.066(0.085)$ & $-3.643(4.645)$ \\
\hline $\mathrm{TSS}+500 \mathrm{bp}$ & 0.035 & $0.113(0.093)$ & $3.243(2.678)$ \\
\hline 3-prime UTR & 0.011 & $-0.019(0.053)$ & $-1.722(4.823)$ \\
\hline 3 -prime UTR $+500 \mathrm{bp}$ & 0.027 & $-0.010(0.063)$ & $-0.367(2.325)$ \\
\hline 5-prime UTR & 0.005 & $0.041(0.084)$ & $7.573(15.417)$ \\
\hline 5 -prime UTR $+500 \mathrm{bp}$ & 0.028 & $0.120(0.066)$ & $4.312(2.389)$ \\
\hline Weak Enhancer & 0.021 & $0.210(0.117)$ & $9.946(5.568)$ \\
\hline Weak Enhancer $+500 \mathrm{bp}$ & 0.089 & $0.313(0.131)$ & $3.523(1.472)$ \\
\hline
\end{tabular}

(S4.I) Proportion of heritability and enrichment for different functional categories for Fasting Glucose. 
bioRxiv preprint doi: https://doi.org/10.1101/014241; this version posted January 23, 2015. The copyright holder for this preprint (which was not certified by peer review) is the author/funder, who has granted bioRxiv a license to display the preprint in perpetuity. It is made available under aCC-BY-ND 4.0 International license.

\begin{tabular}{|c|c|c|c|}
\hline Annotation & Prop. SNPs & Prop. $h^{2}$ & Enrichment \\
\hline Coding & 0.015 & $0.085(0.022)$ & $5.823(1.489)$ \\
\hline Coding $+500 \mathrm{bp}$ & 0.065 & $0.127(0.026)$ & $1.970(0.398)$ \\
\hline Conserved & 0.026 & $0.287(0.044)$ & $11.028(1.677)$ \\
\hline Conserved $+500 \mathrm{bp}$ & 0.333 & $0.658(0.047)$ & $1.979(0.141)$ \\
\hline CTCF & 0.024 & $-0.041(0.032)$ & $-1.716(1.344)$ \\
\hline $\mathrm{CTCF}+500 \mathrm{bp}$ & 0.071 & $0.079(0.033)$ & $1.118(0.460)$ \\
\hline DGF & 0.138 & $0.168(0.083)$ & $1.222(0.604)$ \\
\hline $\mathrm{DGF}+500 \mathrm{bp}$ & 0.542 & $0.667(0.057)$ & $1.232(0.106)$ \\
\hline DHS peaks & 0.112 & $0.066(0.070)$ & $0.587(0.625)$ \\
\hline DHS & 0.168 & $0.175(0.083)$ & $1.045(0.493)$ \\
\hline DHS $+500 b p$ & 0.499 & $0.687(0.058)$ & $1.377(0.115)$ \\
\hline FANTOM5 Enhancer & 0.004 & $-0.024(0.015)$ & $-5.438(3.564)$ \\
\hline FANTOM5 Enhancer + 500bp & 0.019 & $-0.001(0.020)$ & $-0.068(1.033)$ \\
\hline Enhancer & 0.063 & $0.029(0.043)$ & $0.465(0.675)$ \\
\hline Enhancer $+500 \mathrm{bp}$ & 0.154 & $0.238(0.040)$ & $1.544(0.263)$ \\
\hline Fetal DHS & 0.085 & $0.216(0.070)$ & $2.547(0.825)$ \\
\hline Fetal DHS + 500bp & 0.285 & $0.486(0.060)$ & $1.705(0.211)$ \\
\hline $\mathrm{H} 3 \mathrm{~K} 27 \mathrm{ac}^{19}$ & 0.391 & $0.503(0.027)$ & $1.287(0.070)$ \\
\hline $\mathrm{H} 3 \mathrm{~K} 27 \mathrm{ac}^{19}+500 \mathrm{bp}$ & 0.423 & $0.552(0.036)$ & $1.306(0.085)$ \\
\hline $\mathrm{H} 3 \mathrm{~K} 27 \mathrm{ac}^{18}$ & 0.269 & $0.372(0.045)$ & $1.381(0.168)$ \\
\hline $\mathrm{H} 3 \mathrm{~K} 27 \mathrm{ac}^{18}+500 \mathrm{bp}$ & 0.336 & $0.544(0.042)$ & $1.618(0.125)$ \\
\hline H3K4me1 peaks & 0.171 & $0.412(0.072)$ & $2.407(0.420)$ \\
\hline H3K4me1 & 0.427 & $0.646(0.053)$ & $1.514(0.124)$ \\
\hline H3K4me1 + 500bp & 0.609 & $0.794(0.034)$ & $1.304(0.056)$ \\
\hline H3K4me3 peaks & 0.042 & $0.188(0.048)$ & $4.511(1.144)$ \\
\hline H3K4me3 & 0.133 & $0.292(0.046)$ & $2.192(0.342)$ \\
\hline H3K4me3 + 500bp & 0.255 & $0.353(0.040)$ & $1.383(0.156)$ \\
\hline H3K9ac peaks & 0.039 & $0.239(0.042)$ & $6.163(1.085)$ \\
\hline H3К9ас & 0.126 & $0.287(0.051)$ & $2.278(0.404)$ \\
\hline H3K9ac $+500 \mathrm{bp}$ & 0.231 & $0.457(0.037)$ & $1.981(0.161)$ \\
\hline Intron & 0.387 & $0.513(0.024)$ & $1.323(0.063)$ \\
\hline Intron $+500 \mathrm{bp}$ & 0.397 & $0.524(0.019)$ & $1.321(0.047)$ \\
\hline PromoterFlanking & 0.008 & $0.029(0.021)$ & $3.397(2.545)$ \\
\hline PromoterFlanking $+500 \mathrm{bp}$ & 0.033 & $0.070(0.025)$ & $2.099(0.754)$ \\
\hline Promoter & 0.031 & $0.068(0.028)$ & $2.192(0.887)$ \\
\hline Promoter $+500 \mathrm{bp}$ & 0.039 & $0.037(0.021)$ & $0.952(0.531)$ \\
\hline Repressed & 0.461 & $0.450(0.070)$ & $0.975(0.152)$ \\
\hline Repressed $+500 \mathrm{bp}$ & 0.719 & $0.627(0.027)$ & $0.873(0.038)$ \\
\hline Super Enhancer & 0.168 & $0.247(0.022)$ & $1.467(0.130)$ \\
\hline Super Enhancer $+500 b p$ & 0.172 & $0.253(0.019)$ & $1.475(0.113)$ \\
\hline TFBS & 0.132 & $0.217(0.059)$ & $1.639(0.447)$ \\
\hline $\mathrm{TFBS}+500 \mathrm{bp}$ & 0.343 & $0.372(0.059)$ & $1.083(0.171)$ \\
\hline Transcribed & 0.345 & $0.391(0.062)$ & $1.133(0.180)$ \\
\hline Transcribed $+500 \mathrm{bp}$ & 0.763 & $0.812(0.035)$ & $1.064(0.046)$ \\
\hline TSS & 0.018 & $0.053(0.027)$ & $2.918(1.467)$ \\
\hline $\mathrm{TSS}+500 \mathrm{bp}$ & 0.035 & $0.107(0.023)$ & $3.081(0.662)$ \\
\hline 3-prime UTR & 0.011 & $0.062(0.019)$ & $5.583(1.693)$ \\
\hline 3-prime UTR + 500bp & 0.027 & $0.085(0.020)$ & $3.140(0.758)$ \\
\hline 5-prime UTR & 0.005 & $0.020(0.012)$ & $3.656(2.215)$ \\
\hline 5-prime UTR $+500 \mathrm{bp}$ & 0.028 & $0.055(0.020)$ & $1.975(0.710)$ \\
\hline Weak Enhancer & 0.021 & $0.016(0.032)$ & $0.759(1.537)$ \\
\hline Weak Enhancer $+500 \mathrm{bp}$ & 0.089 & $0.146(0.040)$ & $1.643(0.447)$ \\
\hline
\end{tabular}

(S4.J) Proportion of heritability and enrichment for different functional categories for Schizophrenia. For many annotations there is heritability in the 500bp flanking regions, as cautioned by Gusev et al. ${ }^{13}$ We believe, as hypothesized by Gusev et al., that this flanking heritability inflates the estimates of DHS heritability in Gusev et al. However, our work confirms the main message of Gusev et al. that much of the heritability of many traits, including schizophrenia, is located in regulatory regions. 
bioRxiv preprint doi: https://doi.org/10.1101/014241; this version posted January 23, 2015. The copyright holder for this preprint (which was not certified by peer review) is the author/funder, who has granted bioRxiv a license to display the preprint in perpetuity. It is made available under aCC-BY-ND 4.0 International license.

\begin{tabular}{|c|c|c|c|}
\hline Annotation & Prop. SNPs & Prop. $h^{2}$ & Enrichment \\
\hline Coding & 0.015 & $0.186(0.090)$ & $12.671(6.108)$ \\
\hline Coding $+500 \mathrm{bp}$ & 0.065 & $0.200(0.086)$ & $3.098(1.336)$ \\
\hline Conserved & 0.026 & $0.302(0.115)$ & $11.588(4.413)$ \\
\hline Conserved $+500 \mathrm{bp}$ & 0.333 & $0.527(0.115)$ & $1.586(0.345)$ \\
\hline CTCF & 0.024 & $0.013(0.111)$ & $0.556(4.672)$ \\
\hline $\mathrm{CTCF}+500 \mathrm{bp}$ & 0.071 & $0.138(0.104)$ & $1.944(1.466)$ \\
\hline DGF & 0.138 & $0.723(0.241)$ & $5.251(1.754)$ \\
\hline $\mathrm{DGF}+500 \mathrm{bp}$ & 0.542 & $0.854(0.169)$ & $1.578(0.313)$ \\
\hline DHS peaks & 0.112 & $0.447(0.211)$ & $4.001(1.890)$ \\
\hline DHS & 0.168 & $0.670(0.251)$ & $3.993(1.495)$ \\
\hline DHS $+500 \mathrm{bp}$ & 0.499 & $0.735(0.170)$ & $1.474(0.340)$ \\
\hline FANTOM5 Enhancer & 0.004 & $0.013(0.046)$ & $2.987(10.718)$ \\
\hline FANTOM5 Enhancer + 500bp & 0.019 & $-0.106(0.053)$ & $-5.564(2.793)$ \\
\hline Enhancer & 0.063 & $0.317(0.130)$ & $4.999(2.059)$ \\
\hline Enhancer $+500 \mathrm{bp}$ & 0.154 & $0.299(0.123)$ & $1.940(0.797)$ \\
\hline Fetal DHS & 0.085 & $0.264(0.186)$ & $3.120(2.199)$ \\
\hline Fetal DHS + 500bp & 0.285 & $0.555(0.169)$ & $1.947(0.595)$ \\
\hline $\mathrm{H} 3 \mathrm{~K} 27 \mathrm{ac}^{19}$ & 0.391 & $0.456(0.089)$ & $1.166(0.226)$ \\
\hline $\mathrm{H} 3 \mathrm{~K} 27 \mathrm{ac}^{19}+500 \mathrm{bp}$ & 0.423 & $0.564(0.085)$ & $1.335(0.202)$ \\
\hline $\mathrm{H} 3 \mathrm{~K} 27 \mathrm{ac}^{18}$ & 0.269 & $0.574(0.136)$ & $2.132(0.505)$ \\
\hline $\mathrm{H} 3 \mathrm{~K} 27 \mathrm{ac}^{18}+500 \mathrm{bp}$ & 0.336 & $0.727(0.116)$ & $2.162(0.346)$ \\
\hline H3K4me1 peaks & 0.171 & $0.719(0.215)$ & $4.196(1.256)$ \\
\hline H3K4me1 & 0.427 & $0.970(0.166)$ & $2.274(0.389)$ \\
\hline H3K4me1 + 500bp & 0.609 & $0.754(0.099)$ & $1.238(0.162)$ \\
\hline H3K4me 3 peaks & 0.042 & $0.038(0.124)$ & $0.905(2.967)$ \\
\hline $\mathrm{H} 3 \mathrm{~K} 4 \mathrm{me} 3$ & 0.133 & $0.573(0.147)$ & $4.295(1.101)$ \\
\hline $\mathrm{H} 3 \mathrm{~K} 4 \mathrm{me} 3+500 \mathrm{bp}$ & 0.255 & $0.220(0.121)$ & $0.861(0.473)$ \\
\hline H3K9ac peaks & 0.039 & $0.160(0.125)$ & $4.124(3.225)$ \\
\hline H3К9ac & 0.126 & $0.450(0.153)$ & $3.572(1.214)$ \\
\hline H3K9ac $+500 \mathrm{bp}$ & 0.231 & $0.502(0.117)$ & $2.176(0.508)$ \\
\hline Intron & 0.387 & $0.509(0.092)$ & $1.313(0.237)$ \\
\hline Intron $+500 \mathrm{bp}$ & 0.397 & $0.608(0.066)$ & $1.531(0.166)$ \\
\hline PromoterFlanking & 0.008 & $0.051(0.063)$ & $6.090(7.507)$ \\
\hline PromoterFlanking $+500 \mathrm{bp}$ & 0.033 & $0.081(0.085)$ & $2.429(2.541)$ \\
\hline Promoter & 0.031 & $0.140(0.085)$ & $4.500(2.711)$ \\
\hline Promoter $+500 \mathrm{bp}$ & 0.039 & $0.128(0.065)$ & $3.317(1.671)$ \\
\hline Repressed & 0.461 & $0.402(0.184)$ & $0.871(0.400)$ \\
\hline Repressed $+500 \mathrm{bp}$ & 0.719 & $0.460(0.068)$ & $0.640(0.094)$ \\
\hline Super Enhancer & 0.168 & $0.288(0.047)$ & $1.712(0.278)$ \\
\hline Super Enhancer $+500 \mathrm{bp}$ & 0.172 & $0.252(0.043)$ & $1.469(0.250)$ \\
\hline TFBS & 0.132 & $0.459(0.218)$ & $3.462(1.645)$ \\
\hline $\mathrm{TFBS}+500 \mathrm{bp}$ & 0.343 & $0.507(0.153)$ & $1.477(0.444)$ \\
\hline Transcribed & 0.345 & $0.311(0.179)$ & $0.900(0.518)$ \\
\hline Transcribed $+500 \mathrm{bp}$ & 0.763 & $0.773(0.107)$ & $1.013(0.140)$ \\
\hline TSS & 0.018 & $0.081(0.070)$ & $4.435(3.863)$ \\
\hline $\mathrm{TSS}+500 \mathrm{bp}$ & 0.035 & $0.244(0.074)$ & $7.016(2.135)$ \\
\hline 3-prime UTR & 0.011 & $0.094(0.062)$ & $8.508(5.598)$ \\
\hline 3 -prime UTR $+500 \mathrm{bp}$ & 0.027 & $0.072(0.052)$ & $2.664(1.921)$ \\
\hline 5-prime UTR & 0.005 & $0.122(0.052)$ & $22.400(9.543)$ \\
\hline 5 -prime UTR $+500 \mathrm{bp}$ & 0.028 & $0.129(0.052)$ & $4.656(1.873)$ \\
\hline Weak Enhancer & 0.021 & $0.168(0.103)$ & $7.988(4.864)$ \\
\hline Weak Enhancer $+500 \mathrm{bp}$ & 0.089 & $0.217(0.098)$ & $2.435(1.107)$ \\
\hline
\end{tabular}

(S4.K) Proportion of heritability and enrichment for different functional categories for Bipolar disorder. 
bioRxiv preprint doi: https://doi.org/10.1101/014241; this version posted January 23, 2015. The copyright holder for this preprint (which was not certified by peer review) is the author/funder, who has granted bioRxiv a license to display the preprint in perpetuity. It is made available under aCC-BY-ND 4.0 International license.

\begin{tabular}{|c|c|c|c|}
\hline Annotation & Prop. SNPs & Prop. $h^{2}$ & Enrichment \\
\hline Coding & 0.015 & $0.017(0.068)$ & $1.145(4.645)$ \\
\hline Coding $+500 \mathrm{bp}$ & 0.065 & $0.140(0.059)$ & $2.169(0.915)$ \\
\hline Conserved & 0.026 & $0.186(0.110)$ & $7.128(4.214)$ \\
\hline Conserved $+500 \mathrm{bp}$ & 0.333 & $0.635(0.124)$ & $1.910(0.373)$ \\
\hline $\mathrm{CTCF}$ & 0.024 & $0.019(0.098)$ & $0.802(4.130)$ \\
\hline $\mathrm{CTCF}+500 \mathrm{bp}$ & 0.071 & $0.012(0.107)$ & $0.162(1.499)$ \\
\hline DGF & 0.138 & $0.257(0.240)$ & $1.865(1.743)$ \\
\hline $\mathrm{DGF}+500 \mathrm{bp}$ & 0.542 & $0.573(0.144)$ & $1.058(0.266)$ \\
\hline DHS peaks & 0.112 & $0.041(0.212)$ & $0.367(1.894)$ \\
\hline DHS & 0.168 & $-0.021(0.272)$ & $-0.126(1.623)$ \\
\hline DHS $+500 \mathrm{bp}$ & 0.499 & $0.780(0.173)$ & $1.564(0.346)$ \\
\hline FANTOM5 Enhancer & 0.004 & $-0.118(0.044)$ & $-27.161(10.087)$ \\
\hline FANTOM5 Enhancer + 500bp & 0.019 & $0.037(0.050)$ & $1.915(2.600)$ \\
\hline Enhancer & 0.063 & $0.117(0.117)$ & $1.852(1.845)$ \\
\hline Enhancer $+500 \mathrm{bp}$ & 0.154 & $0.237(0.112)$ & $1.537(0.731)$ \\
\hline Fetal DHS & 0.085 & $0.222(0.199)$ & $2.618(2.343)$ \\
\hline Fetal DHS + 500bp & 0.285 & $0.458(0.169)$ & $1.606(0.595)$ \\
\hline H3К $27 \mathrm{ac}^{19}$ & 0.391 & $0.528(0.077)$ & $1.350(0.197)$ \\
\hline $\mathrm{H} 3 \mathrm{~K} 27 \mathrm{ac}^{19}+500 \mathrm{bp}$ & 0.423 & $0.435(0.089)$ & $1.030(0.211)$ \\
\hline $\mathrm{H} 3 \mathrm{~K} 27 \mathrm{ac}^{18}$ & 0.269 & $0.362(0.136)$ & $1.343(0.503)$ \\
\hline $\mathrm{H} 3 \mathrm{~K} 27 \mathrm{ac}^{18}+500 \mathrm{bp}$ & 0.336 & $0.467(0.116)$ & $1.391(0.344)$ \\
\hline H3K4me1 peaks & 0.171 & $0.481(0.215)$ & $2.806(1.253)$ \\
\hline H3K4me1 & 0.427 & $0.867(0.153)$ & $2.033(0.358)$ \\
\hline H3K4me1 + 500bp & 0.609 & $0.798(0.107)$ & $1.309(0.175)$ \\
\hline H3K4me3 peaks & 0.042 & $0.101(0.116)$ & $2.424(2.770)$ \\
\hline H3K4me3 & 0.133 & $0.205(0.124)$ & $1.538(0.929)$ \\
\hline $\mathrm{H} 3 \mathrm{~K} 4 \mathrm{me} 3+500 \mathrm{bp}$ & 0.255 & $0.277(0.121)$ & $1.086(0.472)$ \\
\hline H3K9ac peaks & 0.039 & $-0.025(0.138)$ & $-0.656(3.572)$ \\
\hline H3K9ac & 0.126 & $0.244(0.129)$ & $1.935(1.019)$ \\
\hline H3K9ac $+500 \mathrm{bp}$ & 0.231 & $0.178(0.122)$ & $0.771(0.528)$ \\
\hline Intron & 0.387 & $0.417(0.066)$ & $1.076(0.170)$ \\
\hline Intron $+500 \mathrm{bp}$ & 0.397 & $0.429(0.054)$ & $1.081(0.137)$ \\
\hline PromoterFlanking & 0.008 & $0.041(0.060)$ & $4.904(7.124)$ \\
\hline PromoterFlanking $+500 \mathrm{bp}$ & 0.033 & $0.114(0.077)$ & $3.412(2.313)$ \\
\hline Promoter & 0.031 & $0.022(0.069)$ & $0.692(2.223)$ \\
\hline Promoter $+500 \mathrm{bp}$ & 0.039 & $-0.027(0.043)$ & $-0.694(1.116)$ \\
\hline Repressed & 0.461 & $0.402(0.179)$ & $0.871(0.389)$ \\
\hline Repressed $+500 \mathrm{bp}$ & 0.719 & $0.724(0.063)$ & $1.006(0.088)$ \\
\hline Super Enhancer & 0.168 & $0.171(0.048)$ & $1.017(0.284)$ \\
\hline Super Enhancer $+500 \mathrm{bp}$ & 0.172 & $0.238(0.045)$ & $1.387(0.263)$ \\
\hline TFBS & 0.132 & $0.309(0.177)$ & $2.330(1.340)$ \\
\hline $\mathrm{TFBS}+500 \mathrm{bp}$ & 0.343 & $0.386(0.159)$ & $1.125(0.462)$ \\
\hline Transcribed & 0.345 & $0.397(0.158)$ & $1.150(0.456)$ \\
\hline Transcribed $+500 \mathrm{bp}$ & 0.763 & $0.685(0.113)$ & $0.897(0.147)$ \\
\hline TSS & 0.018 & $0.078(0.074)$ & $4.287(4.044)$ \\
\hline $\mathrm{TSS}+500 \mathrm{bp}$ & 0.035 & $0.081(0.062)$ & $2.336(1.767)$ \\
\hline 3-prime UTR & 0.011 & $0.005(0.040)$ & $0.477(3.639)$ \\
\hline 3-prime UTR $+500 \mathrm{bp}$ & 0.027 & $0.052(0.047)$ & $1.935(1.737)$ \\
\hline 5-prime UTR & 0.005 & $0.001(0.039)$ & $0.261(7.157)$ \\
\hline 5-prime UTR $+500 \mathrm{bp}$ & 0.028 & $0.029(0.053)$ & $1.041(1.900)$ \\
\hline Weak Enhancer & 0.021 & $0.126(0.085)$ & $5.969(4.039)$ \\
\hline Weak Enhancer $+500 \mathrm{bp}$ & 0.089 & $0.139(0.094)$ & $1.564(1.058)$ \\
\hline
\end{tabular}

(S4.L) Proportion of heritability and enrichment for different functional categories for Anorexia. 
bioRxiv preprint doi: https://doi.org/10.1101/014241; this version posted January 23, 2015. The copyright holder for this preprint (which was not certified by peer review) is the author/funder, who has granted bioRxiv a license to display the preprint in perpetuity. It is made available under aCC-BY-ND 4.0 International license.

\begin{tabular}{|c|c|c|c|}
\hline Annotation & Prop. SNPs & Prop. $h^{2}$ & Enrichment \\
\hline Coding & 0.015 & $0.103(0.045)$ & $7.009(3.040)$ \\
\hline Coding $+500 \mathrm{bp}$ & 0.065 & $0.154(0.053)$ & $2.383(0.821)$ \\
\hline Conserved & 0.026 & $0.398(0.074)$ & $15.273(2.853)$ \\
\hline Conserved $+500 \mathrm{bp}$ & 0.333 & $0.785(0.092)$ & $2.362(0.277)$ \\
\hline CTCF & 0.024 & $-0.040(0.062)$ & $-1.658(2.610)$ \\
\hline $\mathrm{CTCF}+500 \mathrm{bp}$ & 0.071 & $0.063(0.076)$ & $0.888(1.071)$ \\
\hline DGF & 0.138 & $0.065(0.163)$ & $0.474(1.183)$ \\
\hline $\mathrm{DGF}+500 \mathrm{bp}$ & 0.542 & $0.644(0.111)$ & $1.189(0.205)$ \\
\hline DHS peaks & 0.112 & $0.346(0.155)$ & $3.093(1.391)$ \\
\hline DHS & 0.168 & $0.333(0.184)$ & $1.985(1.099)$ \\
\hline DHS $+500 \mathrm{bp}$ & 0.499 & $0.995(0.133)$ & $1.994(0.266)$ \\
\hline FANTOM5 Enhancer & 0.004 & $0.002(0.030)$ & $0.406(7.007)$ \\
\hline FANTOM5 Enhancer + 500bp & 0.019 & $0.074(0.042)$ & $3.860(2.194)$ \\
\hline Enhancer & 0.063 & $0.307(0.085)$ & $4.851(1.342)$ \\
\hline Enhancer $+500 \mathrm{bp}$ & 0.154 & $0.390(0.087)$ & $2.537(0.568)$ \\
\hline Fetal DHS & 0.085 & $0.355(0.146)$ & $4.190(1.728)$ \\
\hline Fetal DHS + 500bp & 0.285 & $0.870(0.128)$ & $3.052(0.450)$ \\
\hline $\mathrm{H} 3 \mathrm{~K} 27 \mathrm{ac}^{19}$ & 0.391 & $0.530(0.060)$ & $1.354(0.154)$ \\
\hline $\mathrm{H} 3 \mathrm{~K} 27 \mathrm{ac}^{19}+500 \mathrm{bp}$ & 0.423 & $0.468(0.077)$ & $1.107(0.182)$ \\
\hline $\mathrm{H} 3 \mathrm{~K} 27 \mathrm{ac}^{18}$ & 0.269 & $0.312(0.099)$ & $1.157(0.369)$ \\
\hline $\mathrm{H} 3 \mathrm{~K} 27 \mathrm{ac}^{18}+500 \mathrm{bp}$ & 0.336 & $0.480(0.083)$ & $1.429(0.248)$ \\
\hline H3K4me1 peaks & 0.171 & $0.602(0.140)$ & $3.511(0.818)$ \\
\hline H3K4me1 & 0.427 & $0.678(0.145)$ & $1.589(0.341)$ \\
\hline H3K4me1 + 500bp & 0.609 & $0.781(0.076)$ & $1.282(0.125)$ \\
\hline H3K4me 3 peaks & 0.042 & $0.147(0.095)$ & $3.510(2.275)$ \\
\hline $\mathrm{H} 3 \mathrm{~K} 4 \mathrm{me} 3$ & 0.133 & $0.358(0.093)$ & $2.685(0.699)$ \\
\hline $\mathrm{H} 3 \mathrm{~K} 4 \mathrm{me} 3+500 \mathrm{bp}$ & 0.255 & $0.401(0.087)$ & $1.569(0.340)$ \\
\hline H3K9ac peaks & 0.039 & $0.299(0.084)$ & $7.717(2.178)$ \\
\hline H3К9ac & 0.126 & $0.442(0.088)$ & $3.509(0.697)$ \\
\hline H3K9ac $+500 \mathrm{bp}$ & 0.231 & $0.500(0.076)$ & $2.170(0.329)$ \\
\hline Intron & 0.387 & $0.471(0.047)$ & $1.215(0.121)$ \\
\hline Intron $+500 \mathrm{bp}$ & 0.397 & $0.464(0.038)$ & $1.169(0.095)$ \\
\hline PromoterFlanking & 0.008 & $0.001(0.045)$ & $0.073(5.314)$ \\
\hline PromoterFlanking $+500 \mathrm{bp}$ & 0.033 & $0.055(0.050)$ & $1.636(1.493)$ \\
\hline Promoter & 0.031 & $0.030(0.047)$ & $0.973(1.521)$ \\
\hline Promoter $+500 \mathrm{bp}$ & 0.039 & $0.041(0.036)$ & $1.070(0.922)$ \\
\hline Repressed & 0.461 & $0.511(0.139)$ & $1.107(0.302)$ \\
\hline Repressed $+500 \mathrm{bp}$ & 0.719 & $0.498(0.050)$ & $0.693(0.070)$ \\
\hline Super Enhancer & 0.168 & $0.188(0.035)$ & $1.113(0.206)$ \\
\hline Super Enhancer $+500 \mathrm{bp}$ & 0.172 & $0.216(0.033)$ & $1.259(0.190)$ \\
\hline TFBS & 0.132 & $0.453(0.135)$ & $3.420(1.020)$ \\
\hline TFBS $+500 \mathrm{bp}$ & 0.343 & $0.457(0.129)$ & $1.330(0.376)$ \\
\hline Transcribed & 0.345 & $0.205(0.110)$ & $0.594(0.320)$ \\
\hline Transcribed $+500 \mathrm{bp}$ & 0.763 & $0.731(0.077)$ & $0.958(0.101)$ \\
\hline TSS & 0.018 & $0.052(0.049)$ & $2.840(2.673)$ \\
\hline $\mathrm{TSS}+500 \mathrm{bp}$ & 0.035 & $0.159(0.050)$ & $4.558(1.428)$ \\
\hline 3-prime UTR & 0.011 & $0.038(0.028)$ & $3.478(2.503)$ \\
\hline 3 -prime UTR $+500 \mathrm{bp}$ & 0.027 & $0.068(0.033)$ & $2.543(1.240)$ \\
\hline 5-prime UTR & 0.005 & $0.056(0.033)$ & $10.371(6.120)$ \\
\hline 5 -prime UTR $+500 \mathrm{bp}$ & 0.028 & $0.132(0.040)$ & $4.754(1.436)$ \\
\hline Weak Enhancer & 0.021 & $0.138(0.069)$ & $6.540(3.277)$ \\
\hline Weak Enhancer $+500 \mathrm{bp}$ & 0.089 & $0.276(0.072)$ & $3.105(0.804)$ \\
\hline
\end{tabular}

(S4.M) Proportion of heritability and enrichment for different functional categories for Years of education. 
bioRxiv preprint doi: https://doi.org/10.1101/014241; this version posted January 23, 2015. The copyright holder for this preprint (which was not certified by peer review) is the author/funder, who has granted bioRxiv a license to display the preprint in perpetuity. It is made available under aCC-BY-ND 4.0 International license.

\begin{tabular}{|c|c|c|c|}
\hline Annotation & Prop. SNPs & Prop. $h^{2}$ & Enrichment \\
\hline Coding & 0.015 & $0.116(0.077)$ & $7.929(5.258)$ \\
\hline Coding $+500 \mathrm{bp}$ & 0.065 & $0.114(0.077)$ & $1.759(1.188)$ \\
\hline Conserved & 0.026 & $0.402(0.125)$ & $15.414(4.811)$ \\
\hline Conserved $+500 \mathrm{bp}$ & 0.333 & $0.750(0.134)$ & $2.256(0.403)$ \\
\hline CTCF & 0.024 & $0.095(0.128)$ & $3.973(5.371)$ \\
\hline $\mathrm{CTCF}+500 \mathrm{bp}$ & 0.071 & $0.215(0.132)$ & $3.029(1.862)$ \\
\hline DGF & 0.138 & $0.419(0.287)$ & $3.048(2.088)$ \\
\hline $\mathrm{DGF}+500 \mathrm{bp}$ & 0.542 & $0.896(0.208)$ & $1.655(0.384)$ \\
\hline DHS peaks & 0.112 & $0.352(0.268)$ & $3.153(2.396)$ \\
\hline DHS & 0.168 & $0.433(0.286)$ & $2.581(1.706)$ \\
\hline DHS $+500 \mathrm{bp}$ & 0.499 & $0.958(0.206)$ & $1.921(0.413)$ \\
\hline FANTOM5 Enhancer & 0.004 & $0.006(0.050)$ & $1.319(11.432)$ \\
\hline FANTOM5 Enhancer + 500bp & 0.019 & $-0.109(0.072)$ & $-5.736(3.778)$ \\
\hline Enhancer & 0.063 & $0.326(0.152)$ & $5.141(2.408)$ \\
\hline Enhancer $+500 \mathrm{bp}$ & 0.154 & $0.387(0.166)$ & $2.513(1.078)$ \\
\hline Fetal DHS & 0.085 & $0.538(0.241)$ & $6.346(2.845)$ \\
\hline Fetal DHS + 500bp & 0.285 & $0.808(0.180)$ & $2.834(0.630)$ \\
\hline $\mathrm{H} 3 \mathrm{~K} 27 \mathrm{ac}^{19}$ & 0.391 & $0.494(0.093)$ & $1.263(0.237)$ \\
\hline $\mathrm{H} 3 \mathrm{~K} 27 \mathrm{ac}^{19}+500 \mathrm{bp}$ & 0.423 & $0.379(0.131)$ & $0.897(0.309)$ \\
\hline $\mathrm{H} 3 \mathrm{~K} 27 \mathrm{ac}^{18}$ & 0.269 & $0.192(0.178)$ & $0.713(0.661)$ \\
\hline $\mathrm{H} 3 \mathrm{~K} 27 \mathrm{ac}^{18}+500 \mathrm{bp}$ & 0.336 & $0.549(0.153)$ & $1.634(0.455)$ \\
\hline H3K4me1 peaks & 0.171 & $0.643(0.257)$ & $3.751(1.501)$ \\
\hline H3K4me1 & 0.427 & $0.946(0.224)$ & $2.218(0.525)$ \\
\hline $\mathrm{H} 3 \mathrm{~K} 4 \mathrm{me} 1+500 \mathrm{bp}$ & 0.609 & $0.750(0.136)$ & $1.231(0.223)$ \\
\hline H3K4me 3 peaks & 0.042 & $0.176(0.180)$ & $4.210(4.313)$ \\
\hline H3K4me3 & 0.133 & $0.275(0.154)$ & $2.066(1.154)$ \\
\hline $\mathrm{H} 3 \mathrm{~K} 4 \mathrm{me} 3+500 \mathrm{bp}$ & 0.255 & $0.259(0.148)$ & $1.016(0.581)$ \\
\hline H3K9ac peaks & 0.039 & $0.233(0.153)$ & $6.009(3.951)$ \\
\hline H3К9ac & 0.126 & $0.252(0.151)$ & $2.002(1.194)$ \\
\hline H3K9ac $+500 \mathrm{bp}$ & 0.231 & $0.162(0.147)$ & $0.702(0.635)$ \\
\hline Intron & 0.387 & $0.372(0.081)$ & $0.960(0.210)$ \\
\hline Intron $+500 \mathrm{bp}$ & 0.397 & $0.443(0.068)$ & $1.115(0.171)$ \\
\hline PromoterFlanking & 0.008 & $-0.017(0.061)$ & $-1.974(7.269)$ \\
\hline PromoterFlanking $+500 \mathrm{bp}$ & 0.033 & $-0.001(0.094)$ & $-0.032(2.795)$ \\
\hline Promoter & 0.031 & $-0.010(0.070)$ & $-0.334(2.245)$ \\
\hline Promoter $+500 \mathrm{bp}$ & 0.039 & $-0.019(0.055)$ & $-0.483(1.420)$ \\
\hline Repressed & 0.461 & $0.192(0.218)$ & $0.417(0.473)$ \\
\hline Repressed $+500 \mathrm{bp}$ & 0.719 & $0.504(0.094)$ & $0.701(0.131)$ \\
\hline Super Enhancer & 0.168 & $0.135(0.061)$ & $0.800(0.365)$ \\
\hline Super Enhancer $+500 \mathrm{bp}$ & 0.172 & $0.071(0.062)$ & $0.414(0.359)$ \\
\hline TFBS & 0.132 & $0.743(0.245)$ & $5.613(1.849)$ \\
\hline $\mathrm{TFBS}+500 \mathrm{bp}$ & 0.343 & $0.385(0.217)$ & $1.121(0.630)$ \\
\hline Transcribed & 0.345 & $0.276(0.197)$ & $0.798(0.570)$ \\
\hline Transcribed $+500 \mathrm{bp}$ & 0.763 & $0.739(0.113)$ & $0.969(0.148)$ \\
\hline TSS & 0.018 & $0.065(0.087)$ & $3.591(4.777)$ \\
\hline $\mathrm{TSS}+500 \mathrm{bp}$ & 0.035 & $0.046(0.081)$ & $1.309(2.315)$ \\
\hline 3-prime UTR & 0.011 & $0.009(0.053)$ & $0.839(4.758)$ \\
\hline 3 -prime UTR $+500 \mathrm{bp}$ & 0.027 & $-0.005(0.054)$ & $-0.171(2.012)$ \\
\hline 5-prime UTR & 0.005 & $-0.009(0.046)$ & $-1.695(8.473)$ \\
\hline 5 -prime UTR $+500 \mathrm{bp}$ & 0.028 & $0.029(0.059)$ & $1.048(2.126)$ \\
\hline Weak Enhancer & 0.021 & $0.136(0.116)$ & $6.438(5.507)$ \\
\hline Weak Enhancer $+500 \mathrm{bp}$ & 0.089 & $0.212(0.129)$ & $2.387(1.450)$ \\
\hline
\end{tabular}

(S4.N) Proportion of heritability and enrichment for different functional categories for Ever smoked. 
bioRxiv preprint doi: https://doi.org/10.1101/014241; this version posted January 23, 2015. The copyright holder for this preprint (which was not certified by peer review) is the author/funder, who has granted bioRxiv a license to display the preprint in perpetuity. It is made available under aCC-BY-ND 4.0 International license.

\begin{tabular}{|c|c|c|c|}
\hline Annotation & Prop. SNPs & Prop. $h^{2}$ & Enrichment \\
\hline Coding & 0.015 & $0.174(0.090)$ & $11.891(6.155)$ \\
\hline Coding $+500 \mathrm{bp}$ & 0.065 & $0.365(0.081)$ & $5.659(1.262)$ \\
\hline Conserved & 0.026 & $0.109(0.115)$ & $4.195(4.402)$ \\
\hline Conserved $+500 \mathrm{bp}$ & 0.333 & $0.771(0.122)$ & $2.319(0.368)$ \\
\hline CTCF & 0.024 & $-0.006(0.113)$ & $-0.261(4.762)$ \\
\hline $\mathrm{CTCF}+500 \mathrm{bp}$ & 0.071 & $-0.152(0.114)$ & $-2.140(1.610)$ \\
\hline DGF & 0.138 & $0.871(0.251)$ & $6.331(1.826)$ \\
\hline $\mathrm{DGF}+500 \mathrm{bp}$ & 0.542 & $1.065(0.147)$ & $1.966(0.271)$ \\
\hline DHS peaks & 0.112 & $0.357(0.255)$ & $3.195(2.283)$ \\
\hline DHS & 0.168 & $0.523(0.272)$ & $3.121(1.619)$ \\
\hline $\mathrm{DHS}+500 \mathrm{bp}$ & 0.499 & $0.858(0.145)$ & $1.719(0.290)$ \\
\hline FANTOM5 Enhancer & 0.004 & $0.158(0.071)$ & $36.410(16.488)$ \\
\hline FANTOM5 Enhancer + 500bp & 0.019 & $0.283(0.084)$ & $14.848(4.407)$ \\
\hline Enhancer & 0.063 & $0.379(0.154)$ & $5.984(2.437)$ \\
\hline Enhancer $+500 \mathrm{bp}$ & 0.154 & $0.668(0.120)$ & $4.342(0.778)$ \\
\hline Fetal DHS & 0.085 & $0.567(0.199)$ & $6.690(2.345)$ \\
\hline Fetal DHS + 500bp & 0.285 & $0.537(0.157)$ & $1.882(0.551)$ \\
\hline $\mathrm{H} 3 \mathrm{~K} 27 \mathrm{ac}^{19}$ & 0.391 & $0.980(0.086)$ & $2.506(0.219)$ \\
\hline $\mathrm{H} 3 \mathrm{~K} 27 \mathrm{ac}^{19}+500 \mathrm{bp}$ & 0.423 & $0.957(0.083)$ & $2.263(0.195)$ \\
\hline $\mathrm{H} 3 \mathrm{~K} 27 \mathrm{ac}^{18}$ & 0.269 & $0.951(0.161)$ & $3.530(0.597)$ \\
\hline $\mathrm{H} 3 \mathrm{~K} 27 \mathrm{ac}^{18}+500 \mathrm{bp}$ & 0.336 & $0.792(0.112)$ & $2.358(0.333)$ \\
\hline H3K4me1 peaks & 0.171 & $0.502(0.201)$ & $2.931(1.173)$ \\
\hline $\mathrm{H} 3 \mathrm{~K} 4 \mathrm{me} 1$ & 0.427 & $0.884(0.191)$ & $2.072(0.448)$ \\
\hline H3K4me1 + 500bp & 0.609 & $1.041(0.085)$ & $1.709(0.140)$ \\
\hline H3K4me3 peaks & 0.042 & $0.313(0.144)$ & $7.501(3.435)$ \\
\hline H3K4me3 & 0.133 & $0.750(0.149)$ & $5.628(1.119)$ \\
\hline H3K4me3 + 500bp & 0.255 & $0.610(0.124)$ & $2.387(0.484)$ \\
\hline H3K9ac peaks & 0.039 & $0.146(0.139)$ & $3.770(3.580)$ \\
\hline H3K9ac & 0.126 & $0.335(0.149)$ & $2.655(1.178)$ \\
\hline H3К $9 \mathrm{ac}+500 \mathrm{bp}$ & 0.231 & $0.434(0.130)$ & $1.883(0.562)$ \\
\hline Intron & 0.387 & $0.416(0.071)$ & $1.073(0.184)$ \\
\hline Intron $+500 \mathrm{bp}$ & 0.397 & $0.513(0.052)$ & $1.291(0.132)$ \\
\hline PromoterFlanking & 0.008 & $0.017(0.073)$ & $2.049(8.639)$ \\
\hline PromoterFlanking $+500 \mathrm{bp}$ & 0.033 & $0.228(0.095)$ & $6.818(2.846)$ \\
\hline Promoter & 0.031 & $0.251(0.079)$ & $8.046(2.526)$ \\
\hline Promoter $+500 \mathrm{bp}$ & 0.039 & $0.169(0.056)$ & $4.364(1.442)$ \\
\hline Repressed & 0.461 & $0.179(0.145)$ & $0.388(0.315)$ \\
\hline Repressed $+500 \mathrm{bp}$ & 0.719 & $0.260(0.078)$ & $0.362(0.109)$ \\
\hline Super Enhancer & 0.168 & $0.563(0.061)$ & $3.341(0.362)$ \\
\hline Super Enhancer $+500 \mathrm{bp}$ & 0.172 & $0.615(0.059)$ & $3.582(0.346)$ \\
\hline TFBS & 0.132 & $0.791(0.221)$ & $5.970(1.666)$ \\
\hline $\mathrm{TFBS}+500 \mathrm{bp}$ & 0.343 & $0.552(0.182)$ & $1.607(0.531)$ \\
\hline Transcribed & 0.345 & $0.302(0.144)$ & $0.875(0.418)$ \\
\hline Transcribed $+500 \mathrm{bp}$ & 0.763 & $0.596(0.104)$ & $0.781(0.136)$ \\
\hline TSS & 0.018 & $0.341(0.091)$ & $18.703(4.996)$ \\
\hline $\mathrm{TSS}+500 \mathrm{bp}$ & 0.035 & $0.372(0.080)$ & $10.679(2.290)$ \\
\hline 3-prime UTR & 0.011 & $0.073(0.047)$ & $6.588(4.219)$ \\
\hline 3 -prime UTR $+500 \mathrm{bp}$ & 0.027 & $0.107(0.055)$ & $3.958(2.056)$ \\
\hline 5-prime UTR & 0.005 & $0.019(0.044)$ & $3.562(8.104)$ \\
\hline 5-prime UTR $+500 \mathrm{bp}$ & 0.028 & $0.150(0.063)$ & $5.381(2.248)$ \\
\hline Weak Enhancer & 0.021 & $0.230(0.116)$ & $10.914(5.510)$ \\
\hline Weak Enhancer $+500 \mathrm{bp}$ & 0.089 & $0.424(0.108)$ & $4.762(1.214)$ \\
\hline
\end{tabular}

(S4.O) Proportion of heritability and enrichment for different functional categories for Rheumatoid arthritis. 
bioRxiv preprint doi: https://doi.org/10.1101/014241; this version posted January 23, 2015. The copyright holder for this preprint (which was not certified by peer review) is the author/funder, who has granted bioRxiv a license to display the preprint in perpetuity. It is made available under aCC-BY-ND 4.0 International license.

\begin{tabular}{|c|c|c|c|}
\hline Annotation & Prop. SNPs & Prop. $h^{2}$ & Enrichment \\
\hline Coding & 0.015 & $0.125(0.071)$ & $8.551(4.851)$ \\
\hline Coding $+500 \mathrm{bp}$ & 0.065 & $0.352(0.065)$ & $5.453(1.007)$ \\
\hline Conserved & 0.026 & $0.069(0.072)$ & $2.640(2.766)$ \\
\hline Conserved $+500 \mathrm{bp}$ & 0.333 & $0.919(0.098)$ & $2.765(0.296)$ \\
\hline CTCF & 0.024 & $-0.050(0.087)$ & $-2.081(3.645)$ \\
\hline $\mathrm{CTCF}+500 \mathrm{bp}$ & 0.071 & $-0.127(0.083)$ & $-1.781(1.174)$ \\
\hline DGF & 0.138 & $0.770(0.182)$ & $5.600(1.324)$ \\
\hline $\mathrm{DGF}+500 \mathrm{bp}$ & 0.542 & $1.088(0.090)$ & $2.009(0.166)$ \\
\hline DHS peaks & 0.112 & $0.303(0.136)$ & $2.713(1.220)$ \\
\hline DHS & 0.168 & $0.154(0.177)$ & $0.915(1.057)$ \\
\hline DHS $+500 \mathrm{bp}$ & 0.499 & $0.713(0.126)$ & $1.430(0.253)$ \\
\hline FANTOM5 Enhancer & 0.004 & $0.169(0.042)$ & $39.042(9.623)$ \\
\hline FANTOM5 Enhancer + 500bp & 0.019 & $0.428(0.073)$ & $22.468(3.853)$ \\
\hline Enhancer & 0.063 & $0.237(0.096)$ & $3.740(1.519)$ \\
\hline Enhancer $+500 \mathrm{bp}$ & 0.154 & $0.554(0.106)$ & $3.600(0.691)$ \\
\hline Fetal DHS & 0.085 & $0.398(0.133)$ & $4.693(1.570)$ \\
\hline Fetal DHS + 500bp & 0.285 & $0.686(0.131)$ & $2.406(0.461)$ \\
\hline $\mathrm{H} 3 \mathrm{~K} 27 \mathrm{ac}^{19}$ & 0.391 & $0.838(0.049)$ & $2.143(0.126)$ \\
\hline $\mathrm{H} 3 \mathrm{~K} 27 \mathrm{ac}^{19}+500 \mathrm{bp}$ & 0.423 & $0.840(0.060)$ & $1.987(0.141)$ \\
\hline $\mathrm{H} 3 \mathrm{~K} 27 \mathrm{ac}^{18}$ & 0.269 & $0.768(0.121)$ & $2.849(0.450)$ \\
\hline $\mathrm{H} 3 \mathrm{~K} 27 \mathrm{ac}^{18}+500 \mathrm{bp}$ & 0.336 & $0.748(0.074)$ & $2.227(0.221)$ \\
\hline H3K4me1 peaks & 0.171 & $0.506(0.169)$ & $2.953(0.987)$ \\
\hline H3K4me1 & 0.427 & $0.742(0.132)$ & $1.739(0.310)$ \\
\hline $\mathrm{H} 3 \mathrm{~K} 4 \mathrm{me} 1+500 \mathrm{bp}$ & 0.609 & $1.004(0.068)$ & $1.648(0.111)$ \\
\hline H3K4me 3 peaks & 0.042 & $0.318(0.157)$ & $7.621(3.765)$ \\
\hline $\mathrm{H} 3 \mathrm{~K} 4 \mathrm{me} 3$ & 0.133 & $0.675(0.147)$ & $5.064(1.100)$ \\
\hline $\mathrm{H} 3 \mathrm{~K} 4 \mathrm{me} 3+500 \mathrm{bp}$ & 0.255 & $0.669(0.126)$ & $2.618(0.492)$ \\
\hline H3K9ac peaks & 0.039 & $0.082(0.113)$ & $2.109(2.926)$ \\
\hline H3К9ac & 0.126 & $0.231(0.122)$ & $1.834(0.964)$ \\
\hline H3K9ac $+500 \mathrm{bp}$ & 0.231 & $0.565(0.101)$ & $2.450(0.438)$ \\
\hline Intron & 0.387 & $0.400(0.068)$ & $1.032(0.176)$ \\
\hline Intron $+500 \mathrm{bp}$ & 0.397 & $0.504(0.054)$ & $1.268(0.135)$ \\
\hline PromoterFlanking & 0.008 & $-0.054(0.045)$ & $-6.361(5.315)$ \\
\hline PromoterFlanking $+500 \mathrm{bp}$ & 0.033 & $0.018(0.066)$ & $0.535(1.959)$ \\
\hline Promoter & 0.031 & $0.146(0.065)$ & $4.685(2.075)$ \\
\hline Promoter $+500 \mathrm{bp}$ & 0.039 & $0.137(0.047)$ & $3.553(1.223)$ \\
\hline Repressed & 0.461 & $0.102(0.114)$ & $0.222(0.248)$ \\
\hline Repressed $+500 \mathrm{bp}$ & 0.719 & $0.392(0.052)$ & $0.545(0.072)$ \\
\hline Super Enhancer & 0.168 & $0.554(0.050)$ & $3.289(0.297)$ \\
\hline Super Enhancer $+500 \mathrm{bp}$ & 0.172 & $0.594(0.046)$ & $3.462(0.270)$ \\
\hline TFBS & 0.132 & $0.614(0.195)$ & $4.635(1.474)$ \\
\hline $\mathrm{TFBS}+500 \mathrm{bp}$ & 0.343 & $0.730(0.133)$ & $2.126(0.386)$ \\
\hline Transcribed & 0.345 & $0.402(0.124)$ & $1.163(0.359)$ \\
\hline Transcribed $+500 \mathrm{bp}$ & 0.763 & $0.747(0.081)$ & $0.978(0.106)$ \\
\hline TSS & 0.018 & $0.248(0.073)$ & $13.613(4.019)$ \\
\hline $\mathrm{TSS}+500 \mathrm{bp}$ & 0.035 & $0.398(0.070)$ & $11.424(2.013)$ \\
\hline 3-prime UTR & 0.011 & $0.021(0.035)$ & $1.909(3.148)$ \\
\hline 3 -prime UTR $+500 \mathrm{bp}$ & 0.027 & $0.171(0.076)$ & $6.347(2.827)$ \\
\hline 5-prime UTR & 0.005 & $0.040(0.045)$ & $7.436(8.298)$ \\
\hline 5 -prime UTR $+500 \mathrm{bp}$ & 0.028 & $0.151(0.047)$ & $5.413(1.703)$ \\
\hline Weak Enhancer & 0.021 & $0.101(0.069)$ & $4.797(3.258)$ \\
\hline Weak Enhancer $+500 \mathrm{bp}$ & 0.089 & $0.258(0.084)$ & $2.903(0.940)$ \\
\hline
\end{tabular}

(S4.P) Proportion of heritability and enrichment for different functional categories for Crohn's disease. 
bioRxiv preprint doi: https://doi.org/10.1101/014241; this version posted January 23, 2015. The copyright holder for this preprint (which was not certified by peer review) is the author/funder, who has granted bioRxiv a license to display the preprint in perpetuity. It is made available under aCC-BY-ND 4.0 International license.

\begin{tabular}{|c|c|c|c|}
\hline Annotation & Prop. SNPs & Prop. $h^{2}$ & Enrichment \\
\hline Coding & 0.015 & $0.172(0.088)$ & $11.727(6.022)$ \\
\hline Coding $+500 \mathrm{bp}$ & 0.065 & $0.421(0.079)$ & $6.529(1.218)$ \\
\hline Conserved & 0.026 & $0.203(0.091)$ & $7.786(3.478)$ \\
\hline Conserved $+500 \mathrm{bp}$ & 0.333 & $0.878(0.123)$ & $2.639(0.369)$ \\
\hline CTCF & 0.024 & $-0.101(0.106)$ & $-4.218(4.430)$ \\
\hline $\mathrm{CTCF}+500 \mathrm{bp}$ & 0.071 & $-0.077(0.111)$ & $-1.087(1.559)$ \\
\hline DGF & 0.138 & $0.901(0.247)$ & $6.546(1.795)$ \\
\hline $\mathrm{DGF}+500 \mathrm{bp}$ & 0.542 & $1.117(0.134)$ & $2.063(0.248)$ \\
\hline DHS peaks & 0.112 & $0.706(0.218)$ & $6.319(1.950)$ \\
\hline DHS & 0.168 & $0.416(0.236)$ & $2.481(1.409)$ \\
\hline DHS $+500 b p$ & 0.499 & $0.815(0.165)$ & $1.635(0.330)$ \\
\hline FANTOM5 Enhancer & 0.004 & $0.181(0.049)$ & $41.783(11.190)$ \\
\hline FANTOM5 Enhancer + 500bp & 0.019 & $0.285(0.076)$ & $14.939(3.999)$ \\
\hline Enhancer & 0.063 & $0.348(0.135)$ & $5.490(2.133)$ \\
\hline Enhancer $+500 \mathrm{bp}$ & 0.154 & $0.699(0.138)$ & $4.544(0.897)$ \\
\hline Fetal DHS & 0.085 & $0.360(0.186)$ & $4.243(2.200)$ \\
\hline Fetal DHS + 500bp & 0.285 & $0.550(0.170)$ & $1.929(0.596)$ \\
\hline $\mathrm{H} 3 \mathrm{~K} 27 \mathrm{ac}^{19}$ & 0.391 & $0.989(0.084)$ & $2.527(0.214)$ \\
\hline $\mathrm{H} 3 \mathrm{~K} 27 \mathrm{ac}^{19}+500 \mathrm{bp}$ & 0.423 & $1.031(0.088)$ & $2.440(0.209)$ \\
\hline $\mathrm{H} 3 \mathrm{~K} 27 \mathrm{ac}^{18}$ & 0.269 & $0.848(0.163)$ & $3.148(0.603)$ \\
\hline $\mathrm{H} 3 \mathrm{~K} 27 \mathrm{ac}^{18}+500 \mathrm{bp}$ & 0.336 & $0.813(0.132)$ & $2.420(0.394)$ \\
\hline H3K4me1 peaks & 0.171 & $0.710(0.243)$ & $4.142(1.418)$ \\
\hline H3K4me1 & 0.427 & $0.774(0.173)$ & $1.814(0.406)$ \\
\hline H3K4me1 + 500bp & 0.609 & $0.911(0.078)$ & $1.495(0.128)$ \\
\hline H3K4me3 peaks & 0.042 & $0.264(0.174)$ & $6.318(4.161)$ \\
\hline H3K4me3 & 0.133 & $0.709(0.179)$ & $5.321(1.345)$ \\
\hline $\mathrm{H} 3 \mathrm{~K} 4 \mathrm{me} 3+500 \mathrm{bp}$ & 0.255 & $0.707(0.137)$ & $2.767(0.536)$ \\
\hline H3K9ac peaks & 0.039 & $0.276(0.144)$ & $7.125(3.713)$ \\
\hline H3K9ac & 0.126 & $0.584(0.172)$ & $4.634(1.367)$ \\
\hline H3K9ac $+500 \mathrm{bp}$ & 0.231 & $0.692(0.122)$ & $3.002(0.531)$ \\
\hline Intron & 0.387 & $0.364(0.082)$ & $0.941(0.210)$ \\
\hline Intron $+500 \mathrm{bp}$ & 0.397 & $0.506(0.055)$ & $1.275(0.138)$ \\
\hline PromoterFlanking & 0.008 & $0.030(0.055)$ & $3.586(6.532)$ \\
\hline PromoterFlanking $+500 \mathrm{bp}$ & 0.033 & $0.049(0.080)$ & $1.464(2.381)$ \\
\hline Promoter & 0.031 & $0.150(0.072)$ & $4.799(2.296)$ \\
\hline Promoter $+500 \mathrm{bp}$ & 0.039 & $0.185(0.054)$ & $4.797(1.392)$ \\
\hline Repressed & 0.461 & $0.065(0.160)$ & $0.140(0.347)$ \\
\hline Repressed $+500 \mathrm{bp}$ & 0.719 & $0.275(0.072)$ & $0.383(0.100)$ \\
\hline Super Enhancer & 0.168 & $0.567(0.062)$ & $3.365(0.367)$ \\
\hline Super Enhancer $+500 \mathrm{bp}$ & 0.172 & $0.616(0.057)$ & $3.593(0.331)$ \\
\hline TFBS & 0.132 & $1.144(0.283)$ & $8.637(2.134)$ \\
\hline $\mathrm{TFBS}+500 \mathrm{bp}$ & 0.343 & $0.660(0.173)$ & $1.921(0.503)$ \\
\hline Transcribed & 0.345 & $0.446(0.162)$ & $1.291(0.470)$ \\
\hline Transcribed $+500 \mathrm{bp}$ & 0.763 & $0.677(0.107)$ & $0.888(0.140)$ \\
\hline TSS & 0.018 & $0.209(0.065)$ & $11.447(3.569)$ \\
\hline $\mathrm{TSS}+500 \mathrm{bp}$ & 0.035 & $0.307(0.076)$ & $8.827(2.188)$ \\
\hline 3-prime UTR & 0.011 & $0.034(0.053)$ & $3.111(4.792)$ \\
\hline 3 -prime UTR $+500 \mathrm{bp}$ & 0.027 & $0.176(0.065)$ & $6.524(2.425)$ \\
\hline 5-prime UTR & 0.005 & $0.097(0.043)$ & $17.831(7.949)$ \\
\hline 5-prime UTR $+500 \mathrm{bp}$ & 0.028 & $0.204(0.073)$ & $7.325(2.612)$ \\
\hline Weak Enhancer & 0.021 & $0.057(0.099)$ & $2.723(4.693)$ \\
\hline Weak Enhancer $+500 \mathrm{bp}$ & 0.089 & $0.328(0.106)$ & $3.690(1.190)$ \\
\hline
\end{tabular}

(S4.Q) Proportion of heritability and enrichment for different functional categories for Ulcerative colitis. 
bioRxiv preprint doi: https://doi.org/10.1101/014241; this version posted January 23, 2015. The copyright holder for this preprint (which was not certified by peer review) is the author/funder, who has granted bioRxiv a license to display the preprint in perpetuity. It is made available under aCC-BY-ND 4.0 International license.

\begin{tabular}{|c|c|c|c|}
\hline Annotation & Prop. SNPs & Prop. $h^{2}$ & Enrichment \\
\hline Coding & 0.015 & $0.108(0.013)$ & $7.357(0.859)$ \\
\hline Coding $+500 \mathrm{bp}$ & 0.065 & $0.192(0.030)$ & $2.979(0.469)$ \\
\hline Conserved & 0.026 & $0.359(0.042)$ & $13.762(1.603)$ \\
\hline Conserved $+500 \mathrm{bp}$ & 0.333 & $0.656(0.026)$ & $1.972(0.080)$ \\
\hline CTCF & 0.024 & $-0.014(0.019)$ & $-0.578(0.807)$ \\
\hline $\mathrm{CTCF}+500 \mathrm{bp}$ & 0.071 & $0.043(0.020)$ & $0.601(0.278)$ \\
\hline DGF & 0.138 & $0.367(0.097)$ & $2.669(0.702)$ \\
\hline $\mathrm{DGF}+500 \mathrm{bp}$ & 0.542 & $0.747(0.071)$ & $1.380(0.132)$ \\
\hline DHS peaks & 0.112 & $0.221(0.065)$ & $1.978(0.584)$ \\
\hline DHS & 0.168 & $0.280(0.071)$ & $1.666(0.420)$ \\
\hline DHS $+500 \mathrm{bp}$ & 0.499 & $0.756(0.040)$ & $1.516(0.081)$ \\
\hline FANTOM5 Enhancer & 0.004 & $-0.004(0.009)$ & $-0.853(2.162)$ \\
\hline FANTOM5 Enhancer + 500bp & 0.019 & $0.016(0.018)$ & $0.815(0.921)$ \\
\hline Enhancer & 0.063 & $0.242(0.051)$ & $3.825(0.811)$ \\
\hline Enhancer $+500 \mathrm{bp}$ & 0.154 & $0.349(0.043)$ & $2.266(0.280)$ \\
\hline Fetal DHS & 0.085 & $0.236(0.044)$ & $2.787(0.517)$ \\
\hline Fetal DHS + 500bp & 0.285 & $0.559(0.059)$ & $1.960(0.207)$ \\
\hline $\mathrm{H} 3 \mathrm{~K} 27 \mathrm{ac}^{19}$ & 0.391 & $0.628(0.055)$ & $1.605(0.141)$ \\
\hline $\mathrm{H} 3 \mathrm{~K} 27 \mathrm{ac}^{19}+500 \mathrm{bp}$ & 0.423 & $0.664(0.060)$ & $1.571(0.142)$ \\
\hline $\mathrm{H} 3 \mathrm{~K} 27 \mathrm{ac}^{18}$ & 0.269 & $0.485(0.056)$ & $1.798(0.207)$ \\
\hline $\mathrm{H} 3 \mathrm{~K} 27 \mathrm{ac}^{18}+500 \mathrm{bp}$ & 0.336 & $0.607(0.042)$ & $1.806(0.124)$ \\
\hline H3K4me1 peaks & 0.171 & $0.464(0.041)$ & $2.711(0.241)$ \\
\hline H3K4me1 & 0.427 & $0.807(0.066)$ & $1.891(0.156)$ \\
\hline H3K4me1 + 500bp & 0.609 & $0.899(0.041)$ & $1.476(0.067)$ \\
\hline H3K4me3 peaks & 0.042 & $0.166(0.026)$ & $3.966(0.616)$ \\
\hline $\mathrm{H} 3 \mathrm{~K} 4 \mathrm{me} 3$ & 0.133 & $0.345(0.045)$ & $2.587(0.335)$ \\
\hline H3K4me3 + 500bp & 0.255 & $0.488(0.058)$ & $1.909(0.227)$ \\
\hline H3K9ac peaks & 0.039 & $0.259(0.025)$ & $6.674(0.635)$ \\
\hline H3К9ac & 0.126 & $0.409(0.057)$ & $3.240(0.452)$ \\
\hline H3K9ac $+500 \mathrm{bp}$ & 0.231 & $0.502(0.041)$ & $2.178(0.178)$ \\
\hline Intron & 0.387 & $0.467(0.014)$ & $1.206(0.035)$ \\
\hline Intron $+500 \mathrm{bp}$ & 0.397 & $0.528(0.015)$ & $1.329(0.037)$ \\
\hline PromoterFlanking & 0.008 & $0.010(0.011)$ & $1.137(1.346)$ \\
\hline PromoterFlanking $+500 \mathrm{bp}$ & 0.033 & $0.083(0.018)$ & $2.488(0.543)$ \\
\hline Promoter & 0.031 & $0.091(0.016)$ & $2.923(0.521)$ \\
\hline Promoter $+500 \mathrm{bp}$ & 0.039 & $0.079(0.017)$ & $2.045(0.441)$ \\
\hline Repressed & 0.461 & $0.268(0.065)$ & $0.581(0.141)$ \\
\hline Repressed $+500 \mathrm{bp}$ & 0.719 & $0.443(0.049)$ & $0.616(0.068)$ \\
\hline Super Enhancer & 0.168 & $0.303(0.036)$ & $1.797(0.214)$ \\
\hline Super Enhancer $+500 \mathrm{bp}$ & 0.172 & $0.316(0.038)$ & $1.843(0.221)$ \\
\hline TFBS & 0.132 & $0.440(0.065)$ & $3.321(0.492)$ \\
\hline TFBS $+500 \mathrm{bp}$ & 0.343 & $0.481(0.054)$ & $1.399(0.156)$ \\
\hline Transcribed & 0.345 & $0.430(0.039)$ & $1.244(0.112)$ \\
\hline Transcribed $+500 \mathrm{bp}$ & 0.763 & $0.726(0.028)$ & $0.951(0.037)$ \\
\hline TSS & 0.018 & $0.105(0.024)$ & $5.768(1.303)$ \\
\hline $\mathrm{TSS}+500 \mathrm{bp}$ & 0.035 & $0.171(0.029)$ & $4.907(0.839)$ \\
\hline 3-prime UTR & 0.011 & $0.053(0.010)$ & $4.781(0.872)$ \\
\hline 3 -prime UTR $+500 \mathrm{bp}$ & 0.027 & $0.075(0.011)$ & $2.792(0.422)$ \\
\hline 5-prime UTR & 0.005 & $0.029(0.008)$ & $5.309(1.402)$ \\
\hline 5 -prime UTR $+500 \mathrm{bp}$ & 0.028 & $0.067(0.011)$ & $2.395(0.384)$ \\
\hline Weak Enhancer & 0.021 & $0.070(0.024)$ & $3.326(1.141)$ \\
\hline Weak Enhancer $+500 \mathrm{bp}$ & 0.089 & $0.190(0.031)$ & $2.138(0.343)$ \\
\hline
\end{tabular}

Table S5: Proportion of heritability and enrichment for different functional categories, metaanalyzed over nine traits, including derived allele frequency bins in the model (Methods). 


\begin{tabular}{|c|c|c|}
\hline Cell type & Cell-type group & Mark \\
\hline Fetal adrenal & H3K4me1 & Adrenal/Pancreas \\
\hline Fetal adrenal & H3K4me3 & Adrenal/Pancreas \\
\hline Pancreas & H3K4me1 & Adrenal/Pancreas \\
\hline Pancreas & H3K4me3 & Adrenal/Pancreas \\
\hline Pancreatic islets & H3K27ac & Adrenal/Pancreas \\
\hline Pancreatic islets & H3K4me1 & Adrenal/Pancreas \\
\hline Pancreatic islets & H3K4me1 & Adrenal/Pancreas \\
\hline Pancreatic islets & H3K4me3 & Adrenal/Pancreas \\
\hline Pancreatic islets & H3K4me3 & Adrenal/Pancreas \\
\hline Pancreatic islets & Н3К9ас & Adrenal/Pancreas \\
\hline Angular gyrus & H3K27ac & CNS \\
\hline Angular gyrus & H3K4me1 & CNS \\
\hline Angular gyrus & H3K4me3 & CNS \\
\hline Angular gyrus & Н3К9ас & CNS \\
\hline Anterior caudate & H3K27ac & CNS \\
\hline Anterior caudate & H3K4me1 & CNS \\
\hline Anterior caudate & H3K4me3 & CNS \\
\hline Anterior caudate & H3К9ac & CNS \\
\hline Cingulate gyrus & H3K27ac & CNS \\
\hline Cingulate gyrus & H3K4me1 & CNS \\
\hline Cingulate gyrus & H3K4me3 & CNS \\
\hline Cingulate gyrus & Н3К9ас & CNS \\
\hline Fetal brain & H3K4me1 & CNS \\
\hline Fetal brain & H3K4me3 & CNS \\
\hline Fetal brain & H3K4me3 & CNS \\
\hline Fetal brain & H3K9ac & CNS \\
\hline Germinal matrix & H3K4me3 & CNS \\
\hline Hippocampus middle & H3K27ac & CNS \\
\hline Hippocampus middle & H3K4me1 & CNS \\
\hline Hippocampus middle & H3K4me3 & CNS \\
\hline Hippocampus middle & Н3К9ас & CNS \\
\hline Inferior temporal lobe & H3K27ac & CNS \\
\hline Inferior temporal lobe & H3K4me1 & CNS \\
\hline Inferior temporal lobe & H3K4me3 & CNS \\
\hline Inferior temporal lobe & Н3К9ас & CNS \\
\hline Mid frontal lobe & H3K27ac & CNS \\
\hline Mid frontal lobe & H3K4me1 & CNS \\
\hline Mid frontal lobe & H3K4me3 & CNS \\
\hline Mid frontal lobe & H3К9ac & CNS \\
\hline
\end{tabular}




\begin{tabular}{|c|}
\hline Neurosphere \\
\hline Substantia nigra \\
\hline Substantia nigra \\
\hline Substantia nigra \\
\hline Substantia nigra \\
\hline Aorta \\
\hline Fetal heart \\
\hline Fetal heart \\
\hline Fetal heart \\
\hline Fetal lung \\
\hline Fetal lung \\
\hline Fetal lung \\
\hline Left Ventricle \\
\hline Left Ventricle \\
\hline Lung \\
\hline Lung \\
\hline Right atrium \\
\hline Right atrium \\
\hline Right ventricle \\
\hline Right ventricle \\
\hline Breast fibroblast primary \\
\hline Breast fibroblast primary \\
\hline Chondrogenic dif \\
\hline Osteoblast \\
\hline Penis foreskin fibroblast primary \\
\hline Penis foreskin fibroblast primary \\
\hline Colon smooth muscle \\
\hline Colon smooth muscle \\
\hline Colon smooth muscle \\
\hline Colon smooth muscle \\
\hline Colonic mucosa \\
\hline Colonic mucosa \\
\hline Colonic mucosa \\
\hline Colonic mucosa \\
\hline Duodenum Mucosa \\
\hline Duodenum Mucosa \\
\hline Duodenum Mucosa \\
\hline Duodenum mucosa \\
\hline Duodenum smooth muscle \\
\hline Duodenum smooth muscle \\
\hline
\end{tabular}

\begin{tabular}{|c|c|}
\hline $\mathrm{H} 3 \mathrm{~K} 27 \mathrm{ac}$ & CNS \\
\hline H3K27ac & CNS \\
\hline H3K4me1 & CNS \\
\hline H3K4me3 & CNS \\
\hline Н3К9ас & CNS \\
\hline H3K4me3 & Cardiovascular \\
\hline H3K4me1 & Cardiovascular \\
\hline H3K4me3 & Cardiovascular \\
\hline Н3К9ас & Cardiovascular \\
\hline H3K4me1 & Cardiovascular \\
\hline H3K4me3 & Cardiovascular \\
\hline H3К9ac & Cardiovascular \\
\hline H3K4me1 & Cardiovascular \\
\hline H3K4me3 & Cardiovascular \\
\hline H3K4me1 & Cardiovascular \\
\hline H3K4me3 & Cardiovascular \\
\hline H3K4me1 & Cardiovascular \\
\hline $\mathrm{H} 3 \mathrm{~K} 4 \mathrm{me} 3$ & Cardiovascular \\
\hline H3K4me1 & Cardiovascular \\
\hline H3K4me3 & Cardiovascular \\
\hline H3K4me1 & Connective/Bone \\
\hline H3K4me3 & Connective/Bone \\
\hline $\mathrm{H} 3 \mathrm{~K} 27 \mathrm{ac}$ & Connective/Bone \\
\hline $\mathrm{H} 3 \mathrm{~K} 27 \mathrm{ac}$ & Connective/Bone \\
\hline H3K4me1 & Connective/Bone \\
\hline H3K4me3 & Connective/Bone \\
\hline $\mathrm{H} 3 \mathrm{~K} 27 \mathrm{ac}$ & Gastrointestinal \\
\hline H3K4me1 & Gastrointestinal \\
\hline H3K4me3 & Gastrointestinal \\
\hline H3К9ac & Gastrointestinal \\
\hline $\mathrm{H} 3 \mathrm{~K} 27 \mathrm{ac}$ & Gastrointestinal \\
\hline H3K4me1 & Gastrointestinal \\
\hline H3K4me3 & Gastrointestinal \\
\hline H3К9ac & Gastrointestinal \\
\hline H3K4me1 & Gastrointestinal \\
\hline H3K4me3 & Gastrointestinal \\
\hline Н3К9ас & Gastrointestinal \\
\hline $\mathrm{H} 3 \mathrm{~K} 27 \mathrm{ac}$ & Gastrointestinal \\
\hline $\mathrm{H} 3 \mathrm{~K} 27 \mathrm{ac}$ & Gastrointestinal \\
\hline H3K4me1 & Gastrointestinal \\
\hline
\end{tabular}


Duodenum smooth muscle

Esophagus

Esophagus

Fetal large intestine

Fetal large intestine

Fetal small intestine

Fetal small intestine

Fetal stomach

Fetal stomach

Gastric

Gastric

Rectal mucosa

Rectal mucosa

Rectal mucosa

Rectal mucosa

Rectal smooth muscle

Rectal smooth muscle

Rectal smooth muscle

Rectal smooth muscle

Sigmoid colon

Sigmoid colon

Small intestine

Small intestine

Stomach mucosa

Stomach mucosa

Stomach mucosa

Stomach smooth muscle

Stomach smooth muscle

Stomach smooth muscle

Stomach smooth muscle

CD14

CD14 primary

CD14 primary

CD15 primary

CD15 primary

CD19

CD19 primary (BI)

CD19 primary (BI)

CD19 primary (UW)

CD19 primary (UW)

\begin{tabular}{|c|c|}
\hline H3K4me3 & Gastrointestinal \\
\hline H3K4me1 & Gastrointestinal \\
\hline H3K4me3 & Gastrointestinal \\
\hline H3K4me1 & Gastrointestinal \\
\hline H3K4me3 & Gastrointestinal \\
\hline H3K4me1 & Gastrointestinal \\
\hline H3K4me3 & Gastrointestinal \\
\hline H3K4me1 & Gastrointestinal \\
\hline H3K4me3 & Gastrointestinal \\
\hline H3K4me1 & Gastrointestinal \\
\hline H3K4me3 & Gastrointestinal \\
\hline H3K27ac & Gastrointestinal \\
\hline H3K4me1 & Gastrointestinal \\
\hline H3K4me3 & Gastrointestinal \\
\hline Н3К9ас & Gastrointestinal \\
\hline H3K27ac & Gastrointestinal \\
\hline H3K4me1 & Gastrointestinal \\
\hline H3K4me3 & Gastrointestinal \\
\hline Н3К9ас & Gastrointestinal \\
\hline H3K4me1 & Gastrointestinal \\
\hline H3K4me3 & Gastrointestinal \\
\hline H3K4me1 & Gastrointestinal \\
\hline H3K4me3 & Gastrointestinal \\
\hline H3K4me1 & Gastrointestinal \\
\hline H3K4me3 & Gastrointestinal \\
\hline Н3К9ас & Gastrointestinal \\
\hline H3K27ac & Gastrointestinal \\
\hline H3K4me1 & Gastrointestinal \\
\hline H3K4me3 & Gastrointestinal \\
\hline Н3К9ас & Gastrointestinal \\
\hline H3K27ac & Immune \\
\hline H3K4me1 & Immune \\
\hline H3K4me3 & Immune \\
\hline H3K4me1 & Immune \\
\hline H3K4me3 & Immune \\
\hline H3K27ac & Immune \\
\hline H3K4me1 & Immune \\
\hline H3K4me3 & Immune \\
\hline H3K4me1 & Immune \\
\hline H3K4me3 & Immune \\
\hline
\end{tabular}




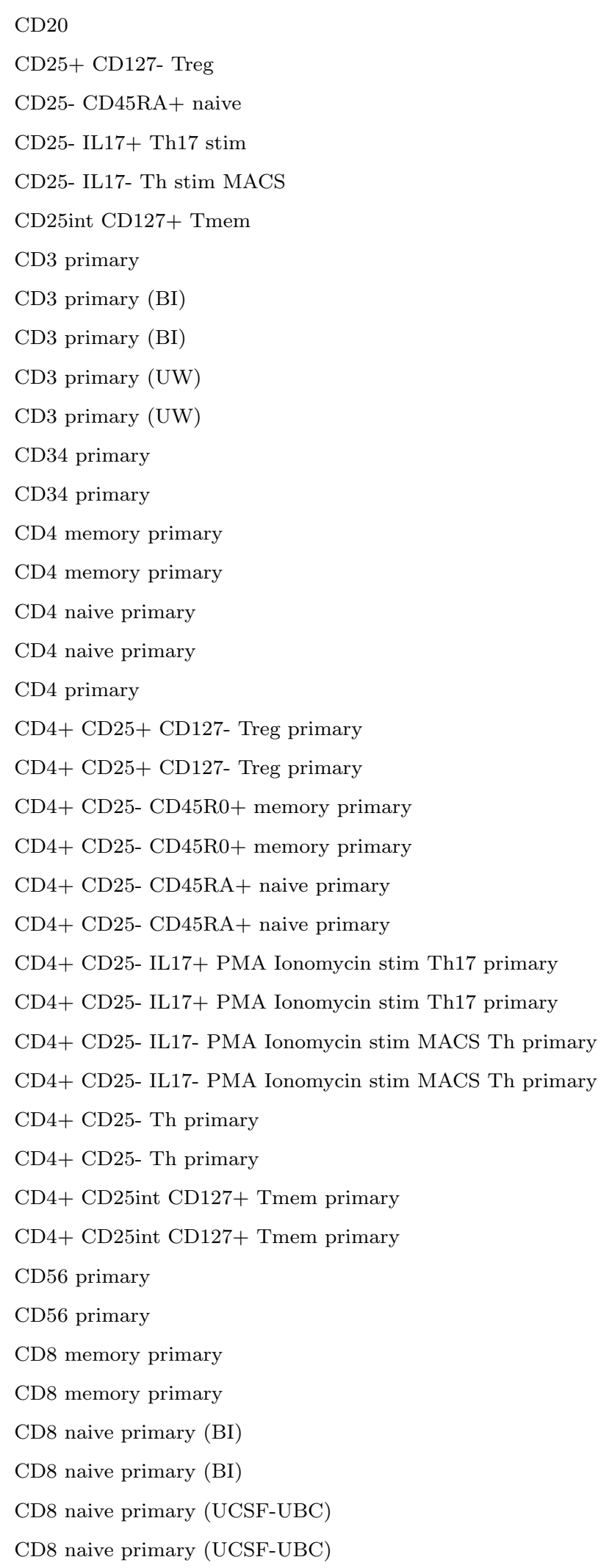

\begin{tabular}{|c|c|}
\hline H3K27ac & Immune \\
\hline H3K27ac & Immune \\
\hline H3K27ac & Immune \\
\hline H3K27ac & Immune \\
\hline H3K27ac & Immune \\
\hline H3K27ac & Immune \\
\hline H3K27ac & Immune \\
\hline H3K4me1 & Immune \\
\hline H3K4me3 & Immune \\
\hline H3K4me1 & Immune \\
\hline H3K4me3 & Immune \\
\hline H3K4me1 & Immune \\
\hline H3K4me3 & Immune \\
\hline H3K4me1 & Immune \\
\hline H3K4me3 & Immune \\
\hline H3K4me1 & Immune \\
\hline $\mathrm{H} 3 \mathrm{~K} 4 \mathrm{me} 3$ & Immune \\
\hline H3K4me3 & Immune \\
\hline H3K4me1 & Immune \\
\hline H3K4me3 & Immune \\
\hline H3K4me1 & Immune \\
\hline H3K4me3 & Immune \\
\hline H3K4me1 & Immune \\
\hline H3K4me3 & Immune \\
\hline H3K4me1 & Immune \\
\hline H3K4me3 & Immune \\
\hline H3K4me1 & Immune \\
\hline H3K4me3 & Immune \\
\hline H3K4me1 & Immune \\
\hline H3K4me3 & Immune \\
\hline H3K4me1 & Immune \\
\hline H3K4me3 & Immune \\
\hline H3K4me1 & Immune \\
\hline H3K4me3 & Immune \\
\hline H3K4me1 & Immune \\
\hline H3K4me3 & Immune \\
\hline H3K4me1 & Immune \\
\hline H3K4me3 & Immune \\
\hline H3K4me1 & Immune \\
\hline H3K4me3 & Immune \\
\hline
\end{tabular}




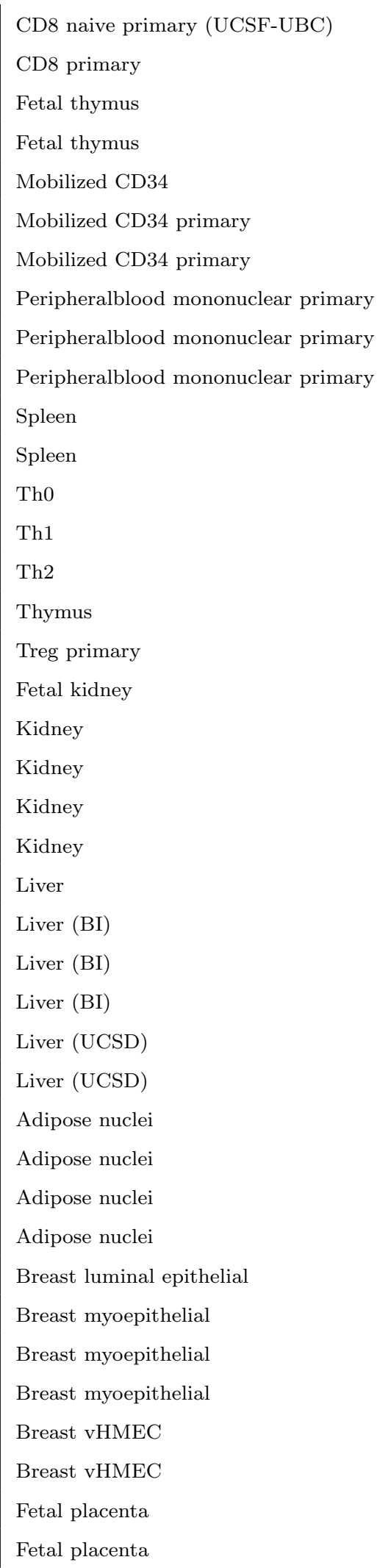

\begin{tabular}{|c|c|}
\hline Н3К9ас & Immun \\
\hline H3K4me3 & Immune \\
\hline H3K4me1 & Immune \\
\hline H3K4me3 & $\operatorname{Immu}$ \\
\hline H3K27ac & Immu \\
\hline H3K4me1 & Immune \\
\hline H3K4me3 & Immun \\
\hline H3K4me1 & $\mathrm{Immu}$ \\
\hline H3K4me3 & $\mathrm{Immu}$ \\
\hline Н3К9ас & Immune \\
\hline H3K4me1 & Immune \\
\hline H3K4me3 & Immun \\
\hline Н3К27ac & Immun \\
\hline H3K27ac & Immun \\
\hline Н3К27ac & Immune \\
\hline H3K4me1 & Immune \\
\hline H3K4me3 & Immune \\
\hline Н3К9ас & Kidney \\
\hline H3К27ac & Kidney \\
\hline H3K4me1 & Kidney \\
\hline H3K4me3 & Kidney \\
\hline Н3К9ас & Kidney \\
\hline H3K27ac & Liver \\
\hline H3K4me1 & Liver \\
\hline H3K4me3 & Liver \\
\hline Н3К $9 \mathrm{ac}$ & Liver \\
\hline H3K4me1 & Liver \\
\hline H3K4me3 & Liver \\
\hline H3К27ac & Other \\
\hline H3K4me1 & Other \\
\hline H3K4me3 & Other \\
\hline Н3К9ас & Other \\
\hline H3K4me1 & Other \\
\hline H3K4me1 & Other \\
\hline H3K4me3 & Other \\
\hline Н3К9ас & Other \\
\hline H3K4me1 & Other \\
\hline H3K4me3 & Other \\
\hline H3K4me1 & Other \\
\hline H3K $4 \mathrm{me} 3$ & Other \\
\hline
\end{tabular}




Ovary
Ovary
Penis foreskin keratinocyte primary
Penis foreskin keratinocyte primary
Penis foreskin keratinocyte primary
Penis foreskin melanocyte primary
Penis foreskin melanocyte primary
Placenta amnion
Placenta amnion
Placenta chorion
Placenta chorion
Fetal leg muscle
Fetal leg muscle
Fetal trunk muscle
Fetal trunk muscle
Psoas muscle
Psoas muscle
Skeletal muscle
Skeletal muscle
Skeletal muscle
Skeletal muscle

\begin{tabular}{|l|l} 
H3K4me1 & Other \\
H3K4me3 & Other \\
H3K4me1 & Other \\
H3K4me3 & Other \\
H3K9ac & Other \\
H3K4me1 & Other \\
H3K4me3 & Other \\
H3K4me1 & Other \\
H3K4me3 & Other \\
H3K4me1 & Other \\
H3K4me3 & Other \\
H3K4me1 & Skeletal muscle \\
H3K4me3 & Skeletal muscle \\
H3K4me1 & Skeletal muscle \\
H3K4me3 & Skeletal muscle \\
H3K4me1 & Skeletal muscle \\
H3K4me3 & Skeletal muscle \\
H3K27ac & Skeletal muscle \\
H3K4me1 & Skeletal muscle \\
H3K4me3 & Skeletal muscle \\
H3K9ac & Skeletal muscle \\
\hline
\end{tabular}

Table S6: Cell types used in the cell-type-specific analysis. When the same cell type in the same histone mark from more than one institution was used, the institution is given in parentheses. 


\begin{tabular}{|c|c|c|c|}
\hline Cell type & Cell type group & Mark & $-\log _{10}(p)$ \\
\hline Chondrogenic dif** & Connective/Bone & H3K27ac & 6.81 \\
\hline Penis foreskin fibroblast primary** & Connective/Bone & H3K4me1 & 6.43 \\
\hline Fetal lung** & Cardiovascular & H3K4me1 & 6.34 \\
\hline Fetal stomach** & GI & H3K4me1 & 5.48 \\
\hline Colon smooth muscle* & GI & H3K4me1 & 4.64 \\
\hline Aorta* & Cardiovascular & H3K4me3 & 4.64 \\
\hline Fetal lung* & Cardiovascular & H3K9ac & 4.31 \\
\hline Stomach smooth muscle* & GI & H3K4me3 & 4.26 \\
\hline Osteoblast* & Connective/Bone & H3К27ac & 4.04 \\
\hline Penis foreskin fibroblast primary* & Connective/Bone & H3K4me3 & 3.96 \\
\hline Stomach smooth muscle* & GI & H3K4me1 & 3.94 \\
\hline Fetal leg muscle* & Skeletal Muscle & H3K4me3 & 3.91 \\
\hline Fetal trunk muscle* & Skeletal Muscle & H3K4me3 & 3.72 \\
\hline Rectal smooth muscle* & GI & H3K4me3 & 3.57 \\
\hline Fetal lung* & Cardiovascular & H3K4me3 & 3.37 \\
\hline Rectal smooth muscle* & GI & H3K4me1 & 3.32 \\
\hline Fetal placenta* & Other & H3K4me3 & 3.26 \\
\hline Adipose nuclei* & Other & H3K4me1 & 3.1 \\
\hline Ovary* & Other & H3K4me1 & 3.06 \\
\hline Fetal large intestine* & GI & H3K4me3 & 3.05 \\
\hline Placenta chorion* & Other & H3K4me3 & 2.98 \\
\hline CD34 primary* & Immune & H3K4me1 & 2.96 \\
\hline Penis foreskin melanocyte primary* & Other & H3K4me1 & 2.95 \\
\hline Skeletal muscle* & Skeletal Muscle & H3К9ас & 2.93 \\
\hline Mobilized CD34 primary* & Immune & H3K4me1 & 2.88 \\
\hline Fetal stomach* & GI & H3K4me3 & 2.87 \\
\hline Mobilized CD34 primary* & Immune & H3K4me3 & 2.87 \\
\hline Fetal adrenal* & Adrenal/Pancreas & H3K4me3 & 2.86 \\
\hline Breast fibroblast primary* & Connective/Bone & H3K4me3 & 2.85 \\
\hline Duodenum smooth muscle* & GI & H3K4me1 & 2.81 \\
\hline Colon smooth muscle* & GI & $\mathrm{H} 3 \mathrm{~K} 4 \mathrm{me} 3$ & 2.76 \\
\hline Ovary* & Other & H3K4me3 & 2.7 \\
\hline Fetal brain* & CNS & H3K4me3 & 2.62 \\
\hline Skeletal muscle* & Skeletal Muscle & H3K4me1 & 2.6 \\
\hline Fetal small intestine* & GI & H3K4me3 & 2.6 \\
\hline Colon smooth muscle* & GI & H3K27ac & 2.57 \\
\hline Lung* & Cardiovascular & H3K4me3 & 2.56 \\
\hline Liver (UCSD)* & Liver & H3K4me3 & 2.53 \\
\hline Esophagus* & GI & H3K4me3 & 2.53 \\
\hline Placenta amnion* & Other & H3K4me3 & 2.48 \\
\hline Right ventricle* & Cardiovascular & H3K4me3 & 2.47 \\
\hline Sigmoid colon* & GI & H3K4me3 & 2.44 \\
\hline Fetal leg muscle* & Skeletal Muscle & H3K4me1 & 2.44 \\
\hline Colonic mucosa* & GI & H3K4me3 & 2.18 \\
\hline Right atrium* & Cardiovascular & H3K4me3 & 2.14 \\
\hline CD34 primary* & Immune & H3K4me3 & 2.13 \\
\hline Gastric* & GI & H3K4me3 & 2.08 \\
\hline Skeletal muscle* & Skeletal Muscle & H3K4me3 & 2.07 \\
\hline Lung* & Cardiovascular & H3K4me1 & 2.06 \\
\hline Pancreatic islets* & Adrenal/Pancreas & H3K4me3 & 2.05 \\
\hline Adipose nuclei* & Other & H3К9ac & 2.01 \\
\hline Right atrium* & Cardiovascular & H3K4me1 & 1.98 \\
\hline Stomach smooth muscle* & GI & H3K27ac & 1.96 \\
\hline Rectal smooth muscle* & GI & H3К27ac & 1.95 \\
\hline Breast fibroblast primary* & Connective/Bone & H3K4me1 & 1.93 \\
\hline Germinal matrix* & $\mathrm{CNS}$ & H3K4me3 & 1.92 \\
\hline Small intestine* & GI & H3K4me3 & 1.91 \\
\hline Fetal placenta* & Other & H3K4me1 & 1.91 \\
\hline
\end{tabular}

(S7.A) Enrichment of top cell types for Height. ${ }^{*}=$ significant at FDR $<0.05 .{ }^{* *}=$ significant at $\mathrm{p}<0.05$ after correcting for multiple hypotheses. 


\begin{tabular}{|c|c|c|c|}
\hline Cell type & Cell type group & Mark & $-\log _{10}(p)$ \\
\hline Fetal brain* & CNS & H3K4me3 & 4.48 \\
\hline Penis foreskin fibroblast primary* & Connective/Bone & H3K4me3 & 4.43 \\
\hline Inferior temporal lobe* & CNS & H3K4me1 & 4.3 \\
\hline Mid frontal lobe* & $\mathrm{CNS}$ & Н3К9ас & 4.25 \\
\hline Anterior caudate* & CNS & H3K4me3 & 4.25 \\
\hline Mid frontal lobe* & $\mathrm{CNS}$ & H3K27ac & 3.96 \\
\hline Anterior caudate* & $\mathrm{CNS}$ & H3K9ac & 3.91 \\
\hline Cingulate gyrus* & $\mathrm{CNS}$ & H3K4me1 & 3.73 \\
\hline Inferior temporal lobe* & $\mathrm{CNS}$ & H3K4me3 & 3.73 \\
\hline Penis foreskin keratinocyte primary* & Other & H3K9ac & 3.72 \\
\hline Mid frontal lobe* & $\mathrm{CNS}$ & H3K4me3 & 3.71 \\
\hline Hippocampus middle* & $\mathrm{CNS}$ & H3K4me1 & 3.66 \\
\hline Inferior temporal lobe* & CNS & H3K9ac & 3.59 \\
\hline Fetal brain* & $\mathrm{CNS}$ & H3K9ac & 3.57 \\
\hline Hippocampus middle* & $\mathrm{CNS}$ & H3K9ac & 3.47 \\
\hline Cingulate gyrus* & $\mathrm{CNS}$ & H3К9ac & 3.46 \\
\hline Hippocampus middle* & $\mathrm{CNS}$ & H3K4me3 & 3.4 \\
\hline Germinal matrix* & $\mathrm{CNS}$ & H3K4me3 & 3.4 \\
\hline Cingulate gyrus* & $\mathrm{CNS}$ & H3K4me3 & 3.4 \\
\hline Anterior caudate* & $\mathrm{CNS}$ & H3K4me1 & 3.31 \\
\hline Substantia nigra* & CNS & H3K4me3 & 3.24 \\
\hline Angular gyrus* & $\mathrm{CNS}$ & H3K27ac & 3.05 \\
\hline Penis foreskin melanocyte primary* & Other & H3K4me3 & 2.83 \\
\hline Angular gyrus* & $\mathrm{CNS}$ & H3K4me3 & 2.76 \\
\hline Substantia nigra* & $\mathrm{CNS}$ & H3K4me1 & 2.75 \\
\hline Pancreatic islets* & Adrenal/Pancreas & H3K4me3 & 2.6 \\
\hline Cingulate gyrus* & CNS & H3K27ac & 2.57 \\
\hline Fetal adrenal* & Adrenal/Pancreas & H3K4me3 & 2.57 \\
\hline Angular gyrus* & $\mathrm{CNS}$ & H3K9ac & 2.51 \\
\hline Inferior temporal lobe* & $\mathrm{CNS}$ & H3K27ac & 2.39 \\
\hline Breast myoepithelial* & Other & H3K4me3 & 2.35 \\
\hline Substantia nigra* & $\mathrm{CNS}$ & H3K9ac & 2.26 \\
\hline Substantia nigra* & $\mathrm{CNS}$ & H3K27ac & 2.22 \\
\hline Hippocampus middle* & $\mathrm{CNS}$ & H3K27ac & 2.07 \\
\hline
\end{tabular}

(S7.B) Enrichment of top cell types for BMI. ${ }^{*}=$ significant at FDR $<0.05 .^{* *}=$ significant at $\mathrm{p}<0.05$ after correcting for multiple hypotheses. 


\begin{tabular}{|c|c|c|c|}
\hline Cell type & Cell type group & Mark & $-\log _{10}(p)$ \\
\hline Fetal brain** & CNS & H3K4me3 & 12.25 \\
\hline Pancreatic islets** & Adrenal/Pancreas & H3K4me3 & 11.73 \\
\hline Angular gyrus** & $\mathrm{CNS}$ & H3K4me3 & 11.22 \\
\hline Germinal matrix** & CNS & H3K4me3 & 11.18 \\
\hline Fetal adrenal** & Adrenal/Pancreas & H3K4me3 & 11.12 \\
\hline Mid frontal lobe** & CNS & H3K4me3 & 11.11 \\
\hline Inferior temporal lobe** & CNS & H3K4me3 & 10.22 \\
\hline Cingulate gyrus** & CNS & H3K4me3 & 9.94 \\
\hline Anterior caudate** & CNS & H3K4me3 & 8.91 \\
\hline Psoas muscle** & Skeletal Muscle & H3K4me3 & 8.66 \\
\hline Right ventricle** & Cardiovascular & H3K4me3 & 8.58 \\
\hline Pancreatic islets** & Adrenal/Pancreas & Н3К9ас & 7.74 \\
\hline Fetal leg muscle** & Skeletal Muscle & H3K4me3 & 7.71 \\
\hline Pancreas** & Adrenal/Pancreas & H3K4me3 & 7.26 \\
\hline Hippocampus middle** & CNS & H3K4me3 & 7.19 \\
\hline Breast myoepithelial ${ }^{* *}$ & Other & H3K4me3 & 6.93 \\
\hline Fetal trunk muscle** & Skeletal Muscle & H3K4me3 & 6.87 \\
\hline Peripheralblood mononuclear primary** & Immune & H3K4me3 & 6.66 \\
\hline Penis foreskin melanocyte primary** & Other & H3K4me3 & 6.53 \\
\hline Fetal stomach** & GI & H3K4me3 & 6.26 \\
\hline Gastric** & GI & H3K4me3 & 6.24 \\
\hline Right atrium** & Cardiovascular & H3K4me3 & 6.24 \\
\hline CD4+ CD25- CD45RA+ naive primary** & Immune & H3K4me3 & 6.16 \\
\hline CD4+ CD25int CD127+ Tmem primary** & Immune & H3K4me3 & 5.96 \\
\hline Ovary** & Other & H3K4me3 & 5.64 \\
\hline Penis foreskin fibroblast primary** & Connective/Bone & H3K4me3 & 5.57 \\
\hline Substantia nigra** & CNS & H3K4me3 & 5.41 \\
\hline Esophagus** & GI & H3K4me3 & 5.35 \\
\hline Colonic mucosa** & GI & H3K4me3 & 5.3 \\
\hline Fetal large intestine ${ }^{* *}$ & GI & H3K4me3 & 5.14 \\
\hline Fetal placenta** & Other & H3K4me3 & 5.07 \\
\hline Fetal brain** & CNS & H3K9ac & 5.05 \\
\hline Aorta* & Cardiovascular & H3K4me3 & 4.74 \\
\hline CD8 naive primary $(\mathrm{BI})^{*}$ & Immune & H3K4me3 & 4.49 \\
\hline CD14 primary* & Immune & H3K4me3 & 4.49 \\
\hline Fetal small intestine* & GI & H3K4me3 & 4.43 \\
\hline Breast vHMEC* & Other & H3K4me3 & 4.39 \\
\hline CD4+ CD25- Th primary* & Immune & H3K4me3 & 4.38 \\
\hline CD34 primary* & Immune & H3K4me3 & 4.37 \\
\hline Placenta amnion* & Other & H3K4me3 & 4.34 \\
\hline Angular gyrus* & CNS & H3К9ас & 4.33 \\
\hline Penis foreskin keratinocyte primary* & Other & H3K4me3 & 4.3 \\
\hline Pancreatic islets* & Adrenal/Pancreas & H3K4me3 & 4.26 \\
\hline Mid frontal lobe* & CNS & H3К9ас & 4.23 \\
\hline CD4+ CD25- CD45R0+ memory primary* & Immune & H3K4me3 & 4.14 \\
\hline Rectal smooth muscle* & GI & H3K4me3 & 4.12 \\
\hline Left Ventricle* & Cardiovascular & H3K4me3 & 4.11 \\
\hline CD8 memory primary* & Immune & H3K4me3 & 4.06 \\
\hline CD4+ CD25+ CD127- Treg primary* & Immune & H3K4me3 & 4.05 \\
\hline Placenta chorion* & Other & H3K4me3 & 4.05 \\
\hline CD8 naive primary (UCSF-UBC)* & Immune & H3K4me3 & 3.77 \\
\hline Anterior caudate* & $\mathrm{CNS}$ & Н3К9ас & 3.73 \\
\hline Cingulate gyrus* & CNS & H3K9ac & 3.69 \\
\hline CD19 primary $(\mathrm{UW})^{*}$ & Immune & H3K4me3 & 3.63 \\
\hline CD4+ CD25- IL17+ PMA Ionomycin stim Th17 primary* & Immune & H3K4me3 & 3.58 \\
\hline CD4 naive primary* & Immune & H3K4me3 & 3.53 \\
\hline Fetal brain* & CNS & H3K4me3 & 3.53 \\
\hline Lung* & Cardiovascular & H3K4me3 & 3.5 \\
\hline Mid frontal lobe* & CNS & H3К27ac & 3.43 \\
\hline Breast fibroblast primary* & Connective/Bone & H3K4me3 & 3.41 \\
\hline
\end{tabular}

(S7.C) Enrichment of top cell types for Age at menarche. ${ }^{*}=$ significant at FDR $<0.05 .{ }^{* *}=$ significant at $\mathrm{p}<$ 0.05 after correcting for multiple hypotheses. 


\begin{tabular}{llll} 
Cell type & Cell type group & Mark & $-\log _{10}(p)$ \\
\hline Liver $(\mathrm{BI})^{*}$ & Liver & H3K4me1 & 4.76 \\
Fetal adrenal* & Adrenal/Pancreas & H3K4me1 & 3.41 \\
CD14 primary* & Immune & H3K4me1 & 3.33 \\
Liver* & Liver & H3K27ac & 2.97 \\
Adipose nuclei & Other & H3K9ac & 2.71
\end{tabular}

(S7.D) Enrichment of top cell types for LDL. ${ }^{*}=$ significant at FDR $<0.05$. ${ }^{* *}=$ significant at $\mathrm{p}<0.05$ after correcting for multiple hypotheses.

\begin{tabular}{llll} 
Cell type & Cell type group & Mark & $-\log _{10}(p)$ \\
\hline Liver (BI)* & Liver & H3K4me1 & 4.51 \\
Adipose nuclei* & Other & H3K4me1 & 4.26 \\
Liver* & Liver & H3K27ac & 3.61 \\
Adipose nuclei* & Other & H3K9ac & 3.34 \\
Adipose nuclei* & Other & H3K4me3 & 3.08 \\
CD14 primary* & Immune & H3K4me1 & 2.86 \\
Adipose nuclei* & Other & H3K27ac & 2.84 \\
Liver (BI)* & Liver & H3K9ac & 2.74 \\
Liver (BI)* & Liver & H3K4me3 & 2.66
\end{tabular}

(S7.E) Enrichment of top cell types for HDL. ${ }^{*}=$ significant at FDR $<0.05 . * *=$ significant at $\mathrm{p}<0.05$ after correcting for multiple hypotheses.

\begin{tabular}{llll} 
Cell type & Cell type group & Mark & $-\log _{10}(p)$ \\
\hline Liver $(\mathrm{BI})^{*}$ & Liver & H3K4me1 & 3.99 \\
Liver* & Liver & H3K27ac & 3.66 \\
Liver (BI)* & Liver & H3K9ac & 3.02 \\
Duodenum Mucosa & GI & H3K4me3 & 2.71 \\
Liver (UCSD) & Liver & H3K4me3 & 2.68
\end{tabular}

(S7.F) Enrichment of top cell types for Triglycerides. ${ }^{*}=$ significant at FDR $<0.05 .{ }^{* *}=$ significant at $\mathrm{p}<0.05$ after correcting for multiple hypotheses.

\begin{tabular}{llll} 
Cell type & Cell type group & Mark & $-\log _{10}(p)$ \\
\hline Adipose nuclei* & Other & H3K4me1 & 4.21 \\
Duodenum Mucosa* & GI & H3K4me1 & 3.43 \\
Colonic mucosa* & GI & H3K9ac & 3.01 \\
Duodenum Mucosa & GI & H3K9ac & 2.78 \\
Rectal mucosa & GI & H3K9ac & 2.68
\end{tabular}

(S7.G) Enrichment of top cell types for Coronary artery disease. ${ }^{*}=$ significant at FDR $<0.05 . * *=$ significant at $\mathrm{p}<0.05$ after correcting for multiple hypotheses.

\begin{tabular}{llll} 
Cell type & Cell type group & Mark & $-\log _{10}(p)$ \\
\hline Pancreatic islets & Adrenal/Pancreas & H3K4me3 & 2.87 \\
Pancreatic islets & Adrenal/Pancreas & H3K27ac & 2.73 \\
Fetal large intestine & GI & H3K4me1 & 2.49 \\
Fetal small intestine & GI & H3K4me1 & 2.31 \\
Adipose nuclei & Other & H3K9ac & 2.27
\end{tabular}

(S7.H) Enrichment of top cell types for Type 2 Diabetes. ${ }^{*}=$ significant at FDR $<0.05 .{ }^{* *}=$ significant at $\mathrm{p}<$ 0.05 after correcting for multiple hypotheses.

\begin{tabular}{llll} 
Cell type & Cell type group & Mark & $-\log _{10}(p)$ \\
\hline Pancreatic islets* & Adrenal/Pancreas & H3K27ac & 3.93 \\
Pancreatic islets* & Adrenal/Pancreas & H3K4me1 & 3.1 \\
Pancreatic islets & Adrenal/Pancreas & H3K4me3 & 2.93 \\
Pancreatic islets & Adrenal/Pancreas & H3K4me3 & 2.25 \\
Fetal small intestine & GI & H3K4me1 & 2.18
\end{tabular}

(S7.I) Enrichment of top cell types for Fasting Glucose. ${ }^{*}=$ significant at FDR $<0.05 .{ }^{* *}=$ significant at $\mathrm{p}<0.05$ after correcting for multiple hypotheses. 
bioRxiv preprint doi: https://doi.org/10.1101/014241; this version posted January 23, 2015. The copyright holder for this preprint (which was not

\begin{tabular}{|c|c|c|c|}
\hline Cell type & Cell type group & Mark & $-\log _{10}(p)$ \\
\hline Fetal brain** & CNS & H3K4me3 & 18.51 \\
\hline Mid frontal lobe** & CNS & H3K4me3 & 14.44 \\
\hline Germinal matrix** & CNS & H3K4me3 & 12.68 \\
\hline Mid frontal lobe** & CNS & H3K9ac & 11.27 \\
\hline Angular gyrus** & CNS & H3K4me3 & 10.89 \\
\hline Inferior temporal lobe** & CNS & H3K4me3 & 10.77 \\
\hline Cingulate gyrus** & CNS & H3K9ac & 10.27 \\
\hline Fetal brain** & CNS & H3K9ac & 10.24 \\
\hline Anterior caudate ${ }^{* *}$ & CNS & H3K4me3 & 9.66 \\
\hline Cingulate gyrus** & CNS & H3K4me3 & 9.34 \\
\hline Pancreatic islets** & Adrenal/Pancreas & H3K4me3 & 8.65 \\
\hline Anterior caudate** & $\mathrm{CNS}$ & H3K9ac & 8.5 \\
\hline Angular gyrus** & CNS & H3K9ac & 8.33 \\
\hline Mid frontal lobe** & CNS & H3K27ac & 8.1 \\
\hline Anterior caudate $^{* *}$ & CNS & H3K4me1 & 7.92 \\
\hline Inferior temporal lobe** & CNS & H3K4me1 & 7.43 \\
\hline Psoas muscle** & Skeletal Muscle & H3K4me3 & 7.38 \\
\hline Fetal brain** & CNS & H3K4me1 & 7.21 \\
\hline Inferior temporal lobe** & CNS & H3K9ac & 7.03 \\
\hline Hippocampus middle** & CNS & H3K9ac & 6.03 \\
\hline Pancreatic islets** & Adrenal/Pancreas & Н3К9ас & 5.79 \\
\hline Penis foreskin melanocyte primary** & Other & H3K4me3 & 5.68 \\
\hline Angular gyrus ${ }^{* *}$ & CNS & H3K27ac & 5.63 \\
\hline Cingulate gyrus** & CNS & H3K4me1 & 5.55 \\
\hline Hippocampus middle** & CNS & H3K4me3 & 5.55 \\
\hline CD34 primary** & Immune & H3K4me3 & 5.33 \\
\hline Sigmoid colon** & GI & H3K4me3 & 5.3 \\
\hline Fetal adrenal** & Adrenal/Pancreas & H3K4me3 & 5.2 \\
\hline Inferior temporal lobe** & $\mathrm{CNS}$ & H3K27ac & 5.08 \\
\hline Peripheralblood mononuclear primary** & Immune & H3K4me3 & 5.03 \\
\hline Gastric $* *$ & GI & H3K4me3 & 4.93 \\
\hline Substantia nigra* & CNS & H3K4me3 & 4.71 \\
\hline Fetal brain* & CNS & H3K4me3 & 4.58 \\
\hline Hippocampus middle* & CNS & H3K4me1 & 4.48 \\
\hline Ovary* & Other & H3K4me3 & 4.19 \\
\hline CD19 primary $(\mathrm{UW})^{*}$ & Immune & H3K4me3 & 4.15 \\
\hline Small intestine* & GI & H3K4me3 & 4.07 \\
\hline Lung* & Cardiovascular & H3K4me3 & 3.93 \\
\hline Fetal stomach* & GI & H3K4me3 & 3.89 \\
\hline Fetal leg muscle* & Skeletal Muscle & H3K4me3 & 3.82 \\
\hline Spleen* & Immune & H3K4me3 & 3.77 \\
\hline Breast fibroblast primary* & Connective/Bone & H3K4me3 & 3.69 \\
\hline Right ventricle* & Cardiovascular & H3K4me3 & 3.67 \\
\hline CD4+ CD25- Th primary* & Immune & H3K4me3 & 3.66 \\
\hline CD4+ CD25- IL17- PMA Ionomycin stim MACS Th primary* & Immune & H3K4me1 & 3.66 \\
\hline CD8 naive primary (UCSF-UBC)* & Immune & H3K4me3 & 3.65 \\
\hline Pancreas* & Adrenal/Pancreas & H3K4me3 & 3.63 \\
\hline CD4+ CD25- Th primary* & Immune & H3K4me1 & 3.56 \\
\hline CD4+ CD25- CD45RA+ naive primary* & Immune & H3K4me1 & 3.56 \\
\hline Colonic mucosa* & GI & H3K4me3 & 3.49 \\
\hline Right atrium* & Cardiovascular & H3K4me3 & 3.48 \\
\hline Fetal trunk muscle* & Skeletal Muscle & H3K4me3 & 3.47 \\
\hline CD4+ CD25int CD127+ Tmem primary* & Immune & H3K4me3 & 3.46 \\
\hline Substantia nigra* & CNS & H3K9ac & 3.44 \\
\hline Placenta amnion* & Other & H3K4me3 & 3.38 \\
\hline Breast myoepithelial* & Other & H3К9ас & 3.26 \\
\hline CD8 naive primary $(\mathrm{BI})^{*}$ & Immune & H3K4me1 & 3.24 \\
\hline Substantia nigra* & CNS & H3K4me1 & 3.18 \\
\hline Cingulate gyrus* & CNS & H3K27ac & 3.1 \\
\hline CD4+ CD25- CD45RA+ naive primary* & Immune & H3K4me3 & 3.06 \\
\hline
\end{tabular}

(S7.J) Enrichment of top cell types for Schizophrenia. $*=$ significant at FDR $<0.05$. ** $=$ significant at $\mathrm{p}<0.05$ after correcting for multiple hypotheses. 


\begin{tabular}{llll} 
Cell type & Cell type group & Mark & $-\log _{10}(p)$ \\
\hline Mid frontal lobe* & CNS & H3K27ac & 4.42 \\
Penis foreskin keratinocyte primary & Other & H3K9ac & 3.05 \\
Fetal brain & CNS & H3K9ac & 2.92 \\
Fetal brain & CNS & H3K4me3 & 2.9 \\
Mid frontal lobe & CNS & H3K4me3 & 2.78
\end{tabular}

(S7.K) Enrichment of top cell types for Bipolar disorder. $*=$ significant at $\mathrm{FDR}<0.05$. $^{* *}=$ significant at $\mathrm{p}<^{*}$ 0.05 after correcting for multiple hypotheses.

\begin{tabular}{llll} 
Cell type & Cell type group & Mark & $-\log _{10}(p)$ \\
\hline Angular gyrus & CNS & H3K9ac & 2.61 \\
Mid frontal lobe & CNS & H3K9ac & 2.38 \\
Mid frontal lobe & CNS & H3K4me1 & 2.36 \\
Anterior caudate & CNS & H3K9ac & 2.28 \\
Cingulate gyrus & CNS & H3K9ac & 2.22
\end{tabular}

(S7.L) Enrichment of top cell types for Anorexia. $*=$ significant at $\mathrm{FDR}<0.05 . * *=$ significant at $\mathrm{p}<0.05$ after correcting for multiple hypotheses. 
bioRxiv preprint doi: https://doi.org/10.1101/014241; this version posted January 23, 2015. The copyright holder for this preprint (which was not certified by peer review) is the author/funder, who has granted bioRxiv a license to display the preprint in perpetuity. It is made available under aCC-BY-ND 4.0 International license.

\begin{tabular}{|c|c|c|c|}
\hline Cell type & Cell type group & Mark & $-\log _{10}(p)$ \\
\hline Angular gyrus** & CNS & H3K4me3 & 6.63 \\
\hline Fetal brain** & CNS & H3K4me3 & 6.05 \\
\hline Mid frontal lobe** & CNS & H3K4me3 & 5.99 \\
\hline Anterior caudate** & $\mathrm{CNS}$ & H3K4me3 & 5.73 \\
\hline Inferior temporal lobe** & CNS & H3K4me3 & 5.63 \\
\hline CD56 primary** & Immune & H3K4me3 & 5.32 \\
\hline Germinal matrix** & $\mathrm{CNS}$ & H3K4me3 & 5.29 \\
\hline Mid frontal lobe** & CNS & H3К9ac & 5.26 \\
\hline Cingulate gyrus** & CNS & Н3К9ас & 4.98 \\
\hline Cingulate gyrus** & CNS & H3K4me3 & 4.94 \\
\hline CD8 naive primary (UCSF-UBC)* & Immune & H3K4me3 & 4.88 \\
\hline Penis foreskin melanocyte primary* & Other & H3K4me3 & 4.73 \\
\hline Mid frontal lobe* & $\mathrm{CNS}$ & H3K27ac & 4.43 \\
\hline Peripheralblood mononuclear primary* & Immune & H3K4me3 & 4.39 \\
\hline CD34 primary* & Immune & H3K4me3 & 4.12 \\
\hline Fetal brain* & CNS & H3K9ac & 4.03 \\
\hline CD14 primary* & Immune & H3K4me3 & 4.01 \\
\hline Inferior temporal lobe* & CNS & H3K9ac & 3.98 \\
\hline Angular gyrus* & $\mathrm{CNS}$ & H3K9ac & 3.96 \\
\hline Sigmoid colon* & GI & H3K4me3 & 3.83 \\
\hline Pancreatic islets* & Adrenal/Pancreas & H3К9ac & 3.83 \\
\hline CD4+ CD25int CD127+ Tmem primary* & Immune & H3K4me3 & 3.72 \\
\hline Anterior caudate* & CNS & H3К9ас & 3.65 \\
\hline Hippocampus middle* & $\mathrm{CNS}$ & H3K4me3 & 3.65 \\
\hline CD19 primary $(\mathrm{UW})^{*}$ & Immune & H3K4me3 & 3.63 \\
\hline Small intestine* & GI & H3K4me3 & 3.52 \\
\hline CD4+ CD25- Th primary* & Immune & H3K4me3 & 3.45 \\
\hline Lung* & Cardiovascular & H3K4me3 & 3.19 \\
\hline CD4+ CD25- CD45R0+ memory primary* & Immune & H3K4me3 & 3.19 \\
\hline Hippocampus middle* & $\mathrm{CNS}$ & H3K9ac & 3.17 \\
\hline Liver (UCSD)* & Liver & H3K4me3 & 3.08 \\
\hline Fetal placenta* & Other & H3K4me3 & 3.08 \\
\hline Fetal adrenal* & Adrenal/Pancreas & H3K4me3 & 3.04 \\
\hline Right atrium* & Cardiovascular & H3K4me3 & 2.99 \\
\hline Pancreatic islets* & Adrenal/Pancreas & H3K4me3 & 2.96 \\
\hline CD8 naive primary (UCSF-UBC)* & Immune & H3K9ac & 2.95 \\
\hline CD3 primary $(\mathrm{BI})^{*}$ & Immune & H3K4me3 & 2.94 \\
\hline Angular gyrus* & $\mathrm{CNS}$ & H3K27ac & 2.93 \\
\hline CD4+ CD25- CD45RA+ naive primary* & Immune & H3K4me3 & 2.93 \\
\hline Gastric* & GI & H3K4me3 & 2.92 \\
\hline CD4 naive primary* & Immune & H3K4me3 & 2.89 \\
\hline CD8 memory primary* & Immune & H3K4me3 & 2.78 \\
\hline CD3 primary $(\mathrm{UW})^{*}$ & Immune & H3K4me3 & 2.76 \\
\hline Rectal smooth muscle* & GI & H3K4me3 & 2.73 \\
\hline Fetal brain* & CNS & H3K4me3 & 2.67 \\
\hline Esophagus* & GI & H3K4me3 & 2.66 \\
\hline CD8 naive primary $(\mathrm{BI})^{*}$ & Immune & H3K4me3 & 2.58 \\
\hline Left Ventricle* & Cardiovascular & H3K4me3 & 2.56 \\
\hline CD19 primary $(\mathrm{BI})^{*}$ & Immune & H3K4me3 & 2.56 \\
\hline Fetal thymus* & Immune & H3K4me3 & 2.52 \\
\hline Breast vHMEC** & Other & H3K4me3 & 2.51 \\
\hline CD8 primary* & Immune & H3K4me3 & 2.51 \\
\hline Psoas muscle* & Skeletal Muscle & H3K4me3 & 2.51 \\
\hline Peripheralblood mononuclear primary* & Immune & Н3К9ас & 2.5 \\
\hline Ovary* & Other & H3K4me3 & 2.47 \\
\hline Pancreas* & Adrenal/Pancreas & H3K4me3 & 2.46 \\
\hline Breast fibroblast primary* & Connective/Bone & H3K4me3 & 2.45 \\
\hline CD4+ CD25+ CD127- Treg primary* & Immune & H3K4me3 & 2.36 \\
\hline Placenta amnion* & Other & H3K4me3 & 2.34 \\
\hline Right ventricle* & Cardiovascular & H3K4me3 & 2.33 \\
\hline
\end{tabular}

(S7.M) Enrichment of top cell types for Years of education. ${ }^{*}=$ significant at $\mathrm{FDR}<0.05$. $^{* *}=$ significant at $\mathrm{p}<$ 0.05 after correcting for multiple hypotheses. 


\begin{tabular}{llll} 
Cell type & Cell type group & Mark & $-\log _{10}(p)$ \\
\hline Inferior temporal lobe* & CNS & H3K4me3 & 3.21 \\
Cingulate gyrus* & CNS & H3K27ac & 3.2 \\
Substantia nigra* & CNS & H3K27ac & 3.16 \\
Hippocampus middle* & CNS & H3K27ac & 3.13 \\
Breast myoepithelial* & Other & H3K9ac & 3.06 \\
Inferior temporal lobe* & CNS & H3K4me1 & 2.93 \\
Anterior caudate* & CNS & H3K27ac & 2.81 \\
Inferior temporal lobe* & CNS & H3K27ac & 2.81 \\
Angular gyrus* & CNS & H3K27ac & 2.77 \\
Pancreatic islets* & Adrenal/Pancreas & H3K4me1 & 2.55
\end{tabular}

(S7.N) Enrichment of top cell types for Ever smoked. ${ }^{*}=$ significant at FDR $<0.05 .{ }^{* *}=$ significant at $\mathrm{p}<0.05$ after correcting for multiple hypotheses.

\begin{tabular}{|c|c|c|c|}
\hline Cell type & Cell type group & Mark & $-\log _{10}(p)$ \\
\hline CD4+ CD25- IL17+ PMA Ionomycin stim Th17 primary** & Immune & H3K4me1 & 6.76 \\
\hline CD4+ CD25- IL17- PMA Ionomycin stim MACS Th primary** & Immune & H3K4me1 & 6.11 \\
\hline CD4+ CD25- CD45R0+ memory primary** & Immune & H3K4me1 & 5.92 \\
\hline CD4 memory primary** & Immune & H3K4me1 & 5.88 \\
\hline CD4+ CD25+ CD127- Treg primary** & Immune & H3K4me1 & 5.83 \\
\hline CD25- IL17- Th stim MACS** & Immune & H3K27ac & 5.7 \\
\hline $\mathrm{Th} 2^{* *}$ & Immune & H3K27ac & 5.5 \\
\hline CD8 memory primary** & Immune & H3K4me1 & 5.38 \\
\hline CD4 naive primary** & Immune & H3K4me1 & 5.26 \\
\hline CD4+ CD25- Th primary** & Immune & H3K4me1 & 5.25 \\
\hline CD19 primary $(\mathrm{UW})^{* *}$ & Immune & H3K4me1 & 5.25 \\
\hline CD4+ CD25int CD127+ Tmem primary* & Immune & H3K4me1 & 4.88 \\
\hline CD4+ CD25- CD45RA+ naive primary* & Immune & H3K4me1 & 4.75 \\
\hline CD3 primary $(\mathrm{BI})^{*}$ & Immune & H3K4me1 & 4.64 \\
\hline CD3 primary $(\mathrm{UW})^{*}$ & Immune & H3K4me1 & 4.63 \\
\hline CD25- IL17+ Th17 stim* & Immune & H3K27ac & 4.55 \\
\hline CD8 naive primary (UCSF-UBC)* & Immune & H3K4me1 & 4.49 \\
\hline CD8 naive primary $(\mathrm{BI})^{*}$ & Immune & H3K4me1 & 4.45 \\
\hline $\mathrm{Th} 0^{*}$ & Immune & $\mathrm{H} 3 \mathrm{~K} 27 \mathrm{ac}$ & 4.09 \\
\hline CD25+ CD127- Treg* & Immune & H3K27ac & 4.09 \\
\hline Th1* & Immune & H3K27ac & 3.96 \\
\hline CD19 primary $(\mathrm{BI}) *$ & Immune & H3K4me1 & 3.91 \\
\hline CD56 primary* & Immune & H3K4me1 & 3.77 \\
\hline Treg primary* & Immune & H3K4me3 & 3.63 \\
\hline CD3 primary* & Immune & H3K27ac & 3.62 \\
\hline CD20* & Immune & H3K27ac & 3.45 \\
\hline CD4+ CD25- IL17- PMA Ionomycin stim MACS Th primary* & Immune & H3K4me3 & 3.45 \\
\hline CD4+ CD25- IL17+ PMA Ionomycin stim Th17 primary* & Immune & H3K4me3 & 3.17 \\
\hline CD4+ CD25+ CD127- Treg primary* & Immune & H3K4me3 & 3.1 \\
\hline CD4+ CD25int CD127+ Tmem primary* & Immune & H3K4me3 & 2.76 \\
\hline Peripheralblood mononuclear primary* & Immune & H3K9ac & 2.58 \\
\hline CD25int CD127+ Tmem* & Immune & H3K27ac & 2.27 \\
\hline CD4+ CD25- CD45R0+ memory primary* & Immune & H3K4me3 & 2.24 \\
\hline CD4+ CD25- CD45RA+ naive primary* & Immune & H3K4me3 & 2.2 \\
\hline CD8 memory primary* & Immune & H3K4me3 & 2.17 \\
\hline CD19* & Immune & H3K27ac & 2.13 \\
\hline CD4 memory primary* & Immune & H3K4me3 & 2.12 \\
\hline Peripheralblood mononuclear primary* & Immune & H3K4me1 & 2.12 \\
\hline CD4+ CD25- Th primary* & Immune & H3K4me3 & 1.98 \\
\hline
\end{tabular}

(S7.O) Enrichment of top cell types for Rheumatoid arthritis. ${ }^{*}=$ significant at FDR $<0.05 .{ }^{* *}=$ significant at $\mathrm{p}$ $<0.05$ after correcting for multiple hypotheses. 


\begin{tabular}{|c|c|c|c|}
\hline Cell type & Cell type group & Mark & $-\log _{10}(p)$ \\
\hline CD4+ CD25- IL17+ PMA Ionomycin stim Th17 primary** & Immune & H3K4me1 & 7.59 \\
\hline Th1** & Immune & $\mathrm{H} 3 \mathrm{~K} 27 \mathrm{ac}$ & 6.54 \\
\hline CD25- IL17+ Th17 stim** & Immune & H3K27ac & 6.5 \\
\hline CD4+ CD25- IL17- PMA Ionomycin stim MACS Th primary** & Immune & H3K4me1 & 6.24 \\
\hline CD4 memory primary** & Immune & H3K4me1 & 5.88 \\
\hline $\mathrm{Th} 2 * *$ & Immune & H3K27ac & 5.87 \\
\hline CD4+ CD25- Th primary** & Immune & H3K4me1 & 5.59 \\
\hline CD8 memory primary** & Immune & H3K4me1 & 5.13 \\
\hline CD14 primary** & Immune & H3K4me1 & 5.03 \\
\hline CD3 primary $(\mathrm{UW})^{* *}$ & Immune & H3K4me1 & 4.96 \\
\hline Th0* & Immune & H3K27ac & 4.8 \\
\hline CD56 primary* & Immune & H3K4me1 & 4.8 \\
\hline CD25- IL17- Th stim MACS* & Immune & H3K27ac & 4.72 \\
\hline CD4+ CD25- CD45R0+ memory primary* & Immune & H3K4me1 & 4.7 \\
\hline CD4 naive primary* & Immune & H3K4me1 & 4.51 \\
\hline CD4+ CD25int CD127+ Tmem primary* & Immune & H3K4me1 & 4.44 \\
\hline CD4+ CD25- CD45RA+ naive primary* & Immune & H3K4me1 & 4.36 \\
\hline CD8 naive primary $(\mathrm{BI})^{*}$ & Immune & H3K4me1 & 4.31 \\
\hline CD19 primary $(\mathrm{UW})^{*}$ & Immune & H3K4me1 & 4.26 \\
\hline CD8 naive primary (UCSF-UBC)* & Immune & H3K4me1 & 4.2 \\
\hline CD4+ CD25- IL17+ PMA Ionomycin stim Th17 primary* & Immune & H3K4me3 & 4.18 \\
\hline CD19 primary $(\mathrm{BI})^{*}$ & Immune & H3K4me1 & 4.17 \\
\hline CD3 primary $(\mathrm{BI})^{*}$ & Immune & H3K4me1 & 3.73 \\
\hline CD4+ CD25+ CD127- Treg primary* & Immune & H3K4me1 & 3.62 \\
\hline CD3 primary* & Immune & H3K27ac & 3.25 \\
\hline CD4+ CD25- IL17- PMA Ionomycin stim MACS Th primary* & Immune & H3K4me3 & 3.16 \\
\hline CD34 primary* & Immune & H3K4me1 & 2.87 \\
\hline Peripheralblood mononuclear primary* & Immune & H3К9ас & 2.87 \\
\hline CD15 primary* & Immune & H3K4me1 & 2.85 \\
\hline Spleen* & Immune & H3K4me1 & 2.7 \\
\hline CD4 primary* & Immune & H3K4me3 & 2.49 \\
\hline Peripheralblood mononuclear primary* & Immune & H3K4me1 & 2.46 \\
\hline CD8 primary* & Immune & H3K4me3 & 2.44 \\
\hline CD14* & Immune & H3K27ac & 2.18 \\
\hline CD4 memory primary* & Immune & H3K4me3 & 2.12 \\
\hline Colonic mucosa* & GI & H3K4me1 & 2.11 \\
\hline CD19 primary $(\mathrm{BI})^{*}$ & Immune & H3K4me3 & 2.1 \\
\hline CD4 naive primary* & Immune & H3K4me3 & 2.09 \\
\hline Mobilized CD34 primary* & Immune & H3K4me1 & 2.08 \\
\hline CD25int CD127+ Tmem* & Immune & H3K27ac & 2.04 \\
\hline
\end{tabular}

(S7.P) Enrichment of top cell types for Crohn's disease. ${ }^{*}=$ significant at FDR $<0.05 .{ }^{* *}=$ significant at $\mathrm{p}<0.05$ after correcting for multiple hypotheses. 


\begin{tabular}{|c|c|c|c|}
\hline Cell type & Cell type group & Mark & $-\log _{10}(p)$ \\
\hline CD4+ CD25- IL17+ PMA Ionomycin stim Th17 primary** & Immune & H3K4me1 & 6.37 \\
\hline CD25- IL17+ Th17 stim** & Immune & $\mathrm{H} 3 \mathrm{~K} 27 \mathrm{ac}$ & 5.53 \\
\hline CD4+ CD25- CD45R0+ memory primary** & Immune & H3K4me1 & 5.48 \\
\hline CD4 memory primary** & Immune & H3K4me1 & 5.19 \\
\hline CD4+ CD25+ CD127- Treg primary* & Immune & H3K4me1 & 4.88 \\
\hline CD4+ CD25- IL17- PMA Ionomycin stim MACS Th primary* & Immune & H3K4me1 & 4.73 \\
\hline CD3 primary* & Immune & H3K27ac & 4.72 \\
\hline Th2* & Immune & $\mathrm{H} 3 \mathrm{~K} 27 \mathrm{ac}$ & 4.5 \\
\hline CD25+ CD127- Treg* & Immune & H3K27ac & 4.42 \\
\hline Colonic mucosa* & GI & H3K4me1 & 4.17 \\
\hline Spleen* & Immune & H3K4me1 & 4.06 \\
\hline CD4+ CD25- IL17+ PMA Ionomycin stim Th17 primary* & Immune & H3K4me3 & 4.04 \\
\hline CD4+ CD25- Th primary* & Immune & H3K4me1 & 4.03 \\
\hline Colonic mucosa* & GI & H3K27ac & 4.0 \\
\hline Th1* & Immune & H3K27ac & 3.96 \\
\hline CD4 naive primary* & Immune & H3K4me1 & 3.91 \\
\hline CD4+ CD25int CD127+ Tmem primary* & Immune & H3K4me1 & 3.87 \\
\hline CD8 memory primary* & Immune & H3K4me1 & 3.84 \\
\hline Rectal mucosa* & GI & H3K4me1 & 3.74 \\
\hline CD19 primary $(\mathrm{UW})^{*}$ & Immune & H3K4me1 & 3.72 \\
\hline Colonic mucosa* & GI & H3К9ас & 3.63 \\
\hline Rectal mucosa* & GI & H3К9ас & 3.57 \\
\hline CD25- IL17- Th stim MACS* & Immune & H3K27ac & 3.54 \\
\hline CD25int CD127+ Tmem* & Immune & H3K27ac & 3.45 \\
\hline Th0* & Immune & H3K27ac & 3.44 \\
\hline CD8 naive primary (UCSF-UBC)* & Immune & H3K4me1 & 3.43 \\
\hline CD56 primary* & Immune & H3K4me1 & 3.21 \\
\hline Rectal mucosa* & GI & H3K27ac & 3.16 \\
\hline CD19 primary $(\mathrm{BI})^{*}$ & Immune & H3K4me1 & 2.95 \\
\hline Treg primary* & Immune & H3K4me3 & 2.93 \\
\hline CD8 naive primary $(\mathrm{BI})^{*}$ & Immune & H3K4me1 & 2.91 \\
\hline CD3 primary $(\mathrm{UW})^{*}$ & Immune & H3K4me1 & 2.83 \\
\hline CD4+ CD25- CD45RA+ naive primary* & Immune & H3K4me1 & 2.7 \\
\hline CD3 primary $(\mathrm{BI})^{*}$ & Immune & H3K4me1 & 2.44 \\
\hline Rectal mucosa* & GI & H3K4me3 & 2.29 \\
\hline CD4+ CD25- IL17- PMA Ionomycin stim MACS Th primary* & Immune & H3K4me3 & 2.24 \\
\hline Duodenum smooth muscle* & GI & H3K27ac & 2.17 \\
\hline Duodenum Mucosa* & GI & H3K4me1 & 2.15 \\
\hline CD34 primary* & Immune & H3K4me1 & 2.12 \\
\hline
\end{tabular}

(S7.Q) Enrichment of top cell types for Ulcerative colitis. $*=$ significant at $\mathrm{FDR}<0.05$. $* *=$ significant at $\mathrm{p}<$ 0.05 after correcting for multiple hypotheses. 

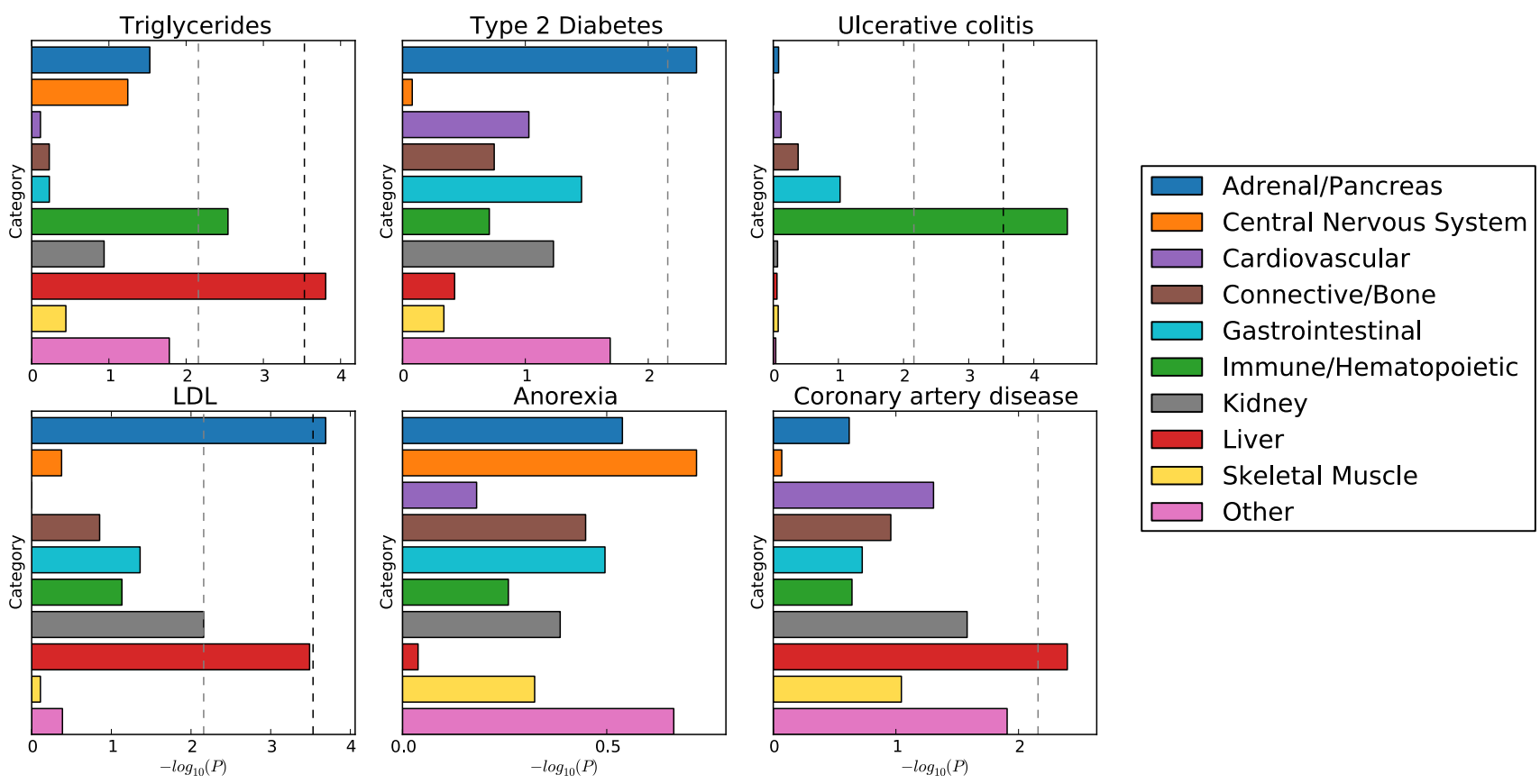

Figure S1: Enrichment of cell type groups for traits not included in Figure 4. The black dotted line at $-\log _{10}(P)=3.5$ is the cutoff for Bonferroni significance. The grey dotted line at $-\log _{10}(P)=2.1$ is the cutoff for FDR $<0.05$. 